Copyright

by

Zhi Guo

2008 
The Dissertation Committee for Zhi Guo certifies that this is

the approved version of the following dissertation

ATM Activation by Oxidative Stress

Committee:

Tanya Paull, Supervisor

Kelvin Dalby

George Georgiou

Jon Huibregtse

David Johnson 


\title{
ATM Activation by Oxidative Stress
}

\author{
by \\ Zhi Guo, B.S.; M.S.
}

Dissertation

Presented to the Faculty of the Graduate School of

The University of Texas at Austin

in Partial Fulfillment

of the Requirements

for the Degree of

\section{Doctor of Philosophy}

The University of Texas at Austin

August 2009 


\section{Acknowledgements}

I would like to express my gratitude to Dr.Tanya Paull for her constant guidance and motivation towards the successful completion of my degree. Sincere thanks to my committee members: Drs. Kelvin Dalby, George Georgiou, Jon Huibregtse and David Johnson for providing me with insightful comments. I would like to express my heartfelt thanks to all my family and friends without whom this study would have been extremely difficult and incomplete. 


\title{
ATM Activation by Oxidative Stress
}

\author{
Zhi Guo, Ph.D. \\ The University of Texas at Austin, 2009 \\ Supervisor: Tanya T. Paull
}

The Ataxia-telangiectasia mutaed (ATM) protein is regarded as the major regulator of the cellular response to DNA double Strand Breaks (DSBs). In response to DSBs, ATM dimers dissociates into active monomers in a process promoted by Mre11-Rad50Nbs1 (MRN) complex. ATM-deficient cells exhibit signs of chronic oxidative stress, suggesting that ATM plays an important role in the regulation of reactive oxygen species (ROS). I show for the first time that ATM can be activated by oxidative stress directly in the form of exposure to $\mathrm{H}_{2} \mathrm{O}_{2}$. In vitro kinase assays with purified ATM suggest that the activation by $\mathrm{H}_{2} \mathrm{O}_{2}$ is independent of DSBs and the MRN complex. In 293T cells, $\mathrm{H}_{2} \mathrm{O}_{2}$ induces ATM autophosphorylation on serine 1981. p53 and Chk2 are also phosphorylated by ATM after $\mathrm{H}_{2} \mathrm{O}_{2}$ treatment but not histone $\mathrm{H} 2 \mathrm{AX}$ and heterochromatin protein Kap1, indicating that ATM activation by $\mathrm{H}_{2} \mathrm{O}_{2}$ in human cells is independent of DNA damage. I also show that the cysteine residue 2991 is critical for ATM activation by $\mathrm{H}_{2} \mathrm{O}_{2}$ in vitro. 


\section{Table of Contents}

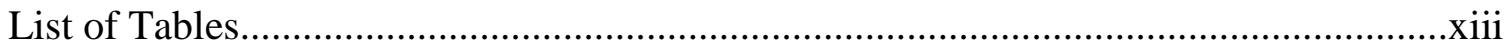

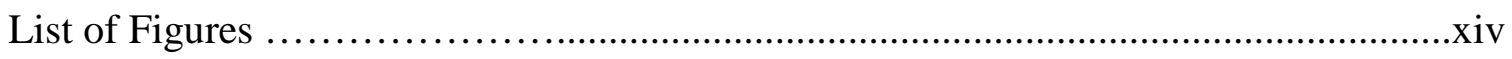

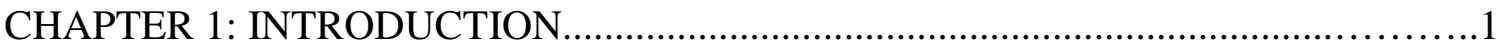

ATAXIA-TELANGIECTASIA AND ATM.................................................

ATM AND DNA DAMAGE RESPONSE......................................................

ATM STRUCTURE AND ACTIVATION...................................

ATM DEFICIENCY AND OXIDATIVE STRESS .............................13

REDOX ENVIRONMENT IN CELLS.....................................15

OXIDATIVE STRESS IN CELLS.......................................

ATM ACTIVATION BY OXIDATIVE STRESS...........................23

CHAPTER 2: MATERIALS AND METHODS...................................26

MUTAGENESIS AND CLONING.......................................26

ATM PURIFICATION.................................................26

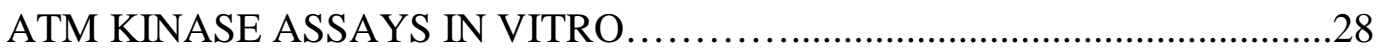

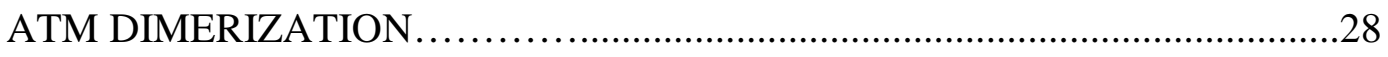

ATM IN-GEL TRYPTIC DIGESTION.................................................29

ATM CYANYLATION CLEAVAGE........................................................31

MAMMALIAN CELL CULTURE .........................................................35

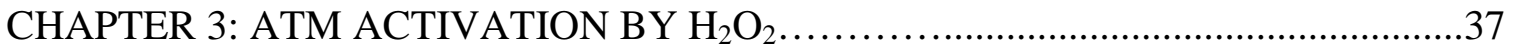

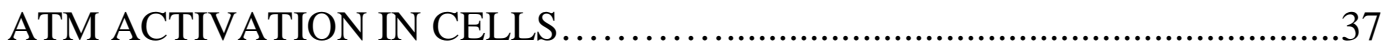

ATM activation by $\mathrm{H}_{2} \mathrm{O}_{2}$ in $293 \mathrm{~T}$ cells........................................38

ATM dimerization by $\mathrm{H}_{2} \mathrm{O}_{2}$ in cells..........................................42

ATM activation by $\mathrm{H}_{2} \mathrm{O}_{2}$ in NBS cells........................................45

ATM activation by $\mathrm{H}_{2} \mathrm{O}_{2}$ in primary cells.....................................4

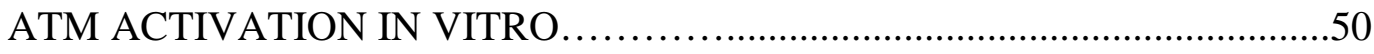

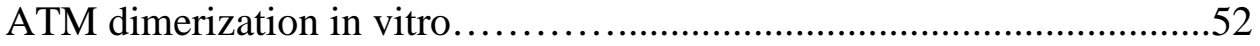


Autophosphorylation is not required for ATM activation by $\mathrm{H}_{2} \mathrm{O}_{2}$ in

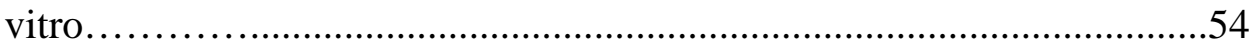

$\mathrm{H}_{2} \mathrm{O}_{2}$ increases substrate binding to ATM....................................56

ATM oxidative activation compensates MRN/DNA dependent

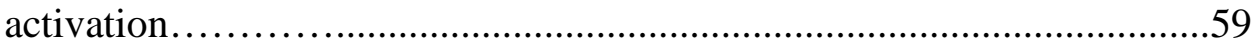

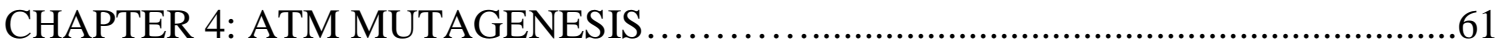

OXIDATION OF CYSTEINE RESIDUES IS RESPONSIBLE FOR ATM

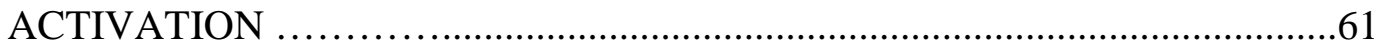

CONSERVED CYSTEINE RESIDUES IN ATM....................................63

IDENTIFY ACTIVE CYSTEINE RESIDUES WITH MASS

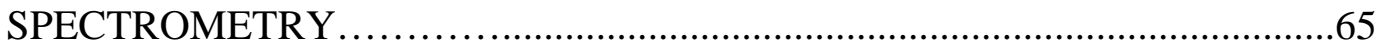

SELECTIVE CYANYLATION OF CYSTEINE RESIDUES IN ATM...........69 MUTATION OF CYSTEINE 2991 ABOLISH ATM ACTIVATION BY

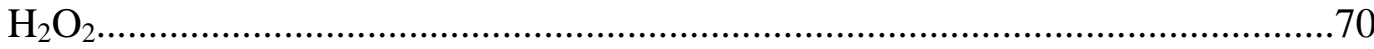

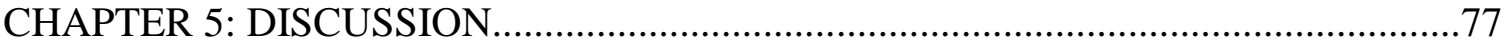

ATM REGULATES CELLULAR RESPONSE TO DNA DAMAGE AND

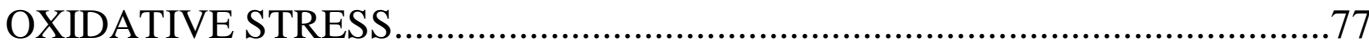

ATM ACTIVATION INDEPENDENT OF DNA DAMAGE..................79

FATC DOMAIN IS IMPORTANT FOR ATM ACTIVATION BY $\mathrm{H}_{2} \mathrm{O}_{2} \ldots \ldots \ldots .82$ DIRECT ACTIVATION BY OXIDATIVE STRESS IS IMPORTANT FOR ATM FUNCTION IN CELLS .84 DOWNSTREAM TARGETS OF ATM OXIDATIVE ACTIVATION PATHWAY .88

REFERENCES............................................................92

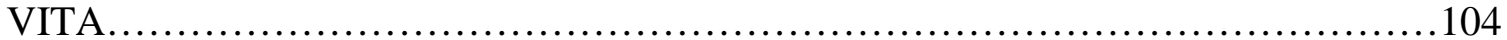




\section{List of Tables}

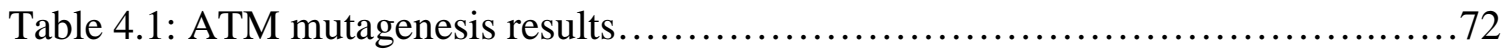

Table 4.2: Predicted pI of ATM domains......................................73 


\section{List of Figures}

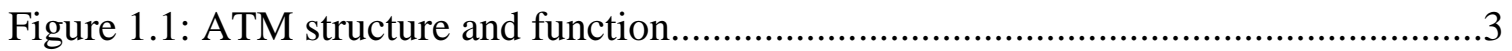

Figure 1.2: ATM activation and autophosphorylation.................................11

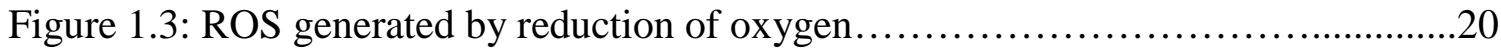

Figure 2.1: Nco I digestion of pCDNA3-ATM..................................27

Figure 2.2: Diagram for biotinylation of ATM with Biotin-HPDP.......................32

Figure 2.3: Diagram for identification of reactive cysteines with selective cyanylation...34

Figure 3.1: ATM is activated by $\mathrm{H}_{2} \mathrm{O}_{2}$ in cells in the absence of DSBs................39-41

Figure 3.2: The oligomerization of ATM with $\mathrm{H}_{2} \mathrm{O}_{2}$ treatment in a cell line stably

expressing Flag-tagged wild-type ATM..............................................43

Figure 3.3: Diamide induces ATM autophosphorylation and p53 phosphorylation.......44

Figure 3.4: $\mathrm{H}_{2} \mathrm{O}_{2}$ activates ATM in NBS cells....................................46

Figure 3.5: $\mathrm{H}_{2} \mathrm{O}_{2}$ activates ATM in normal primary fibroblasts ............................49

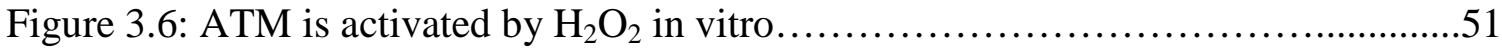

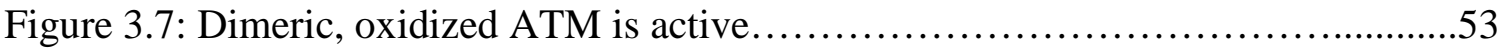

Figure 3.8: ATM autophosphorylation on serine 1981 is not required for ATM activation

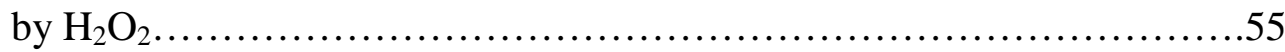

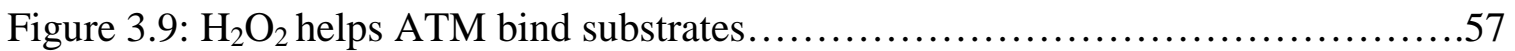

Figure 3.10: $\mathrm{H}_{2} \mathrm{O}_{2}$ stimulate ATP binding by ATM.................................58

Figure 3.11: $\mathrm{H}_{2} \mathrm{O}_{2}$ attenuate MRN and DNA dependent ATM activation...............60

Figure 4.1: ATM is activated and dimerized by diamide in vitro......................62

Figure 4.2: Tel1 does not regulate cellular response to oxidative stress in yeast..........64

Figure 4.3: Map of conserved ATM cysteines.........................................65

Figure 4.4: Reaction scheme for biotinylation of ATM with Biotin-HPDP...............68

Figure 4.5: Map of ATM cysteine mutations identified by mass spectrometry...........68

Figure 4.6: Map of ATM cysteine mutation identified by selective cyanylation..........69

Figure 4.7: Alignment of ATM FATC domain.......................................71

Figure 4.8: ATM C2991L and C2991T kinase assay................................74 
Figure 4.9: ATM heterodimer C2991L-WT kinase assay...........................76

Figure 5.1: ATM can be oxidized and activated directly in the absence of DSB.........86 


\section{CHAPTER 1: INTRODUCTION}

\section{ATAXIA-TELANGIECTASIA AND ATM}

Ataxia-telangiectasia (A-T) is a rare autosomal recessive disorder (1 in 40,000 to 100,000 people worldwide). The most striking clinical signs in A-T are progressive neurodegeneration, which is characterized by progressive difficulty with coordinating movements beginning in early childhood (progressive cerebellar ataxia), small clusters of enlarged blood vessels occuring in the eyes (oculocutaneous telangiectasia), a weakened immune system and increased risk of developing cancer, especially lymphoid tumors. Various other abnormalities are also associated with this disorder, including the absence or the rudimentary appearance of a thymus, insulin-resistant diabetes, clinical and cellular radiosensitivity [1-3].

The ATM (A-T Mutated) protein was identified as the product of the gene that is mutated in A-T [4]. Several hundred mutations have been found in the ATM gene in A-T patients. Most of these are nonsense mutations which generate truncated, nonfunctional versions of the ATM protein. Cells from A-T patients are hypersensitive to radiation and deficient in checkpoint activation at the $G_{1} / S$, intra-S, and $G_{2} / M$ phases of the cell cycle $[5,6]$. Dysfunctional ATM allows mutations to accumulate in genome which may lead to oncogenic transformation.

ATM is a member of the phospho-inositide 3-kinase (PI3K)-related protein kinase (PIKK) family (Figure 1.1A), which also includes ATM and Rad3-related protein kinase 
(ATR), the catalytic subunit of DNA-dependent protein kinase (DNA-PKcs) and SMG1 [7]. ATM regulates the DNA damage response by phosphorylating its downstream targets at specific $\mathrm{S} / \mathrm{T}(\mathrm{Q})$ sites in response to DNA double strand breaks (DSBs) (Figure 1.1B). ATM also responds to physiological breaks in DNA during the development and differentiation of $\mathrm{B}$ and $\mathrm{T}$ cells [8]. Increased accumulation of unrepaired ends during antigen receptor-gene assembly was reported in ATM-deficient lymphocytes [9]. ATM deficiency also impairs class-switch recombination of immunoglobulin genes [10]. An increased number of chromosomal abnormalities were observed in lymphocytes from AT patients, which may explain why up to $30 \%$ of A-T patients develop lymphoid tumors. Most of known functions of ATM can be attributed to its primary response to DNA double strand breaks [11].

However, there is also evidence for an extranuclear role for ATM. ATM-deficient cells have reduced internalization of phytohaemagglutinin (PHA), defective cellular responses to metal ion treatment, greater growth factor demand, and defective signalling through the epidermal growth factor (EGF) receptor [1]. In addition, insulin was also shown to activate ATM and some A-T patients develop insulin-resistant diabetes [12]. Chloroquine, known to enhance ATM activity without DNA damage, can protect against metabolic syndrome and glucose resistance [13]. It has also been suggested that ATM is predominantly cytoplasmic in neuronal cells [14], although this finding is controversial [15]. In contrast to cultured proliferating cells, organtypic slices of cerebella from mice confirmed the existence of cytoplasmic ATM. ATM also interacts with a protein involved 
A

1

ATM

13056

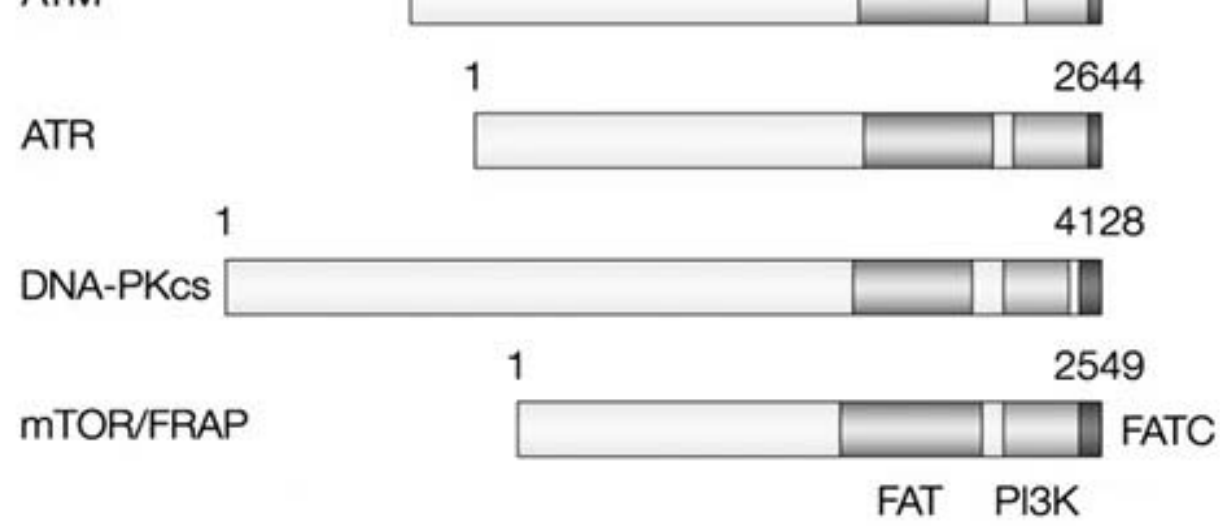

B
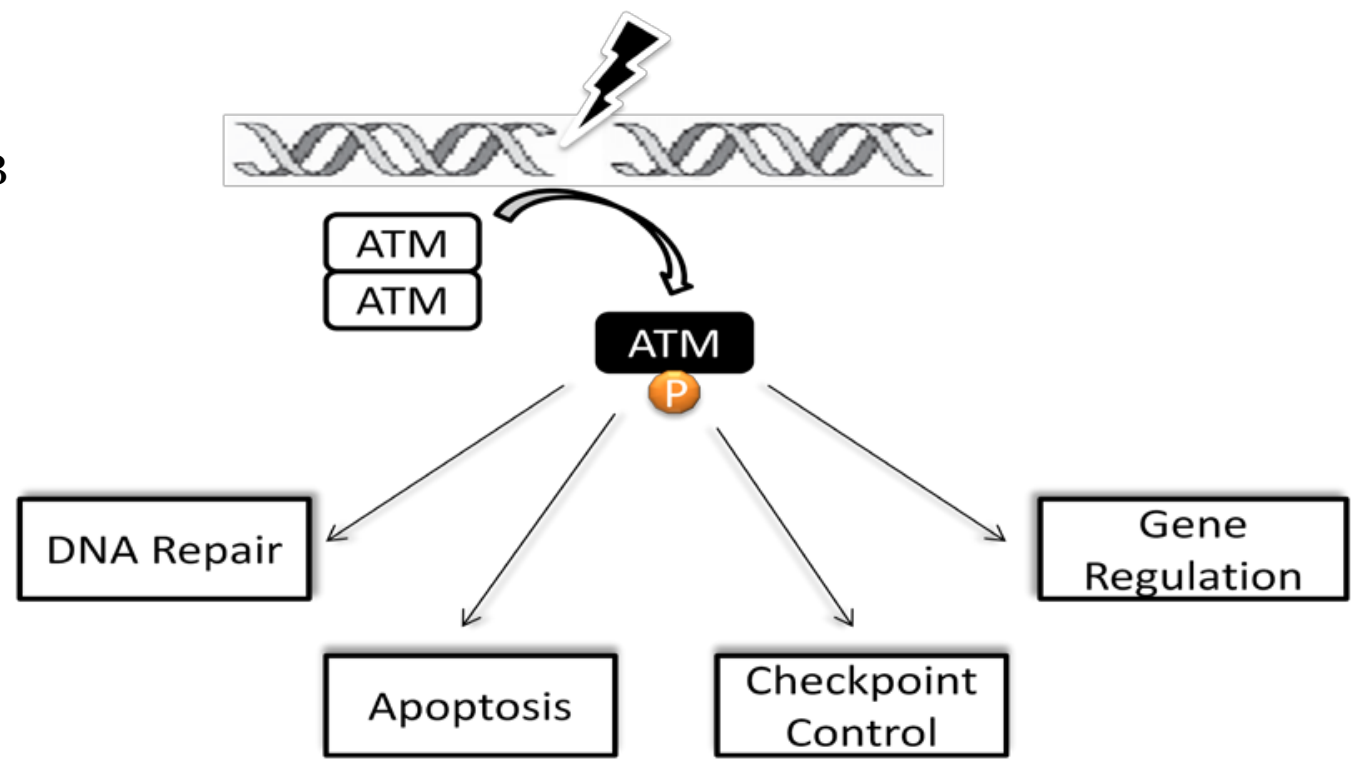

Figure 1.1 ATM structure and function. (A) ATM is a member of PI3K-like (PIKK) protein kinase family. ATM, ATR, DNA-PKcs and mTOR share similar C-terminal domains. (B) ATM activation by DSBs and regulation of cellular response. Inactive ATM dimer senses DSB events through the MRN complex, autophosphorylates and dissociates into active monomers. ATM can regulate cellular responses to DNA damage, including DNA repair, apoptosis, checkpoint arrest, and gene regulation. 
in the import of proteins into the peroxisome matrix and regulates peroxisome function [16]. More and more evidence for the existence of extranuclear ATM suggests that ATM may respond to stimuli other than DSBs.

\section{ATM AND THE DNA DAMAGE RESPONSE}

DSBs are highly cytotoxic DNA lesions, which can be induced by exposure to ionizing radiation or radiomimetic drugs. DSBs also occur during processes such as meiotic recombination and the assembly of the T-cell receptor and immunoglobulin genes via $V(D) J$ recombination. If not repaired, DSBs can lead to chromosomal fragmentation and genomic rearrangements. To avoid these outcomes, cells mount a complex DNA-damage response (DDR). In eukaryotic cells, DSBs are recognized through the recruitment of repair and signaling proteins to DSB sites to form ionizing radiation-induced foci (IRIF) [17]. IRIF formation depends on phosphorylation of the histone variant H2AX ( $\gamma$-H2AX) by ATM or DNA-PK [18-20]. $\gamma$-H2AX is then bound by MDC1 mediator of DNA damage checkpoint 1), which promotes IRIF formation by helping to recruit other proteins. MDC1 is also a substrate of ATM and its phosphorylation by ATM is important for its interaction with the FHA domains of RINGfinger ubiquitin ligase RNF8, which also assembles at the DSB sites. The ubiquitylation of H2AX by RNF8 facilitates the accumulation p53-binding protein-1 (53BP1) and breast cancer 1 (BRCA1) at the DSB sites, both of which are also substrates for ATM [21]. ATM has a critical role in phosphorylating various proteins that constitute the core components of the DSBs recognition machinery, among which is Nijmegen-breakage- 
syndrome protein (NBS1), part of the multifunctional complex Mre11-Rad50-Nbs1 $(\mathrm{MRN})[22,23]$.

The MRN complex stably binds to the DSB sites independent of ATM and functions as a sensor of DNA DSBs [24]. ATM activation is inhibited in cells deficient in NBS1 or Mre11 in response to DNA DSBs [25]. MRN was also shown to facilitate phosphorylation of downstream substrates by ATM [26]. In NBS1-deficient cells, activated ATM does not appear in DNA-damaged-induced foci but is present in a diffuse form throughout the nucleus, and phosphorylation of downstream substrates is defective in response to radiation doses less than 1 Gy [27]. But when the IR dose is over 1 Gy, ATM appears to be activated normally in NBS1-deficient cells but the phosphorylation of some downstream targets, like structure maintenance of chromosome 1 protein (SMC1), is still defective. This supports an adaptor role for the MRN complex in facilitating phosphorylation of ATM substrates. Some of the ATM substrates depend on the presence of MRN more than others.

Activation of cell cycle checkpoints is another hallmark of DDR [28, 29]. In mammalian cells these swift responses are also regulated through the ATM signaling pathway. Recent proteomic analysis of protein phosphorylation induced by DSBs shows that many checkpoint-regulation proteins are ATM substrates [30]. Among them, p53 was the first substrate of ATM to be identified because the stabilization and activation of p53 is defective in A-T cells [5]. ATM phosphorylation of p53 on Ser15 enhances the activity of p53 as a transcription factor, which mediates the G1/S cell cycle checkpoint 
[11, 31]. ATM also phosphorylates and activates checkpoint kinase 2 (Chk2), which in turn phosphorylates p53, BRCA1, CDC25A and CDC25C [32]. ATM can regulate intraS checkpoint pathway by phosphorylating SMC1, and inhibition of this phosphorylation abrogates the S-phase checkpoint [33, 34]. Interestingly, a recent combined proteomic and functional checkpoint screen showed that 9 proteins of the ubiquitin-proteasome system (UPS) were also phosphorylated by ATM and that they are also required for mammalian DNA damage checkpoint control, particularly the G1/S cell cycle checkpoint [35]. In addition, many DNA repair and signaling factors are regulated by ATM phosphorylation, including Mre11, Nbs1, LKB1, Ctip, FANCD2, RPA32, Chk1 and BLM.

ATM also directly contributes to DSBs repair. Loss of ATM results in a fraction of unrepaired DNA DSBs in A-T cells after ionizing irradiation [36]. In mamalian cells, DSBs are predominately repaired through the non-homologous end-joining (NHEJ) pathway in which the break ends are directly ligated without the need for a homologous template. In comparison to homologous recombination (HR), which requires a homologous sequence to guide repair, NHEJ is imprecise and often leads to loss of nucleotides at the break sites. $\mathrm{HR}$ is limited to $\mathrm{S}$ and $\mathrm{G}_{2}$ phases of the cell cycle because it can only occur when a homologous chromosome, usually a sister chromatid, is available. In contrast, the NHEJ pathway can repair DSBs in virtually any stage of cell cycle. In higher organisms most DSBs are repaired through the NHEJ pathway. In human cells up to $90 \%$ of DSBs are repaired in an ATM-independent way while a subset of DSBs 
localized to heterochromatin need ATM to facilitate entry of the DNA-repair machinery into heterochromatin by phosphorylating the transcriptional corepressor Kruppelassociated box (KRAB)-associated protein-1 (KAP1) [36]. ATM was also shown to stabilize DNA double-strand-break complexes during V(D)J recombination [8]. A recent study in yeast showed that interchromosomal end joining is efficiently suppressed by Tel1, an ATM orthologue [37]. This suggests that ATM serves as a key regulator for chromosome integrity that reduces the risk for DSB-induced chromosome translocations.

ATM is also important for telomere length maintainence. In Saccharomyces cerevisiae, Tel1 mutants have shortened but stable telomeres [38]. Mutations in the Drosophila ATM homolog lead to telomere fusions and consequent genome instability [39]. ATM protects chromatin architecture for loading of telomere-elongating, capping, and silencing proteins. However, in mammalian cells TRF2, a component of telomere shelterin complex, represses ATM-dependent nonhomologous end joining of dysfunctional telomeres [40]. Because ATM is a dominant DNA damage regulation kinase in mammalian cells, telomeres need to avoid DNA damage surveillance and shortened telomeres by repressing ATM.

\section{ATM STRUCTURE AND ACTIVATION}

ATM is a 3056 amino acid protein that is primarily present in low abundance in the nucleus of human cells [41]. Relatively little is known about structure of ATM. ATM contains a c-terminal domain with motifs that are typical of the lipid kinase 
phosphatidylinositol 3 kinase (PI3K, Figure 1.1). The PI3K domain is the catalytic site of ATM. On the $\mathrm{N}$ terminal side of the PI3K domain is the FAT domain. The domain contains approximately 500 amino acids and is relatively conserved across the PI3K family of kinases. The ATM autophosphorylation site Ser1981, which is important for ATM activation in human cells, was found in the $\mathrm{N}$ terminus of the FAT domain [42]. On the C- terminal side of kinase domain is the FATC (C-terminal FAT) domain. Recent research identified an acetylation site at lysine 3016 located in the conserved FATC domain and showed that the acetylation of this site is necessary for both ATM autophosphorylation and activation in human cells [43]. Sequence analysis also revealed a C-terminal peroxisome targeting signal in the FATC domain [16, 44]. Little is known about the structure of the N-terminus of ATM but it was shown to contain a protein interaction domain required for the association between ATM and its substrates, including BRCA1, p53 and LKB1, induced by DNA damage [45]. The overall shape of ATM was shown in a three-dimensional structure obtained with single-particle electron microscopy, in which ATM is composed of a head and an arm domain. DNA binding to ATM induces a large conformational movement of the arm-like domain. It suggests that ATM is capable of interacting with DNA, using its arm to clamp around the double helix [46]. But the conformational change happens in the absence of other DNA damage response proteins such as MRN complex, which binds both ATM and DNA, and is required for ATM activation by DSB in cells. The presence of MRN and other proteins might change the way that ATM interacts with DNA and conformational changes in the ATM protein. 
In the absence of DSBs, ATM molecules are inactive dimers [42]. Following DNA damage, ATM arrives early at the DNA DSB sites, associating either with DNA that flank the break, or with the MRN complex at the break site through the $\mathrm{C}$ terminus of NBS1 [47, 48]. ATM also associates with MDC1, which mediates the interaction between ATM and gamma-H2AX [22, 23, 49]. Subunits within each ATM dimer phosphorylate each other on serine 1981 within the N-terminus of the FAT domain, dissociating the dimer into fully active monomers [42]. However, the precise mechanisms that regulate ATM activation are not fully understood and there are still controversies about whether autophosphorylation on serine 1981 is necessary. For example, in vitro kinase assays with a S1981A mutant showed that autophosphorylation is not essential for MRN-dependent stimulation of dimeric ATM by linear dsDNA [24]. Moreover, ATMdependent DNA damage responses are functional at the organismal and cellular level in mice that only express the S1987A (Ser1981 in human) mutant form of ATM. In addition, the S1981A mutant does not show dominant-negative interference when expressed in ATM heterozygous mice [50]. In contrast, two more functionally important radiationinduced autophosphorylation events (Ser367 and Ser1893) have been identified during ATM activation. The phosphorylation site mutants (S367A and S1893A), like autophosphorylation site mutant S1981A, were both defective in ATM regulated DDR in human cells in tissure culture and both failed to correct radiosensitivity, genomic instability, and cell cycle checkpoint defects in Ataxia-Telangiectasia cells compared to wt-ATM [51]. This suggests that more elements need to be considered into the model, 
like other ATM-interacting proteins and the local environment at DSB sites in human cells.

Recent research showed that the involvement of protein phosphatases and acetylases are also critical for ATM regulation. For example, in the absence of DNA damage ATM interacts with protein phosphatase 2A (PP2A) [52]. IR induces dissociation of PP2A from ATM, allowing the serine 1981-phosphorylated form of ATM to accumulate in the nucleus. This suggests that PP2A plays an important role in the regulation of ATM autophosphorylation and activity, perhaps through its interaction with and continous dephosphorylation of certain sites. In contrast, DNA damage induces the interaction between protein serine-threonine phosphatase 5 (PP5) and ATM [53]. Reduced expression of PP5 attenuates the phosphorylation of ATM substrates and the autophosphorylation of ATM on Ser 1981, and causes an S-phase checkpoint defect in DNA-damaged cells. Lastly, the histone acetyltransferase Tip60 has been shown to acetylate ATM on lysine 3016 upon DNA damge [43]. Mutation of lysine 3016 inhibits autophosphorylation and abolishes ATM activation by preventing the dissociation of inactive ATM dimers to active ATM monomers.

Shortly after DSBs occur in cells, ATM is recruited to DSB sites, where it interacts with multiple proteins. The MRN complex binds to ATM, recruits ATM to broken DNA ends, and is essential for ATM activation in vivo and in vitro [24-26]. Results from a purified in vitro system showed that MRN acts as a DSB sensor for ATM, and that unwinding of DNA ends by MRN was essential for ATM activation [24]. 


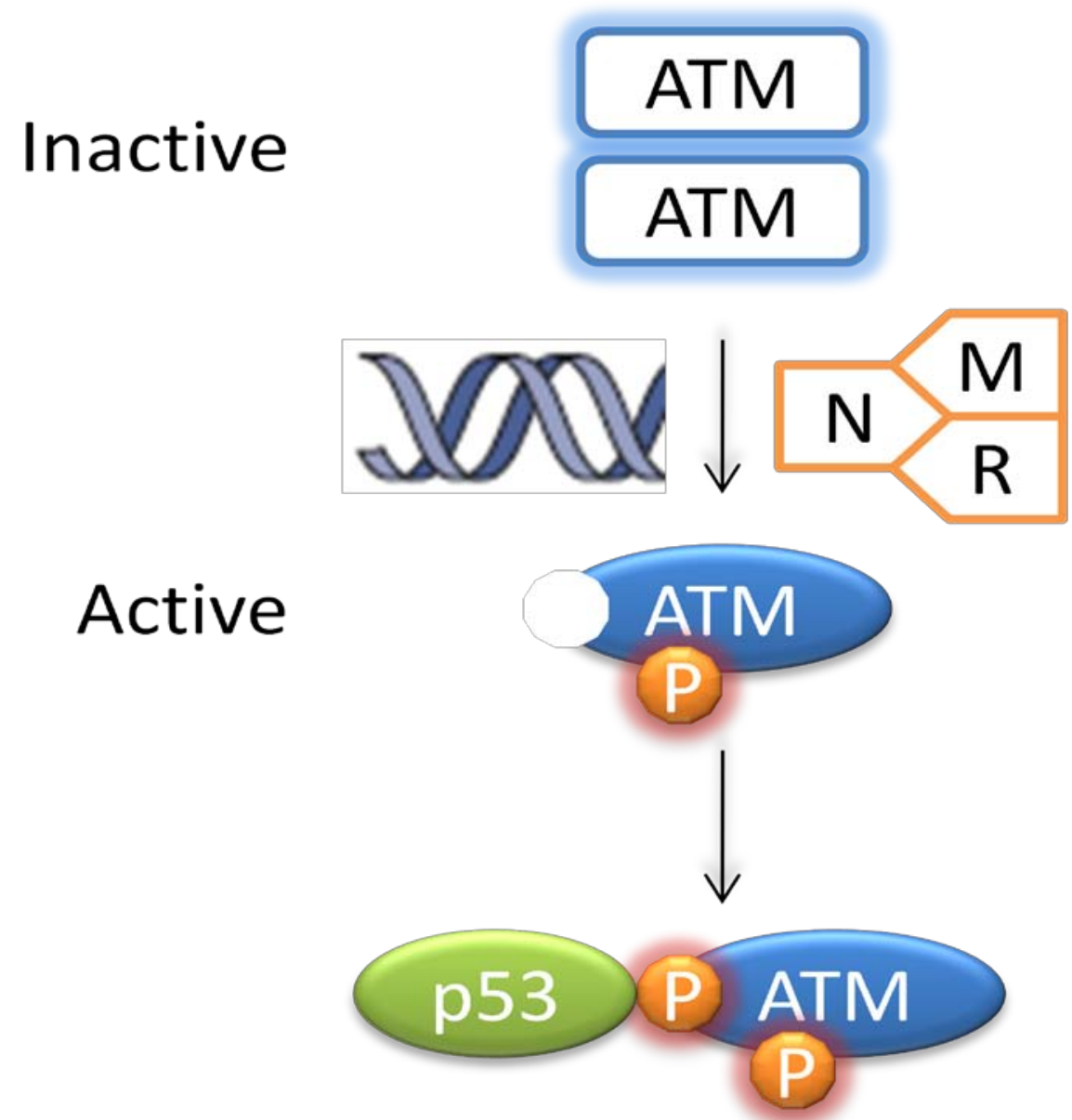

Figure 1.2 ATM activation and autophosphorylation. ATM is an inactive dimer in cells. ATM is activated by DSBs and MRN complex. ATM is autophosphorylated on serine 1981and dissociates into active monomers. Active ATM phosphorylates downstream substrates, including p53. 
MRN-dependent ATM activation by DSBs was also demonstrated in Xenopus egg extracts which also suggested that MRN facilitates the dissociation of dimeric ATM by tethering DNA, thereby increasing the local concentration of damaged DNA [54]. ATM activation in human cells has similarly shown strong correlation of ATM activity with the number of DSBs but not other forms of DNA lesions [55]. ATM activation is also dependent on DNA fragment length and the concentration of DNA ends. The minimal DNA length required for efficient ATM autophosphorylation was shown to be approximately 200 base pairs [56], although recent studies with human cell extracts and defined DNA structures showed that a 70bp dsDNA fragment with blunt ends could efficiently induce ATM autophosphorylation. This research also showed that ATM activation depends on the length of dsDNA, although longer DNA fragment were more efficient in ATM activation. Short single-stranded DNA oligonucleotides processed from DSB ends were also shown to constitute a unique signal of ongoing DSB repair, stimulating ATM activity in extracts in vitro [57].

Besides responding to DSBs, ATM can also be activated by treatment of cells with hypotonic buffer, chloroquine or histone deacetylase inhibitors, all of which are believed to induce overall structural changes in chromatin [42]. These treatments activate ATM in the absence of detectable DNA strands breaks, as shown by an absence of $\gamma$ H2AX . A recent study showed that the nucleosome-binding protein HMGN1 modulates the interaction of ATM with chromatin before DNA damage and optimizes its activation by regulating the levels of histone acetylation [58]. These results, together with the fact 
that ATM phosphorylates heterochromatin protein Kap1 and histone H2AX in response to DNA damage, suggest that ATM plays an important role in sensing changes in chromatin structure.

\section{ATM DEFICIENCY AND OXIDATIVE STRESS}

A-T is a neurodegenerative disorder and the primary site of degeneration is the cerebellum. ATM deficiency induces intrinsic growth defects, oxidative stress, endoplasmic reticulum (ER) stress, and ERK activation in astrocytes [59]. The neurodegeneration in A-T has been attributed to genome instability induced by ATM deficiency. ATM deficiency induces genome instability mainly through its inability to regulate cell cycle progression and checkpoint control, which leads to gradual accumulation of DNA damage. However, ATM-deficient cells show normal DNA repair ability, other than the $10 \%$ of DSBs that occur in heterochromatin and have been shown to be ATM-dependent for their repair [36]. It is not clear how deficient DNA repair causes the loss of differentiated non-dividing neuron cells, and whether the neuronal degeneration observed in A-T patients is due to the accumulation of unrepaired DNA lesions.

Considering the high level of metabolism in neuronal cells and high oxygen concentration in brain tissue, an important product induced by ATM deficiency, oxidative stress, could significantly contribute to the degenerative process. ROS control has been reported to be abnormal in A-T cells [59]. First, A-T cells respond abnormally to agents 
that induce oxidative stress. A-T fibroblasts are more sensitive to oxidative stress than healthy fibroblasts. Increased ROS mediated damage to proteins occurs in ATM-deficient brain tissue [60]. Secondly, the levels and function of antioxidant systems is abnormal in A-T cells [60]. Clinical research showed that A-T patients have significantly reduced levels of total plasma antioxidant capacity to about $77 \%$ of normal capacity. A-T cells also have reduced level of the important antioxidants vitamin A and E, impaired GSH biosynthesis and reduced levels of cyclic nucleotides such as NADH and NADPH. These may account for increased oxidative stress in ATM-deficient cell lines and tissues. Progressive deterioration of the redox balance was also found in ATM-deficient mice [61]. ATM-deficient mice showed progressive bone marrow failure resulting from a defect in the function of haematopoietic stem cells (HSC) that was associated with elevated reactive oxygen species. Treatment with anti-oxidative agents restored the reconstitutive capacity of HSC and prevented bone marrow failure [62]. Importantly, oxidative stress in A-T cells was shown to be alleviated by the antioxidants catalase and $\mathrm{N}$-acetyl cysteine (NAC) which neutralize ROS production in A-T cells [60].

The abnormality of ROS control in A-T cells suggests that ATM could help to regulate and maintain the reducing environment inside cells, which is critical for cell function. The regulation of redox state by ATM could be either through regulating the transcription of genes that encode proteins involved in antioxidant systems or by modifying the activity of such proteins via post-translational phosphorylation. There is also the possibility that ATM could directly sense and respond to increased ROS levels, 
as a significant portion of cytoplasmic ATM was detected in peroxisomes [16]. ATM contains a peroxisomal targeting signal sequence in its carboxy-terminus and co-localizes with the peroxisomal protein catalase. Significantly decreased catalase activity and increased lipid peroxidation in several A-T cell lines suggests that ATM might sense the change of redox state in cytosol and regulate the ability of peroxisome to eliminate the $\mathrm{H}_{2} \mathrm{O}_{2}$. On the other hand, ATM was shown to be downstream of platelet-derived growth factor beta (PDGF beta) receptor activation by hydrogen peroxide, which leads to the phosphorylation and activation of the p53 [63]. In mammalian cells, oxidative stress also leads to the activation of MAP kinases, p38 MAPK and JNK pathways, which might contribute to the activation of ATM through crosstalk between these pathways [64, 65].

\section{REDOX ENVIRONMENT IN CELLS}

Schafer et al gave a definition of the redox environment as a linked set of redox couples found in a biological fluid, organelle, cell, or tissue. The summation of the products of the reduction poteintial and reducing capacity of the linked redox couples present the overall redox environment in cells [66]. Redox potential can be presented as a voltage. Reducing capacity would be total reducing charge stored in cell. Reducing capacity can be estimated by determining the concentration of the reduced species in a redox couple and the reduction environment can be estimated with Nerst equation:

$$
\text { redox environment }=\sum_{\mathrm{i}=1}^{\text {a(couple })} \mathrm{E}_{\mathrm{i}} \times[\text { reduced species }]_{\mathrm{i}}
$$


Here $\mathrm{E}_{\mathrm{i}}$ is the half-cell reduction potential for a given redox pair and [reduced species], $\mathrm{i}$ is the concentration of the reduced species. In a given biological system there are always multiple redox pairs, and a representative redox pair is usually used as an indicator for changes in overall redox environment. In the cell, the GSSG/2GSH couple is regarded as the representative pair because it provides a much larger pool of reducing equivalents than other couples. Therefore, the redox state of GSSG/2GSH couple could be used as an indicator for the redox environment of the cell. According to Schafer et al, the redox state of a redox couple is defined by the half-cell reduction potential and the reducing capacity of that couple [66].

In cells, glutathione is considered to be the major redox buffer because the GSH concentration in the cytosol is $1-11 \mathrm{mM}$ on average. This is far higher than most other redox active compounds like the NAD+/NADH. The Nernst equation for the reduction potential of the GSSG/2GSH half-cell has the form below. This means that the reduction potential is dependent on the GSH/GSSG ratio and the absolute concentration of GSH.

$$
\mathrm{E}=-240-(59.1 / 2) \log \left([\mathrm{GSH}]^{2} /[\mathrm{GSSG}]\right) \mathrm{mV} \quad \text { at } 25^{\circ} \mathrm{C}, \mathrm{pH} 7.0
$$

The half cell potential of NADP+/NADPH couple is dependent on the ratio of the reduced and oxidized forms while independent of the absolute concentration of either species as shown by the Nerst equation below. In cells the concentration ratio of $\mathrm{NADP}+\mathrm{NADPH}$ is approximately 1:100. NADPH is also a cofactor in many reductive reactions and serves as a source of electrons. The reducing nature of the NADP+/NADPH 
couple in cells makes it the primary source of reducing equivalents for the glutathione system, which is especially important to counter an oxidative stress.

$$
\mathrm{E}=-315-(59.1 / 2) \log ([\mathrm{NADPH}] /[\mathrm{NADP}+]) \mathrm{mV} \quad \text { at } 25^{\circ} \mathrm{C}, \mathrm{pH} 7.0
$$

Other than the inorganic small molecule redox couples, protein is also an important redox regulating component, mainly through reducing and oxidating cysteine residues. Some of these are even specialized to help regulating redox environment, like thioredoxin. Thioredoxin is an important thiol-system in the cell. Intracellular concentrations of thioredoxin range from 1 to $10 \mu \mathrm{M}$ in bovine tissue and up to $15 \mu \mathrm{M}$ in bacteria [66]. The thiols of mammalian thioredoxin serve as electron donors for ribonucleotide reductase as well as for methionine sulfoxide reductase. Thioredoxin also helps the refolding of disulfide-containing proteins and regulates the DNA binding activity of some transcription factors [67]. The expression of thioredoxin is also regulated by the redox state change. Another redox regulating protein, thioltranferase, has also been shown to catalyze the reactivation of many oxidized proteins [68].

All redox couples in cells are thermodynamically connected to each other. The redox environment of cells and tissues is determined by the half-cell potentials of these linked redox couples. As the principal redox buffer of the cell, the majority of GSH in cells is synthesized in the cytosol. The endoplasmic reticulum is more oxidizing than the cytosol. The ratio of GSH/GSSG appears to range from 1:1 to 3:1, compared to the overall ratio in a cell, which is typically greater than 30:1 and usually $\geq 100: 1$ [69]. The 
more oxidizing environment of the endoplasmic reticulum is needed to produce proteins that have necessary disulfide bonds. The cytosol exchanges GSH with intracellular compartments; however, the GSH pool in the nucleus is relatively independent from the cytosol [70]. GSH in the nucleus maintains the redox state of critical protein sulfhydryls, which are necessary for DNA replication and cell cycle progression. Most eukaryotic transcription factors need to be in the reduced form to maintain their DNA binding ability and transcriptional acitvity [71].

Recent data indicate that intracellular GSH levels fluctuate during the embryogenic development, cell differentiation [72] and the cell cycle [73]. Many studies suggest that a more reducing environment is associated with proliferation and a more oxidizing environment initiates differentiation. The regulation of redox state throughout the life cycle of cells is critical for cells to regulate survival, replication, and apoptosis.

\section{OXIDATIVE STRESS IN CELLS}

Because the redox state is so critical for cell survival, the oxygen concentrations within cells and tissues are maintained within a narrow range (normoxia), to prevent oxidative damage from excess oxygen (hyperoxia), and to prevent metabolic demise from insufficient oxygen (hypoxia). Normoxia for cells is dependent on the specific localization of the cell in organs and functional status of the specific tissue [74]. Highly active reactive oxygen species (ROS), including the oxygen molecule $\left(\mathrm{O}_{2}\right)$, some

partially reduced oxygen species, the superoxide anion radical $\left(\mathrm{O}^{2-}\right)$, hydrogen peroxide 
$\left(\mathrm{H}_{2} \mathrm{O}_{2}\right)$, hydroxyl radical (-OH); nitric oxide (NO) and peroxinitrite anion ( $\left.\mathrm{ONOO}^{-}\right)$, are constantly produced in metabolic processes (Figure 1.3). Oxidative phosphorylation in the mitochondria and pathological processes such as inflammation can all produce ROS. Exogenous sources of ROS include exposure to ionizing radiation (IR) or radiomimetic chemicals. During times of environmental stress, ROS levels also increase dramatically. The effect of excessive production of ROS and/or the inadequacy of the anti-oxidant cellular defense systems to neutralize them are commonly referred to as oxidative stress [74].

Oxidative stress is a popular topic in medical research. Oxidative stress induction by urban fine particles has been discussed as a possible risk factor for cardiovascular diseases [75]. Recently, also diisocyanates, fluoride, N-nitrosofenfluramine, and the frequently used non-steroidal anti-inflammatory drug indomethacin have been reported to cause oxidative stress-mediated toxicity. In addition, metals such as nickel, lead and zinc all induce oxidative stress in cells [76]. Oxidative stress is widely accepted as a critical carcinogenesis mechanism. In cells under oxidative stress, unbalanced ROS can cause protein, lipid, and DNA damage. Accumulation of this damage may lead to cancer and aging [77-79].

In dividing cells, the $\mathrm{G}_{1} / \mathrm{S}$, intra-S and $\mathrm{G}_{2} / \mathrm{M}$ checkpoint responses allow damaged cells to either repair DNA damage, undergo apoptosis, or enter into a permanently growth-arrested state. ROS have been found to initiate checkpoint arrest in several cell types. Hydrogen peroxide induced a $G_{1}$ checkpoint response that could be attenuated by 


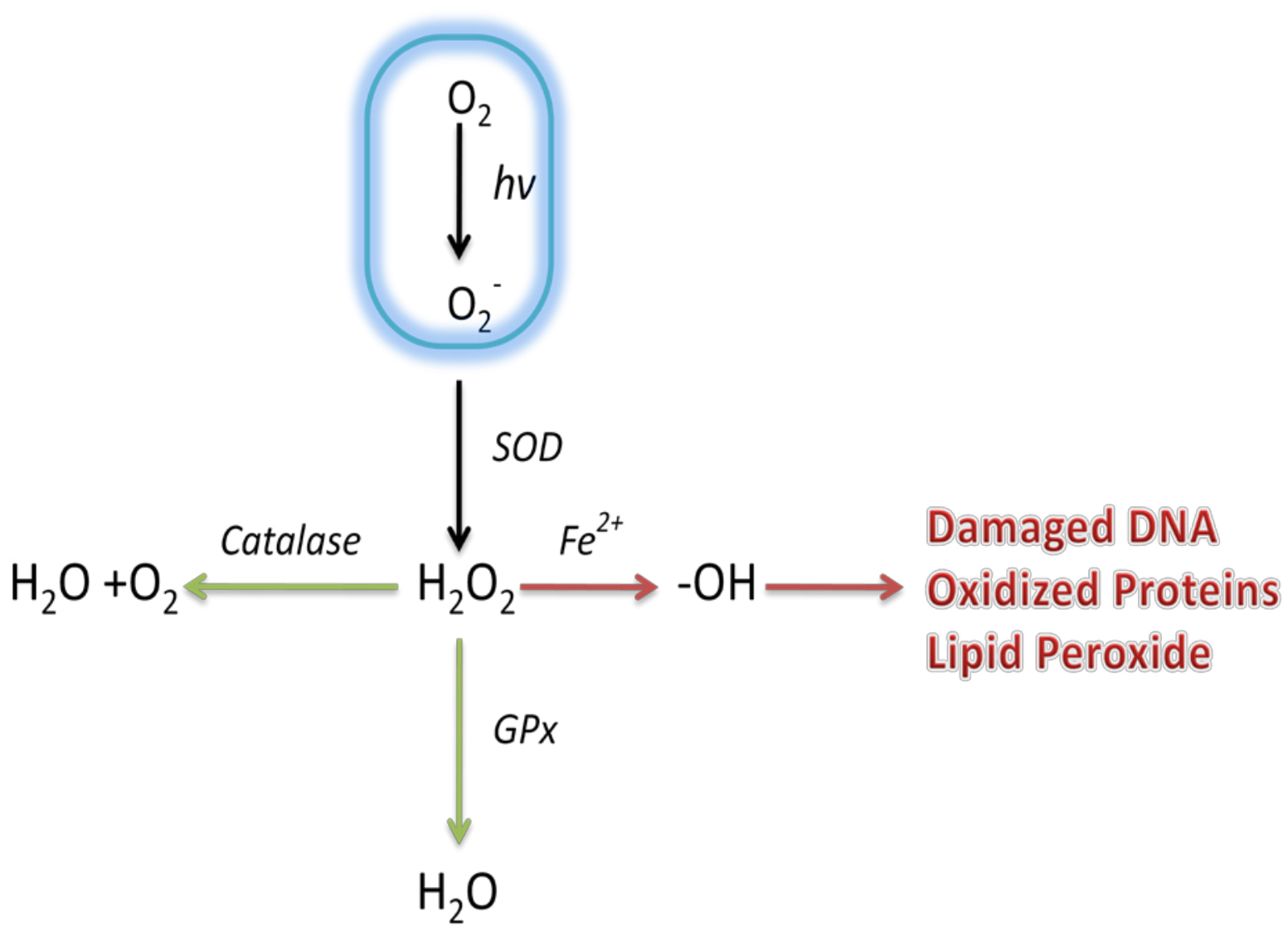

Figure 1.3 ROS generated by reduction of oxygen. Oxygen can be partially reduced to generate superoxide anion in mitochondria. The superoxide anion can be converted to hydrogen peroxide either by superoxide dismutases (MnSOD in mitochondrial or $\mathrm{Cu} / \mathrm{ZnSOD}$ in cytosol). Hydrogen peroxide can be neutralized by catalase or GPx otherwise react with $\mathrm{Fe}^{2+}$ to generate the highly reactive hydroxyl radical. Hydroxyl radicals can damage DNA, lipids and proteins. 
the application of antioxidants [80, 81]. In yeast cells, hydrogen peroxide induced a Mec1-dependent phosphorylation of Rad53 and Rad53-dependent cell cycle delay specifically during $\mathrm{S}$ phase [82]. Relatively low steady state levels of $\mathrm{H}_{2} \mathrm{O}_{2}$ also induce apoptosis as a consequence of lysomal rupture [83, 84]. Multiple reports also showed that NF-kB and mitogen-activated protein kinase (MAPK) pathways are involved in apoptosis induced by oxidative stress [85-87].

Due to the presence of unpaired valence shell electrons, highly active ROS can attack DNA at either the sugar or the base, which ultimately leads to single strand DNA breaks [88]. 8-Hydroxydeoxyguanosine (8-OHdG) and 5-hydroxyuracil are the two major oxidative DNA-damage products that can produce mutations by introducing mismatches. DNA single-strand breaks can also be induced by ROS with 3' phosphoglycolate blocked ends; these can be repaired by the DNA base excision repair (BER) pathway. The MutM, MutY and MutT proteins in Escherichia coli and OGG1, MYH and MTH in humans have been identified as DNA repair enzymes involved in removing these lesions [89]. Many of these repair enzymes have been observed to concentrate in the nucleus following exposure of cells to oxidative stress [82, 90].

Oxidative stress also impacts the redox environment of cells, resulting in the formation of GSSG at the expense of GSH. This shift in the ratio of [GSH]/[GSSG] changes the redox state to a more positive potential. The ability to export GSSG is important for cells to reduce redox potential and ultimately survive oxidative stress [91]. The export of GSSG maintains the half-cell reduction potential of the GSSG/2GSH 
couple and promotes a favorable redox environment but results in the loss of glutathione from the cell, thereby decreasing the reducing capacity [66]. Another way for cells to maintain the redox potential is to use the numerous sulfhydryl groups on the protein. The sulfhydryl groups on the cysteine residues can be present as thiols (-SH), disulfides (PSSP), or as mixed disulfides (PS-SG when conjugated with GSH). The oxidation of the thiol form or the reduction of the disulfide form of an enzyme can result in activation or inactivation of enzyme function. The oxidation of protein sulfhydryls to mixed disulfides (PS-SG) has been shown to be one of the early cellular responses to oxidative stress [68, 92-94]. For example, during the respiratory burst of neutrophils, up to $17 \%$ of the GSH can become protein-bound. This reaction preserves glutathione in the cell and serves as a buffer for the redox potential.

Although ROS are toxic at high levels, ROS at normal physiological levels play an important role in regulating signaling pathways and gene expression [95]. Proteins containing deprotonated cysteine residues are susceptible to oxidation by ROS, so it is an essential feature of most ROS-sensing proteins that they contain cysteine residues with a low pKa. Exposure to ROS leads to reversible oxidation of thiol groups of key cysteine residues in many proteins, including transcriptional regulators, kinases, phosphatases, structural proteins, metabolic enzymes, and SUMO ligases [96]. These redox changes are usually associated with altered activities, thus affecting corresponding signaling pathways. Not only are multiple cellular signaling pathways subjected to redox regulation, but cells also express signaling systems that regulate the cellular redox state. ROS are generated 
by specific plasma membrane oxidases in response to growth factors and cytokines and serve as secondary messengers in specific signaling pathways, which might explain the role of redox state change during cell differentiation [97, 98].

\section{ATM ACTIVATION BY OXIDATIVE STRESS}

In healthy cells, ATM was shown to be active under conditions of oxidative stress. In response to $\mathrm{H}_{2} \mathrm{O}_{2}$, phosphorylation of p53 on serine 15 is dependent on ATM in human umbilical vein endothelia cells [63]. Oxidative stress-induced p21 expression in Biliary epithelial cells (BECs) in primary biliary cirrhosis (PBC) is closely associated with the activation of the ATM pathway [99]. ATM is also required for activation of the G1 checkpoint during prolonged oxidative stress [81]. However, the mechanisms of ATM activation by oxidative stress remain unclear. The question is whether ATM responds to oxidative DNA damage or to changes in the intracellular redox state that are independent of DNA damage. Kobayashi and colleagues suggested that ATM was activated by Nmethyl-N'-nitro-nitrosoguanidine (MNNG) and 15-deoxy-Delta (12, 14)-prostaglandin J2 (15d-PGJ2), which they suggested could directly modify free sulfhydryl (SH) groups of ATM and activate it [100]. However, MNNG is also a strong DNA alkylating agent, which may induce DSBs and H2AX phosphorylation. 15d-PGJ2 is a prostaglandin that also regulates the anti-inflammatory response through its interaction with intranuclear receptor PPAR $\gamma$ and covalent activation of MAPK pathway [101]. ATM has also been shown to respond to exposure to hypoxia in the absence of DNA damage detectable by either comet assay or 53BP1 focus formation [102]. However, in A549 cells treated with 
$\mathrm{H}_{2} \mathrm{O}_{2}$, the recruitment of Mre11 and phosphorylation of ATM , Chk2 and H2AX were detected immunocytochemically by laser scanning cytometry [103], demonstrating the possibility of DNA damage during ATM activation under oxidative stress.

In most studies of ATM activation by ROS, oxidative stress was induced by incubating cells with hydrogen peroxide, which is one of the only stable sources of ROS available. More importantly, it is routinely generated as a by-product of oxidative metabolism and can be converted in cells to some extremely powerful oxidants, such as hydroxyl radicals $(-\mathrm{OH})$. These reactive oxygen radicals are major DNA damaging agents, which account for a large portion of the DNA damage events that occur in every cell of the human body every day. But ROS is less likely to induce DNA double strand breaks directly without the conversion from DNA single strand breaks (SSBs) during DNA replication. In fact, Ismail and colleagues’ study showed that hydrogen peroxide failed to induce detectable DSBs with concentrations up to 3mM [55]. During the study of $\mathrm{H}_{2} \mathrm{O}_{2}$ induced cell cycle arrest in yeast, Leroy et al found that the lack of Rad53 mediated cell cycle checkpoints in the $G_{1}$ and $G_{2}$ phases is due to efficient silent repair of oxidative DNA lesions produced at these stages by the base excision repair (BER) pathway, which also suggests that no DSBs are induced during $\mathrm{H}_{2} \mathrm{O}_{2}$ treatment [82]. ATM was shown to respond specifically to DSBs, with little or no impact from SSBs and other types of DNA damage [55], suggesting that there might be a DNA damage independent pathway accounting for ATM activation under oxidative stress. 
In the studies described here, I investigate ATM activation under oxidative stress. I hypothesize that ATM can be activated through direct oxidation by $\mathrm{H}_{2} \mathrm{O}_{2}$ independent of DNA damage. I show ATM activation in cells by $\mathrm{H}_{2} \mathrm{O}_{2}$ treatment without inducing DSBs, and oxidative activation independent of the MRN complex and DNA with purified ATM in vitro. I conclude that the ATM oxidative activation pathway is responsible for ATM activation by oxidative stress and that it is independent of MRN and DSBs. The oxidative activation pathway can help us to better understand ATM function in cellular response to DNA damage and oxidative stress. It provides us a possible explanation for the well-documented ATM function in the absence of DSBs and may explain some of the deficiencies observed in A-T patients. 


\section{CHAPTER 2: METHODS AND MATERIALS}

\section{MUTAGENESIS AND CLONING}

Mutations in the human ATM gene were made using the Quickchange XL method (Stratagene) in a Flag-ATM/pCDNA3 construct or HA-ATM/pCDNA3 [104] with the following modification.

300ng of cesium quality plasmid DNA were used as a template and the reaction were treated with Dpn I for longer than 6 hours. Reaction was ethanol-precipitated and transformed into chemically competent XL-10 Gold cells (Stratagene). The resulting mutant plasmid were confirmed by sequencing of the entire ATM open reading frame and by restriction digestion with Nco I (Figure 2.1)

\section{ATM PURIFICATION}

Large- scale preparation of mutated ATM plasmids was performed using cesium chloride purification. Nco I digestion was used to verify correct plasmid structure. Calcium chloride transfection of ATM plasmids into human 293T cells was performed as described previously [105]. After the transfection, cells were harvested, frozen with liquid nitrogen and stored at $-80 \mathrm{C}$.

Recombinant ATM protein was prepared with either Flag and HA (Hemagglutinin) epitope tags. 'Monomeric’ ATM consists of Flag-tagged ATM, purified using anti-Flag antibody conjugated to agarose beads (Sigma), under conditions where the majority of 


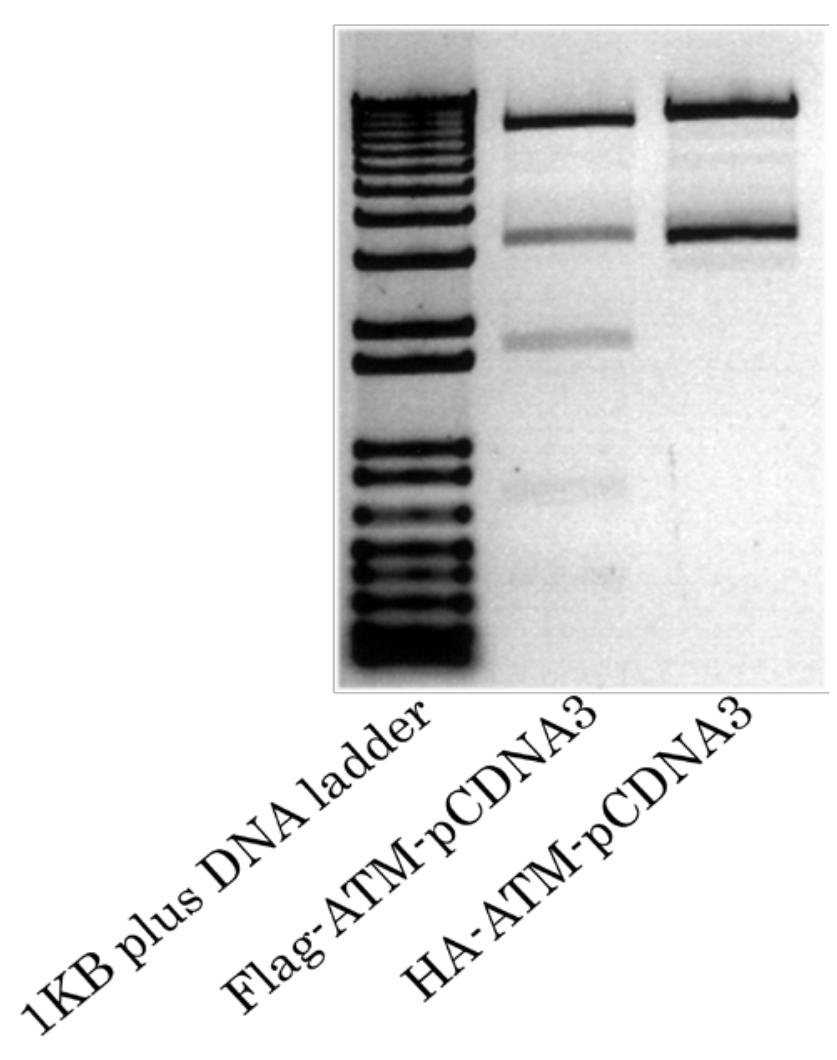

Figure 2.1 Use Nco I digestion to confirm the integrity of ATM plasmid. 1KB plus DNA ladder (invitrogen) is used as marker. Flag-ATM-pCDNA3 is digested by Nco I, shown on $0.8 \%$ agarose gel with 5 bands $(9.2,3.3,1.8,0.7$, and $0.4 \mathrm{~KB})$. HA-ATM-pCDNA3 digestion by Nco I shows two bands (10, and $3.3 \mathrm{~KB}$ ) 
ATM is in monomer form. Dimeric ATM, consists of Flag-ATM, HA-ATM heterodimers, prepared by using sequential anti- Flag and anti-HA antibody columns to purify ATM dimers containing both Flag and HA-tagged subunits. 40 150mm dishes of healthy growing cells were prepared for monomeric ATM preps while dimeric ATM preps required 80 dishes. Recombinant ATM purification was performed as previously described [105].

\section{ATM KINASE ASSAYS IN VITRO}

Each ATM mutant was tested in in-vitro kinase assays as described previously. In experiments where $\mathrm{H}_{2} \mathrm{O}_{2}$ or diamide was used, no additional DTT was added to the reactions. All ATM protein preparations were stored in 1mM DTT, so the final concentration of oxidant was less than the concentration added to the reaction.

\section{ATM DIMERIZATION}

Oxidized ATM was treated with non-reducing SDS loading buffer and then loaded onto a 6\% SDS-PAGE. Western blotting was performed and ATM was detected using a monoclonal antibody directed against ATM (Genetex).

The size of oxidized ATM was also measured with glycerol gradient untracentrifugation, which separates proteins under native condition. 10-20\% glycerol gradients in Tris-HCl buffer $(25 \mathrm{mM}$, pH 8.0, 100mM NaCl) were made as described previously [24]. Total volume of each gradient was $12 \mathrm{ml} .400 \mathrm{ul}$ of Biotinylated ATM 
[106] or high molecular weight protein markers (Bio-rad) in 5\% glycerol were added to the top of gradient. Ultracentrifugation was performed at 29K (SW41 Ti, Beckman) for more than 20 hours and deaccelerated at the slowest speed. $500 \mu \mathrm{l}$ fractions were taken from the top of gradient and filtered through a PVDF membrane with a dot-blot device (Bio-Rad). Biotinylated ATM on the memberane was detected with a streptavidin fluorescence conjugate (Molecular Probes).

\section{ATM IN-GEL TRYPTIC DIGESTION}

To detect peptides containing disulfide bonds, we needed to separate them from the excess of peptides after ATM tryptic digestion. We used a biotin labeling reagent EZlink Biotin-HPDP (N-[6-(Biotinamido)hexyl]-3'-(2'-pyridyldithio)propionamide, Pierce). The reaction scheme for biotinylation of ATM with Biotin-HPDP is shown in Figure 2.2. The protocol for modified in-gel digestion is shown below.

1. $1 \mathrm{mg}$ of ATM was treated with $0.5 \mathrm{mM} \mathrm{H}_{2} \mathrm{O}_{2}$ at $30{ }^{\circ} \mathrm{C}$ for 30 minutes, then loaded on to 6\% non-reducing SDS -PAGE. ATM migrates at higher position than ATM monomer.

2. After staining with Coomassie blue G250, a gel slice contains ATM was cut out, divided into smaller pieces and destained (50\% methanol, 5\% acetic acid) in a $1.5 \mathrm{ml}$ tube overnight at room temperature.

3. Destained gel pieces were dehydrated with acetonitrile. Excessive acetonitrile was removed and any residual acetonitile was evaporated by speedvac. 
4. Iodoacetamide alkylation (50mM iodoacetamide in $100 \mathrm{mM}$ ammonium bicarbonate, room temperature, 1h) was performed to block any free sulfhydryls. Excess iodoacetamide solution was removed and any residual solution was removed by dehydration with acetonitrile.

5. 10mM DTT or tris(2-carboxyethyl)phosphine (TCEP) was added to reduce disulfide bonds (room temperature, $1 \mathrm{~h}$ ). Enough reducing reagent is added to make sure that rehydrated gel pieces were fully submerged. DTT was removed with acetonitrile. Reducing reagents cannot reduce iodoacetamidealkylated sulfhydryls.

6. Biotin-HPDP solution $(0.4 \mathrm{mM})$ was added to the dehydrated gel and incubated at room temperature over 2 hours. Excess biotin-HPDP was removed with acetonitrile.

7. Freshly made trypsin solution (Promega sequencing grade modified trypsin, $20 \mathrm{ng} / \mu \mathrm{l}, 50 \mathrm{mM}$ ammonium bicarbonate solution with $0.1 \%$ rapigest, Waters) was added to fully cover the gel pieces and incubated at $37^{\circ} \mathrm{C}$ overnight.

8. The trypsin digestion product was recovered and incubated with magnetic streptavidin-coated beads (Promega) at room temperature for $30 \mathrm{~min}$. The strepavidin beads were previously washed with $0.1 \%$ rapigest in $50 \mathrm{mM}$ ammonium bicarbonate for 3 times.

9. The supernant was saved for future analysis. The strepavidin beads were washed (0.1\% rapigest, $50 \mathrm{mM}$ ammonium bicarbonate) for 3 times. 
10. $10 \mathrm{mM}$ 2-mercaptolethanol (BME, Sigma, $0.1 \%$ rapigest, 50mM ammonium bicarbonate) was added and incubated for $30 \mathrm{~min}$ at $37^{\circ} \mathrm{C}$ to remove the peptides from streptavidin beads after.

11. Trifluoroacetic acid (TFA, $0.5 \% 37^{\circ} \mathrm{C}$, 30min) was added to degrade rapigest. The sample was centrifuged at maximal speed for 10 minutes to remove the insoluable products of rapigest hydrolysis.

12. The supernant was carefully transfered to another tube and concentrated using a speedvac to approximately $15 \mathrm{ul}$.

The samples are ready for Mass spec analysis. Mass spectrometry analyses were performed in the ICMB/CRED Analytical Instrumentation-Mass Spectrometry Facility Core by Dr. Maria Person. MS and MS/MS were acquired on a MALDI-TOF/TOF (ABI 4700 Proteomics Analyzer, Foster City,CA) and processed using GPS Explorer v3.5. MASCOT V2.0 was used for the database search, using the supplied ATM sequence. Manual analysis was used to identify modified peptides by accurate mass and matching of MS/MS sequence tags.

\section{ATM CYANYLATION CLEAVAGE}

1-cyano-4-dimethylamino-pyridinium tetrafluoroborate (CDAP, cayman) selectively cyanylates free sulfhydryls in a compatible range of $\mathrm{pH}$ with reducing reagent TCEP. Flag-tagged ATM is cleaved at the sites of cyanylation at $\mathrm{pH} 12$. The lengths of peptides detected by anti-Flag antibody (Sigma) indicate the locations of cyanylated 


\section{oxidation}
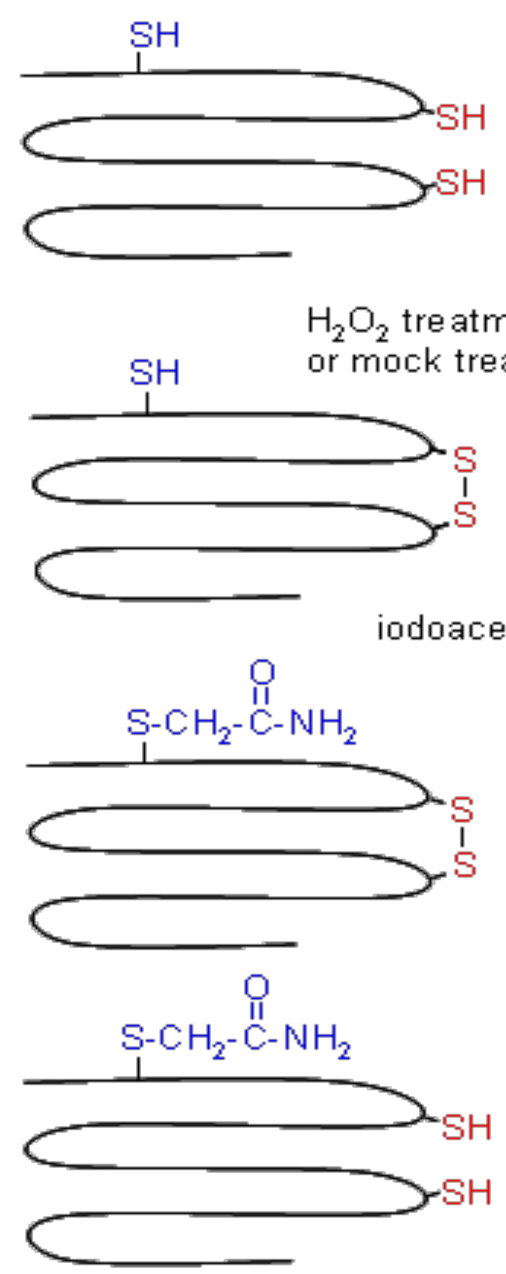

DTT

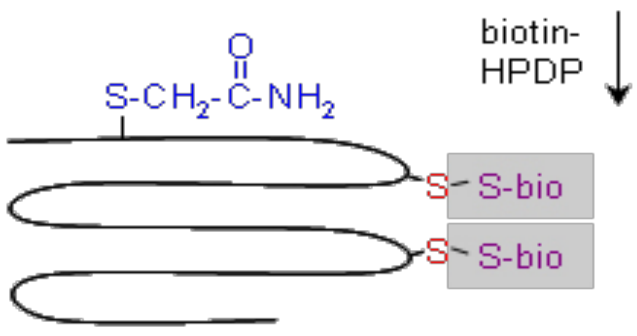

\section{no oxidation}

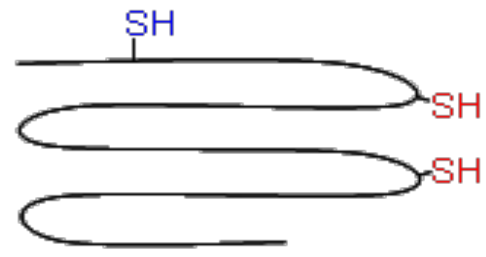

$\mathrm{H}$
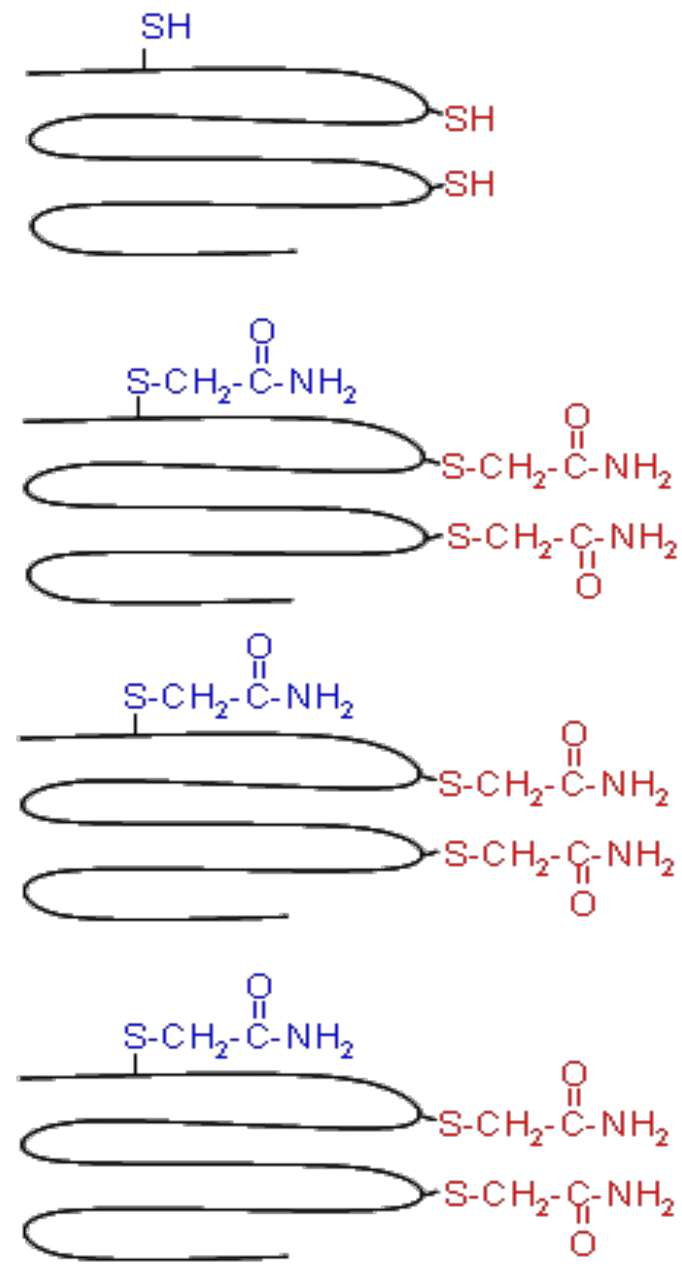

Figure 2.2 Diagram for biotinylation of ATM with Biotin-HPDP. 'SH' in blue represents the cysteine residues that are not oxidized; ' $\mathrm{SH}$ ' in red represents the cysteine residues that form disulfide bonds during exposure to $\mathrm{H}_{2} \mathrm{O}_{2}$. 
sulfhydryls relative to the N-terminus (Figure 2.3). The protocol for ATM cyanylation cleavage is shown below.

1. ATM was bound to argrose beads (Qiagen, $4^{\circ} \mathrm{C}, 30 \mathrm{~min}$ ) and washed 3 times.

2. ATM was treated with $0.5 \mathrm{mM} \mathrm{H}_{2} \mathrm{O}_{2}$ at $30{ }^{\circ} \mathrm{C}$ for 30 min. Exces $\mathrm{H}_{2} \mathrm{O}_{2}$ was removed by washing the beads 3 times with A buffer $(10 \mathrm{mM}$ Tris, $100 \mathrm{mM}$ $\mathrm{NaCl}, 10 \%$ Glycerol, pH 8.0).

3. Free sulfhydryls were blocked by incubation with $10 \mathrm{mM}$ iodoacetamide for $1 \mathrm{~h}$ at room tempreture. Exces iodoacetamide was removed by washing three times with 100mM ammonium bicarbonate.

4. 10mM TCEP was added to reduce the disulfide bonds (room tempreture 30 minutes).

5. $50 \mathrm{mM}$ CDAP was added to cyanylate nascent sulfhydryls at room tempreture for $1 \mathrm{~h}$.

6. $0.01 \mathrm{~N} \mathrm{NaOH}$ was added to raise $\mathrm{pH}$ to 12 . Cleavage finishes in $1 \mathrm{~h}$ at room tempreture.

7. 5X SDS loading buffer was added and boiled for 5 minutes to extract peptides from the beads. The supernant was separated by SDS-PAGE.

8. The resulting peptides were detected by western blotting with anti-Flag antibody and the approximate length of each fragment was determined. 


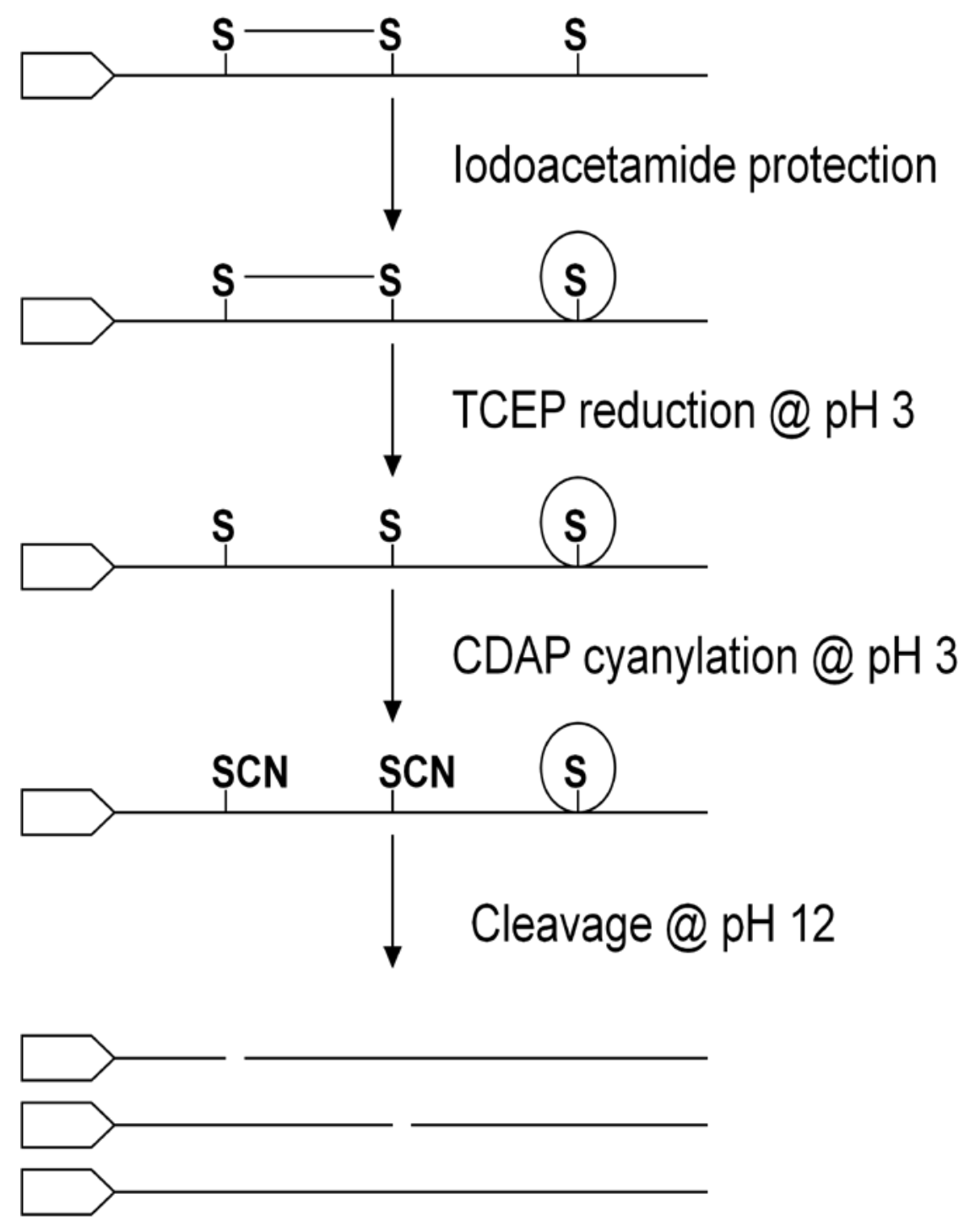

Figure 2.3 Diagram for identification of reactive cysteines with selective cyanylation. After oxidation with $\mathrm{H}_{2} \mathrm{O}_{2}$, free cysteines were protected by iodoacetamide. Cysteines in disulfide bonds were reduced with TCEP, followed by cyanylation with CDAP. The protein was cleaved at the cyanylation sites by raising the $\mathrm{pH}$ to 12 . Anti-Flag antibody was used to detect the peptides with an intact N-terminus. The sizes of the peptides revealed the sites of cyanylation relative to the $\mathrm{N}$ terminus. 


\section{MAMMALIAN CELL CULTURE}

$293 T$ cells (CRL-12688) were cultured in DMEM supplemented with 10\% animal serum complex (Gemini) in a $\mathrm{CO}_{2}(5 \%)$ incubator, at $37^{\circ} \mathrm{C}$. ATM deficient (A-T, GM05849) and NBS1-deficient (NBS, GM15989) fibroblasts were grown in MEM supplemented with 10\% FBS. Healthy fibroblasts (GM08399) were cultured in DMEM supplemented with 10\% FBS and 2mM L-glutamine. A wild-type Flag-tagged ATM stable cell line was obtained by integrating linearized WT-ATM pcDNA3 plasmid [104] into 293 cells and selecting with 400 mM G418 (Invitrogen). Flag-ATM stable cell lines were maintained with DMEM supplemented with 10\% animal serum complex and 200mM G418.

For $\mathrm{H}_{2} \mathrm{O}_{2}$ treatment, cells were grown to near confluence, the growth medium was changed to sterile PBS buffer with different concentrations of $\mathrm{H}_{2} \mathrm{O}_{2}$, and were incubate at $37^{\circ} \mathrm{C}$ for 30 minutes. $\mathrm{H}_{2} \mathrm{O}_{2}$ treatment was stopped by harvesting the cells. The ATM inhibitor (Ku-55933, ameresco) was made as $10 \mathrm{mM}$ stock (1000X) in DMSO. The inhibitor was added to the medium $1 \mathrm{~h}$ before $\mathrm{H}_{2} \mathrm{O}_{2}$ or IR treatment with the same volume of DMSO added as control.

For irradiation treatment, near confluent cells were irradiated with 5 Gray using $\mathrm{C}_{5} 37$ source. The irradiated cells were returned to a $37^{\circ} \mathrm{C}$ incubator for 30 minutes before harvesting the cells. Cells were lysed in $1 \mathrm{X}$ cell lysis buffer that contains $20 \mathrm{mM}$ Tris$\mathrm{HCl}$ (pH 7.5), 150 mM NaCl, 1 mM Na 2 EDTA, 1 mM EGTA, 1\% Triton, 2.5 mM 
sodium pyrophosphate, $1 \mathrm{mM}$ beta-glycerophosphate, $1 \mathrm{mM} \mathrm{Na} 3 \mathrm{VO} 4$, and $1 \mu \mathrm{g} / \mathrm{ml}$ leupeptin (Cell signaling, 9803). 400ul of lysis buffer was used to homogenize cells from each $10 \mathrm{~cm}$ dish. Cells were completely lysed after vortexing and 5 minutes of incubation on ice. 5X SDS loading buffer was added to the whole cell lysate, and 10ul of total cell lysate (approximate $10 \mu \mathrm{g}$, protein concentration was estimated with BCA kit from Pierce) was loaded onto 4-12\% Bis-Tris SDS-PAGE (Invitrogen). ATM and its substrates were separated and transferred to PVDF-FL membrane (Millipore). Antibodies against phosphor-specific ATM and its substrates were used to detect the phosphorylation of ATM and its substrates. 


\section{CHAPTER 3: ATM ACTIVATION BY $\mathrm{H}_{2} \mathrm{O}_{2}$}

\section{ATM ACTIVATION IN CELLS}

Activation of ATM by $\mathrm{H}_{2} \mathrm{O}_{2}$ in cells has been well documented $[63,107,108]$. But whether it is through the ability of $\mathrm{H}_{2} \mathrm{O}_{2}$ to induce DNA damage or through other mechanisms has been controversial. In cells, $\mathrm{H}_{2} \mathrm{O}_{2}$ can be converted to highly active free radicals which attack DNA bases. Base excision repair (BER) is the major cellular mechanism that repairs oxidized DNA throughout the cell cycle [78, 82]. BER is typically initiated by a DNA glycosylase (with OGG1 being the major glycosylase for repairing highly mutagenic 8-oxoguanine and NEIL1, NEIL2 and NEIL3 performing back up roles) and induces DNA single stand breaks (SSBs) at the damage sites. If the concentration of free radicals is high, two DNA SSBs that occur close enough can combine to produce a DSB. Likewise, longer $\mathrm{H}_{2} \mathrm{O}_{2}$ treatment can increase the chance that two SSB events strike the same position on DNA helix, which also leads to SSB/DSB conversion. For cells in S-phase, SSBs induced right before the replication fork can also be converted to DSBs if the replication fork is not stopped in time. Therefore whether $\mathrm{H}_{2} \mathrm{O}_{2}$ can induce DSBs depends on the concentration of $\mathrm{H}_{2} \mathrm{O}_{2}$, the time of $\mathrm{H}_{2} \mathrm{O}_{2}$ treatment and the cell cycle status. To test whether $\mathrm{H}_{2} \mathrm{O}_{2}$-induced ATM activation is caused by DSBs, we did our experiments with low concentrations of $\mathrm{H}_{2} \mathrm{O}_{2}$ with short exposures and assayed for DSB induction by monitoring the phosphorylation of histone H2AX. 


\section{ATM activation by $\mathrm{H}_{2} \mathrm{O}_{2}$ in $293 \mathrm{~T}$ cells}

293T cells were grown to near-confluence and treated with varying concentrations of $\mathrm{H}_{2} \mathrm{O}_{2}$. Cells were lysed and 10ug of total cell lysate was separated by SDS-PAGE and western blotted for phosphorylation of ATM or its substrates. A hallmark of ATM activation, ATM autophosphorylation at serine 1981 was induced by $\mathrm{H}_{2} \mathrm{O}_{2}$ at a concentration of $0.5 \mathrm{mM}$ and was also induced by exposure to ionizing radiation (5 Gy)(Figure 3.1A). With exposure to $0.5 \mathrm{mM} \mathrm{H}_{2} \mathrm{O}_{2}$, we also detected ATM-dependent p53 and Chk2 phosphorylation, but the formation of $\gamma$-H2AX was absent (Figure 3.1B). Since $\mathrm{H} 2 \mathrm{AX}$ is widely regarded as a sign of DNA DSBs, the absence of $\gamma-\mathrm{H} 2 \mathrm{AX}$ after exposure to low levels of $\mathrm{H}_{2} \mathrm{O}_{2}$ suggested that no DSBs were formed under these conditions (these cells exihibit a high level of endogenous $\gamma$-H2AX signal, but no increase of the signal was observed with $\mathrm{H}_{2} \mathrm{O}_{2}$ treatment). At the same time we also failed to detect the phosphorylation of heterochromatin protein Kap1, which was shown to be an ATM substrate upon IR or NCS treatment [36, 109]. Both H2AX and Kap1 are chromatinassociated proteins, only being phosphorylated at the sites where DSBs occur. Therefore, under these conditions, ATM was activated by $\mathrm{H}_{2} \mathrm{O}_{2}$ in 293T cells in the apparent absence of DSBs. 
A

\begin{tabular}{|c|c|c|c|}
\hline IR & - & - & + \\
\hline $\mathrm{H}_{2} \mathrm{O}_{2}$ & - & + & - \\
\hline $\begin{array}{c}\text { Phospho-ATM } \\
(\mathrm{S} 1981)\end{array}$ & & - \\
\hline ATM & - \\
\hline
\end{tabular}

\begin{tabular}{|c|c|c|c|}
\hline IR & - & - & + \\
\hline $\mathrm{H}_{2} \mathrm{O}_{2}$ & - & + & - \\
\hline $\begin{array}{c}\text { Phospho-Chk2 } \\
\text { (T68) }\end{array}$ & - & - & - \\
\hline Chk2 & \multicolumn{2}{|c|}{} \\
\hline
\end{tabular}

\begin{tabular}{|c|c|c|c|}
\hline IR & - & - & + \\
\hline $\mathrm{H}_{2} \mathrm{O}_{2}$ & - & + & - \\
\hline $\begin{array}{c}\text { Phospho-p53 } \\
(\mathrm{S} 15)\end{array}$ & \multicolumn{2}{|c|}{} \\
\hline p53 & \multicolumn{2}{|}{} \\
\hline
\end{tabular}


B

\begin{tabular}{|c|c|c|c|}
\hline $\mathrm{IR}$ & - & - & + \\
\hline $\mathrm{H}_{2} \mathrm{O}_{2}$ & - & + & - \\
\hline $\begin{array}{c}\text { Phospho-Kap1 } \\
(\mathrm{S} 824)\end{array}$ & & & \\
\hline Kap1 & - & \\
\hline
\end{tabular}

\begin{tabular}{|c|c|c|c|}
\hline IR & - & - & + \\
\hline $\mathrm{H}_{2} \mathrm{O}_{2}$ & - & + & - \\
\hline$\gamma-\mathrm{H} 2 \mathrm{AX}$ & - & - & \\
\hline $\mathrm{H} 2 \mathrm{AX}$ & - \\
\hline
\end{tabular}

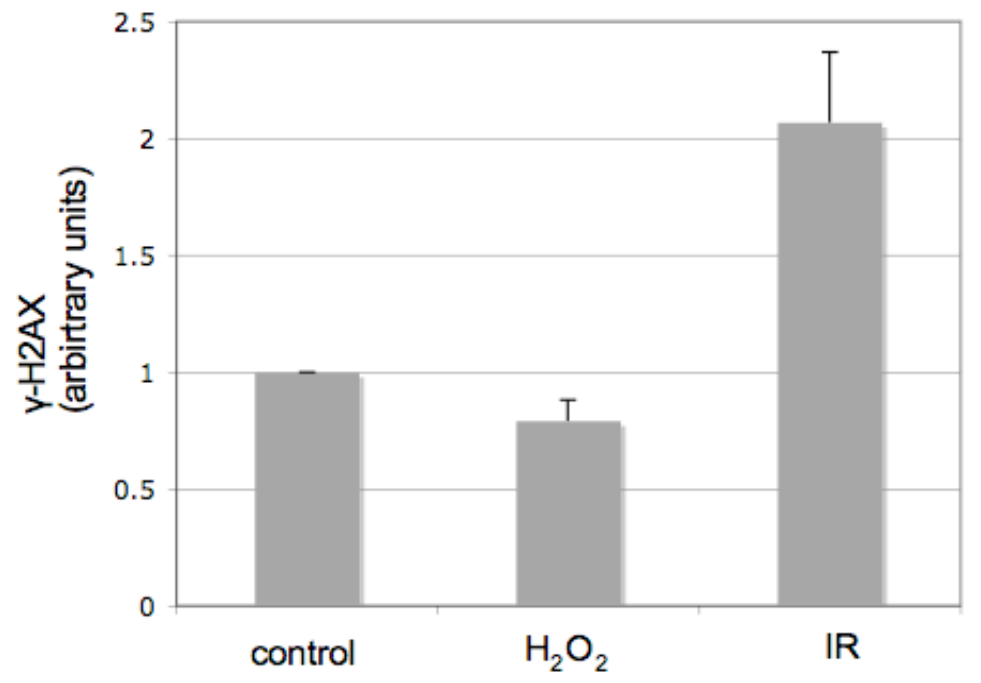


C

\begin{tabular}{|c|c|c|c|c|}
\hline Ku-55933 & - & - & + & + \\
\hline $\mathrm{H}_{2} \mathrm{O}_{2}$ & - & + & - & + \\
\hline Phospho-ATM(S1981) & \multicolumn{2}{|c|}{-} \\
\hline ATM & - & \\
\hline
\end{tabular}

\begin{tabular}{|c|c|c|c|c|}
\hline $\mathrm{Ku}-55933$ & - & - & + & + \\
\hline $\mathrm{H}_{2} \mathrm{O}_{2}$ & - & + & - & + \\
\hline Phospho-p53(S15) & \multicolumn{2}{|c}{} \\
\hline p53 & \multicolumn{1}{|c}{} \\
\hline
\end{tabular}

\begin{tabular}{|c|c|c|c|c|}
\hline Ku-55933 & - & - & + & + \\
\hline $\mathrm{H}_{2} \mathrm{O}_{2}$ & - & + & - & + \\
\hline $\begin{array}{c}\text { Phospho-Chk2 } \\
\text { (T68) }\end{array}$ & & & & \\
\hline Chk2 & & \\
\hline
\end{tabular}

Figure 3.1 ATM is activated by $\mathrm{H}_{2} \mathrm{O}_{2}$ in cells in the absence of DSBs. (A) 293T cells were grown to near confluence and treated with $0.5 \mathrm{mM} \mathrm{H} \mathrm{H}_{2}$ for $30 \mathrm{~min}$. Whole cell lysates were prepared as described in Chapter 2. 10ug of the total cell lysate was separated by SDS-PAGE and analyzed by western blotting. The phosphorylation of ATM and its substrates were detected with phospho-specific antibodies as indicated. (B) 293T cells were treated as in (A) and analyzed for Kap1 phosphorylation and the formation of $\gamma$ H2AX. (C) 293T cells were treated as in (A) and analyzed for ATM autophosphorylation and the phosphorylation of Chk2 and in the presence of ATM inhibitor, Ku-55933 (10 $\mu \mathrm{M})$. Cells were treated with $\mathrm{Ku}-55933$ for 1 hour before the addition of $\mathrm{H}_{2} \mathrm{O}_{2}$. 


\section{ATM dimerization by $\mathrm{H}_{2} \mathrm{O}_{2}$ in cells}

Our explanation for ATM activation by $\mathrm{H}_{2} \mathrm{O}_{2}$ under non-DSB-inducing conditions might be the ability of $\mathrm{H}_{2} \mathrm{O}_{2}$ to oxidize and activate ATM directly. We did observe that after $\mathrm{H}_{2} \mathrm{O}_{2}$ treatment, ATM was crosslinked by disulfide bonds and formed possible dimers or oligomers (Figure 3.2). To test whether direct oxidation of ATM could stimulate ATM activation, we tested cells with diamide, a chemical reagent known to specifically induce the formation of disulfides with a minimum of other effects. As shown in Figure 3.3, ATM autophosphorylation and p53 phosphorylation were induced by diamide treatment. The similarity between $\mathrm{H}_{2} \mathrm{O}_{2}$ and diamide treatments suggests that $\mathrm{H}_{2} \mathrm{O}_{2}$ can activate ATM by inducing disulfide formation in ATM. 


\begin{tabular}{|c|c|c|c|c|c|c|c|c|}
\hline $\mathrm{H}_{2} \mathrm{O}_{2}(\mathrm{mM})$ & \multicolumn{2}{|c|}{0} & \multicolumn{2}{|c|}{0.25} & \multicolumn{2}{|c|}{0.5} & \multicolumn{2}{|c|}{0.75} \\
\hline Loading buffer & $\mathrm{R}$ & NR & $\mathrm{R}$ & $\mathrm{NR}$ & $\mathrm{R}$ & $\mathrm{NR}$ & $\mathrm{R}$ & NR \\
\hline $\begin{array}{c}\text { Phospho-ATM } \\
(\mathrm{S} 1981)\end{array}$ & 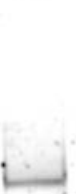 & & a & & 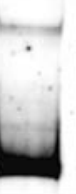 & & - & \\
\hline ATM & & & & & 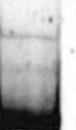 & & 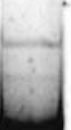 & \\
\hline
\end{tabular}

Figure 3.2 The oligomerization of ATM with $\mathrm{H}_{2} \mathrm{O}_{2}$ treatment in a cell line stably expressing Flag-tagged wild-type ATM. ATM was isolated with Anti-Flag M2 resin (Sigma) from cells lysate prepared from a human 293 cell line stably expressing FlagATM. ATM was eluted with Flag peptide, treated with either reducing (R) or nonreducing (NR) loading buffer, separated in a 6\% SDS-PAGE, western-blotted, and probed with antibodies specific for ATM or ATM phospho- serine 1981. 


\begin{tabular}{|c|c|c|c|}
\hline $\mathrm{H}_{2} \mathrm{O}_{2}$ & \multicolumn{2}{|c|}{-} & + \\
\hline Diamide & - & + & - \\
\hline $\begin{array}{c}\text { Phospho-ATM } \\
(\mathrm{S} 1981)\end{array}$ & & \\
\hline ATM & \\
\hline $\begin{array}{c}\text { Phospho-p53 } \\
\text { (S15) }\end{array}$ & \\
\hline p53 & \\
\hline
\end{tabular}

Figure 3.3 Diamide induces ATM autophosphorylation and p53 phosphorylation. The cell line stably expressing wild-type ATM was cultured to near confluence and treated with $0.5 \mathrm{mM}$ diamide for 30min. Whole cell lysates was seperated by SDS-PAGE and western-blotted with ATM and p53 antibodies as indicated. 


\section{ATM activation by $\mathrm{H}_{2} \mathrm{O}_{2}$ in NBS cells}

We also tested if $\mathrm{H}_{2} \mathrm{O}_{2}$ can induce ATM activation in NBS cells. NBS cells express a truncated form of the NBS1 protein and reduced levels of MRN complex [110, 111]. NBS cells are deficient in the normal cellular response to DSBs; hence this is a good system to test if $\mathrm{H}_{2} \mathrm{O}_{2}$ can induce ATM activation when cells cannot efficiently recognize DSBs. We found that in NBS cells, $\mathrm{H}_{2} \mathrm{O}_{2}$ can induce ATM-dependent p53 and Chk2 phosphorylation (Figure 3.4). To our surprise, ATM autophosphorylation is absent even when ATM is activated by $\mathrm{H}_{2} \mathrm{O}_{2}$ to phosphorylate p53. Autophosphorylation is a controversial issue in the literature $[24,50]$, and it is still not clear whether ATM autophosphorylation is required for ATM activation. It seems that, in our case, ATM autophosphorylation is not necessary for ATM activation by $\mathrm{H} 2 \mathrm{O} 2$ but we can still use it as a hallmark for ATM activation in cells with wildtype NBS1 protein. We will further test ATM autophosphorylation and activation later in our in vitro system. 
A

\begin{tabular}{|c|c|c|c|c|}
\hline Ku-55933 & - & - & + & + \\
\hline $\mathrm{H}_{2} \mathrm{O}_{2}$ & - & + & - & + \\
\hline $\begin{array}{c}\text { Phospho-ATM } \\
(\mathrm{S} 1981)\end{array}$ & wTM & & \\
\hline ATM & & \\
\hline
\end{tabular}

B

\begin{tabular}{|c|c|c|c|c|}
\hline Ku-55933 & - & - & + & + \\
\hline $\mathrm{H}_{2} \mathrm{O}_{2}$ & - & + & - & + \\
\hline T68-P Chk2 & \multicolumn{2}{|c|}{ Ans } \\
\hline Chk2 & \multicolumn{2}{|c}{} \\
\hline
\end{tabular}

C

\begin{tabular}{|c|c|c|c|c|}
\hline $\mathrm{Ku}-55933$ & - & - & + & + \\
\hline $\mathrm{H}_{2} \mathrm{O}_{2}$ & - & + & - & + \\
\hline $\mathrm{S} 15-\mathrm{P}$ P53 & - & - \\
\hline P53 & &
\end{tabular}

Figure $3.4 \mathrm{H}_{2} \mathrm{O}_{2}$ activates ATM in NBS cells. NBS cells were cultured to near confluence and treated with $0.5 \mathrm{mM} \mathrm{H}_{2} \mathrm{O}_{2}$ before lysis and analyzed. The ATM inhibitor $\mathrm{Ku}-55933$ was added to cells 1 hour before exposure to $\mathrm{H}_{2} \mathrm{O}_{2}$ as described in Figure 3.1. (A) $\mathrm{H}_{2} \mathrm{O}_{2}$ does not induce ATM autophosphorylation in the absence of NBS1. (B)(C) H2O2 induces p53 and Chk2 phosphorylation by ATM. 


\section{ATM activation by $\mathrm{H}_{2} \mathrm{O}_{2}$ in primary cells}

The 293T cell line shows relatively high levels of $\gamma$-H2AX in untreated cells (Figure 3.1B). We decided to also test normal primary fibroblasts because of these cells show lower $\gamma$-H2AX in similar experiments (D. Johnson, personal communication). ATM autophosphorylation and substrate phosphorylation induced by $\mathrm{H}_{2} \mathrm{O}_{2}$ were detected

as above. In normal primary fibroblasts, ATM was activated by $\mathrm{H}_{2} \mathrm{O}_{2}$ at the concentration of $0.25 \mathrm{mM}$ without detectable phosphorylation of H2AX and Kap1 (Figure 3.5). The DNA damaging agent bleomycin $(10 \mu \mathrm{M})$ was used as a control. Bleomycin can induce the phosphorylation of H2AX and Kap1 in addition to ATM and p53. This result demonstrated that ATM could be activated by $\mathrm{H}_{2} \mathrm{O}_{2}$ without detectable DSBs in a nontransformed human cell line also. 
A

\begin{tabular}{|c|c|c|c|}
\hline Bleomycin & - & - & + \\
\hline $\mathrm{H}_{2} \mathrm{O}_{2}$ & - & + & - \\
\hline $\begin{array}{c}\text { Phospho-ATM } \\
\text { (S1981) }\end{array}$ & & \\
\hline ATM & \\
\hline
\end{tabular}

\begin{tabular}{|c|c|c|c|}
\hline Bleomycin & - & - & + \\
\hline $\mathrm{H}_{2} \mathrm{O}_{2}$ & - & + & - \\
\hline $\begin{array}{c}\text { Phospho-p53 } \\
(\mathrm{S} 15)\end{array}$ & \multicolumn{3}{|c}{} \\
\hline $\mathrm{p} 53$ & & \\
\hline
\end{tabular}


B

\begin{tabular}{|c|c|c|c|}
\hline Bleomycin & - & - & + \\
\hline $\mathrm{H}_{2} \mathrm{O}_{2}$ & - & + & - \\
\hline $\begin{array}{c}\text { Phospho-Kap1 } \\
(\mathrm{S} 824)\end{array}$ & & - \\
\hline Kap1 & - & - \\
\hline
\end{tabular}

\begin{tabular}{|c|c|c|c|}
\hline Bleomycin & - & - & + \\
\hline $\mathrm{H}_{2} \mathrm{O}_{2}$ & - & + & - \\
\hline$\gamma-\mathrm{H} 2 \mathrm{AX}$ & & & \\
\hline $\mathrm{H} 2 \mathrm{AX}$ & & \\
\hline
\end{tabular}

Figure $3.5 \mathrm{H}_{2} \mathrm{O}_{2}$ activates ATM in normal primary fibroblasts (GM08399). Cells were grown to near confluence and treated with $0.25 \mathrm{mM} \mathrm{H}_{2} \mathrm{O}_{2}$ or $10 \mathrm{uM}$ Bleomycin for 30 minutes. Phosphorylation of ATM and its substrates was detected with phospho-specific antibodies as described in Figure 3.1. (A) $\mathrm{H}_{2} \mathrm{O}_{2}$ induces ATM autophosphorylation and the phosphorylation of p53 in normal primary fibroblast. (B) H2O2 does not induce Kap1 phosphorylation and the formation of $\gamma$-H2AX under the same conditions. 
Many DNA damaging agents, including IR, induce oxidative stress in cells as well as direct DNA damage. It is difficult to tell whether ATM is activated by DSBs or direct oxidation. We carefully chose the concentration and time of $\mathrm{H}_{2} \mathrm{O}_{2}$ treatment to avoid DSBs while selecting conditions to oxidize and activate ATM. In cells, many proteins and pathways could be affected by $\mathrm{H}_{2} \mathrm{O}_{2}$ treatment, which makes it more complicated to explain. Based on my cellular assay we hypothesized that $\mathrm{H}_{2} \mathrm{O}_{2}$ directly activates ATM, a question I further addressed using an in vitro kinase assay.

\section{ATM ACTIVATION IN VITRO}

We tested ATM activation by $\mathrm{H}_{2} \mathrm{O}_{2}$ in vitro with ectopically expressed and purified ATM. $\mathrm{H}_{2} \mathrm{O}_{2}$ was added directly to ATM in the absence of MRN or DNA and activation was measured by p53 phosphorylation. In our in vitro kinase assay we found that ATM is activated by $\mathrm{H}_{2} \mathrm{O}_{2}$ directly and the activation is comparable to ATM activation by MRN and DNA (Figure 3.6).

Using purified dimeric ATM, our laboratory previously showed that ATM can be activated by MRN and DSBs, in which MRN serves as DSB sensor to help ATM recognize DSBs [24]. MRN is necessary for ATM activation by DSBs in vitro. But ATM activation by $\mathrm{H}_{2} \mathrm{O}_{2}$ requires neither DNA nor MRN. ATM activation was measured with a titration of $\mathrm{H}_{2} \mathrm{O}_{2}$ concentrations; I found that ATM was activated by $\mathrm{H}_{2} \mathrm{O}_{2}$ at concentrations as low as $100 \mathrm{uM}$. The activation did not occur when the concentration was over 2mM (Figure 3.6A). Depending on the concentration of ATM used in the kinase 

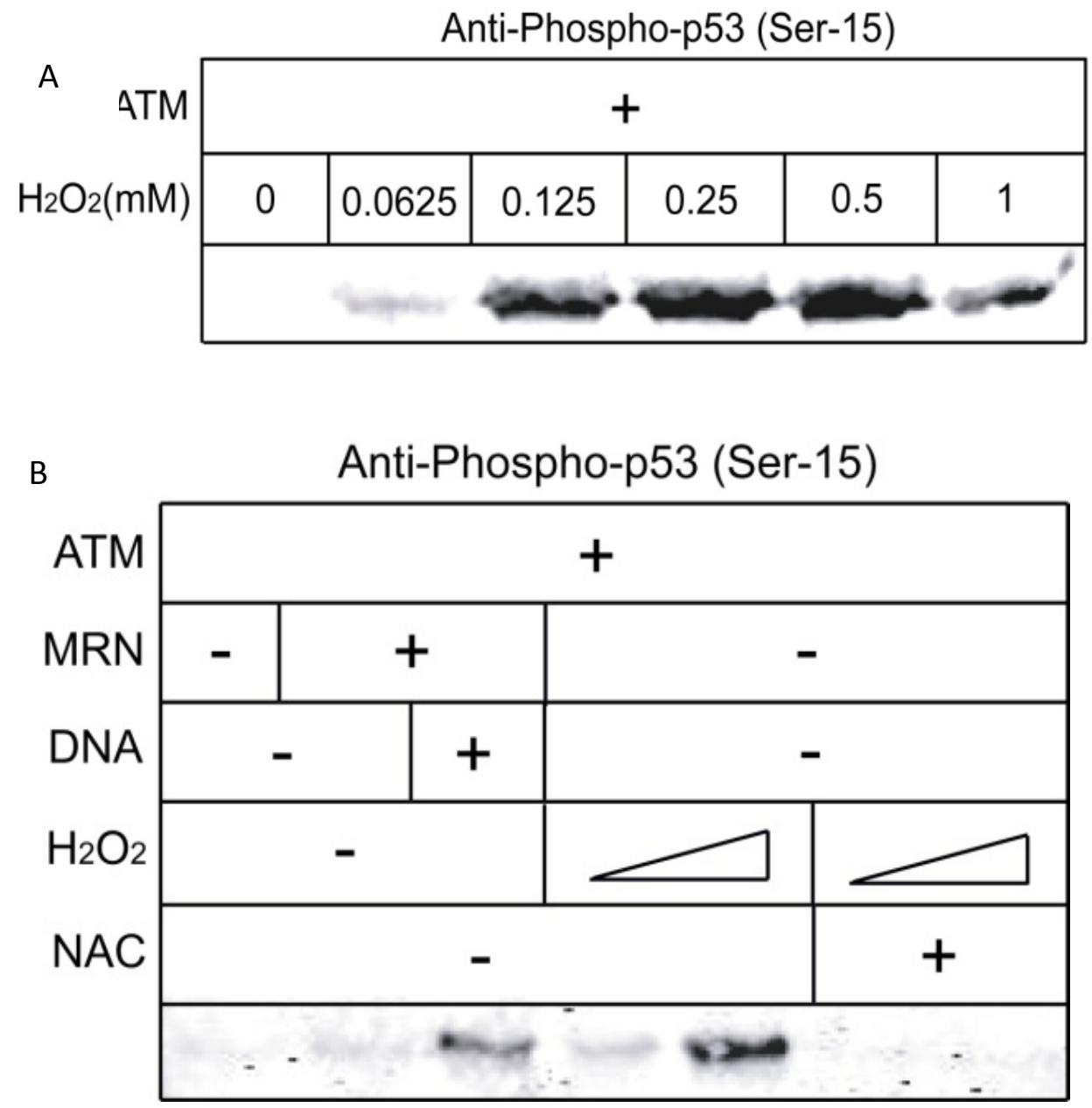

Figure 3.6 ATM is activated by $\mathrm{H}_{2} \mathrm{O}_{2}$ in vitro. (A) Purifed dimeric ATM was incubated with GST-p53 and various concentrations of $\mathrm{H}_{2} \mathrm{O}_{2}$, and phosphorylation by ATM was detected with p53 phospho-ser15 specific antibody. (B) ATM activation by $\mathrm{H}_{2} \mathrm{O}_{2}$ is independent of MRN and DNA and can be attenuated by reducing reagent $\mathrm{N}$-Acetyl Cysteine (NAC). ATM kinase assays were performed as in (A) but also comparing activation by MRN and DNA to $\mathrm{H}_{2} \mathrm{O}_{2}$ activation. The anti-oxiant NAC (1mM) was added as indicated. 
assay, the optimal concentration of $\mathrm{H}_{2} \mathrm{O}_{2}$ may vary. When we purify recombinant ATM

from 293T cells, $1 \mathrm{mM}$ DTT is added to the buffer before storage in order to protect ATM from oxygen, otherwise the ATM appears to be constitutively active (data not shown). Thus, in the in vitro kinase assay more $\mathrm{H}_{2} \mathrm{O}_{2}$ is needed to neutralize DTT in the buffer and react with ATM when a larger volume of ATM is used. The activation of ATM by $\mathrm{H}_{2} \mathrm{O}_{2}$ can be inhibited by reducing reagent NAC, suggesting $\mathrm{H}_{2} \mathrm{O}_{2}$ may activate ATM by direct oxidation (Figure 3.6B).

\section{ATM dimerization in vitro}

In vitro experiments also showed that ATM was crosslinked by intermolecular difulfide bonds when treated by $\mathrm{H}_{2} \mathrm{O}_{2}$, similar to the result with $\mathrm{H}_{2} \mathrm{O}_{2}$ treatment of 293 cells (Figure 3.7A). Instead of being dissociated into active monomers, like in the MRN and DNA dependent activation [42], ATM retained its dimer form upon $\mathrm{H}_{2} \mathrm{O}_{2}$ treatment. I measured the size of oxidized ATM by glycerol gradient ultracentrifugation and found that it is a dimer (Figure 3.7B). 
A

\begin{tabular}{|c|c|c|c|c|c|c|c|c|}
\hline $\mathrm{H}_{2} \mathrm{O}_{2}(\mathrm{mM})$ & \multicolumn{2}{|c|}{0} & \multicolumn{2}{|c|}{0.125} & \multicolumn{2}{|c|}{0.25} & \multicolumn{2}{|c|}{0.5} \\
\hline Loading buffer & $\mathrm{R}$ & NR & $\mathrm{R}$ & NR & $\mathrm{R}$ & NR & $\mathrm{R}$ & NR \\
\hline ATM & & . & & & & & & \\
\hline & & & $E$ & & 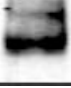 & & $\therefore i$ & . \\
\hline
\end{tabular}

B

monomer dimer

\begin{tabular}{|c|c|c|c|c|c|c|c|c|c|}
\hline Fraction & 9 & 10 & 11 & 12 & 13 & 14 & 15 & 16 & 17 \\
\hline$-\mathrm{H}_{2} \mathrm{O}_{2}$ & $\therefore$ & 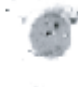 & 2 & & & $\theta$ & 0 & : & 4 \\
\hline$+\mathrm{H}_{2} \mathrm{O}_{2}$ & 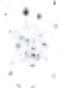 & & (4) & : & & 0 & & 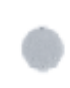 & \\
\hline
\end{tabular}

Figure 3.7 Dimeric, oxidized ATM is active. (A) ATM oxidized by various concentrations of $\mathrm{H}_{2} \mathrm{O}_{2}$ in vitro was treated with reducing or non-reducing loading buffer, separated by $6 \%$ SDS-PAGE and analyzed by western blotting. ATM was detected by ATM antibody. (B) The size of ATM before and after $\mathrm{H}_{2} \mathrm{O}_{2}$ treatment was arrayed by separating biotinylated ATM in a 10-20\% glycerol gradient. 500ul fractions of the gradient were taken from the top and tested for biotinylated ATM with a dot-blot, using a streptavidin/IR onjugate to detect ATM. The positions of monomeric and dimeric ATM were determined by separation of gel filtration markers (GE) in a similar gradient as described previously [24]. 


\section{Autophosphorylation is not required for ATM activation by $\mathrm{H}_{2} \mathrm{O}_{2}$ in vitro}

Autophosphorylation on serine 1981 was proposed to be important for ATM dimer dissociation and activation [42], but results in both in vitro kinase assays and knock-in mutant mice showed that the ATM S1981A mutant are fully active. I investigated whether $\mathrm{H}_{2} \mathrm{O}_{2}$ could induce ATM autophosphorylation in vitro. In my kinase assay conditions, $\mathrm{H}_{2} \mathrm{O}_{2}$ does not induce ATM autophosphorylation as detected by the incorporation of $\gamma$-ATP (Figure 3.8A). The ATM S1981A mutant was also fully activated by $\mathrm{H}_{2} \mathrm{O}_{2}$ in vitro (Figure 3.8B). Therefore autophosphorylation on serine 1981 is not necessary for ATM activation by $\mathrm{H}_{2} \mathrm{O}_{2}$. 
A

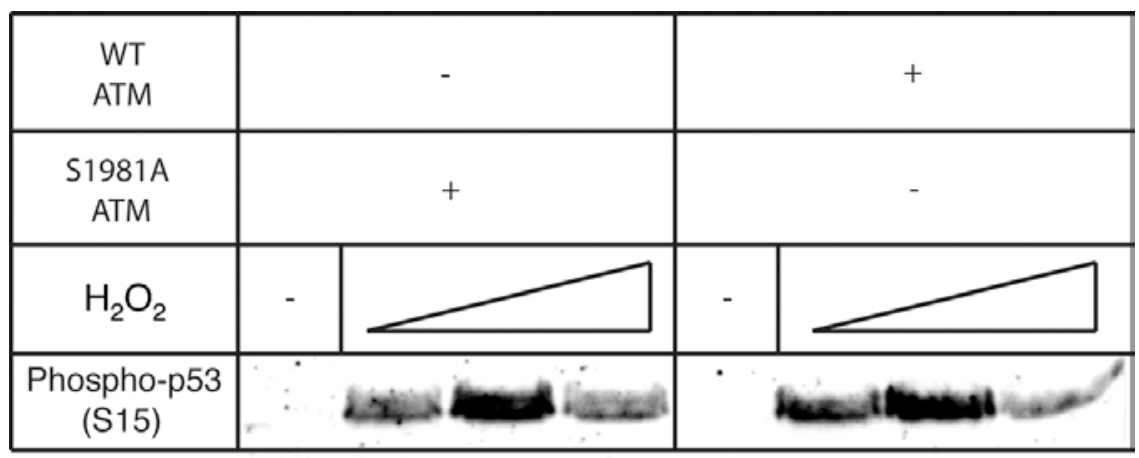

B

\begin{tabular}{|c|c|c|c|c|}
\hline MRN & \multicolumn{2}{|c|}{+} \\
\hline DNA & \multicolumn{3}{|c|}{+} \\
\hline $\mathrm{H}_{2} \mathrm{O}_{2}$ & - & + & - \\
\hline ATM & & \multicolumn{3}{|c|}{} \\
\hline
\end{tabular}

Figure 3.8 ATM autophosphorylation on serine 1981 is not required for ATM activation by $\mathrm{H}_{2} \mathrm{O}_{2}$. (A) ATM S1981A is activated by $\mathrm{H}_{2} \mathrm{O}_{2}$. Wild-type and S1981A dimeric ATM were incubated with various concentrations of $\mathrm{H}_{2} \mathrm{O}_{2}(0.81,2.4$ and $7.3 \mathrm{mM})$ and analyzed by western blotting as described in Figure 3.1. (B) $\mathrm{H}_{2} \mathrm{O}_{2}$ does not induce ATM autophosphorylation in vitro. The wild-type ATM was used in a kinase assay in vitro in the presence of $50 \mathrm{uM}$ cold ATP and $1 \mathrm{ul} \gamma-\left[{ }^{32} \mathrm{P}\right]-$ ATP and $0.8 \mathrm{mM} \mathrm{H}_{2} \mathrm{O}_{2}$. The products were visualized using phosphorimager analysis. ATM autophosphorylation by MRN and DNA was used as control. 


\section{$\mathrm{H}_{2} \mathrm{O}_{2}$ increases substrate binding to ATM}

MRN activates ATM by facilitating DSB recognition, dimer dissociation, and substrate binding [26]. While $\mathrm{H}_{2} \mathrm{O}_{2}$ activates ATM independently of both MRN and DSBs and appears to dimerize ATM, we tested if $\mathrm{H}_{2} \mathrm{O}_{2}$ can help substrate binding, as oxidation might change the conformation of substrate binding sites in ATM. Biotinylated ATM bound to streptavidin beads was used to pull down GST-p53 in the absence or presence of $0.25 \mathrm{mM} \mathrm{H}_{2} \mathrm{O}_{2}$. As shown in Figure 3.9, $\mathrm{H}_{2} \mathrm{O}_{2}$ increases the ability of ATM to bind GST-p53.

Manganese allows ATM to be active in vitro in the absence of MRN and DNA $[11,26]$. Figure 3.10 shows that in the presence of $2.5 \mathrm{mM} \mathrm{Mn}^{2+}, \mathrm{H}_{2} \mathrm{O}_{2}$ can stimulate ATM more efficiently in the presence of lower ATP concentrations. This suggests that $\mathrm{H}_{2} \mathrm{O}_{2}$ also promotes ATP binding by ATM (Figure 3.10). 


\begin{tabular}{|l|c|c|c|c|}
\hline ATM & \multicolumn{2}{|c|}{-} & \multicolumn{2}{|c|}{+} \\
\hline $\mathrm{H}_{2} \mathrm{O}_{2}$ & - & + & - & + \\
\hline GST & mene \\
\hline
\end{tabular}

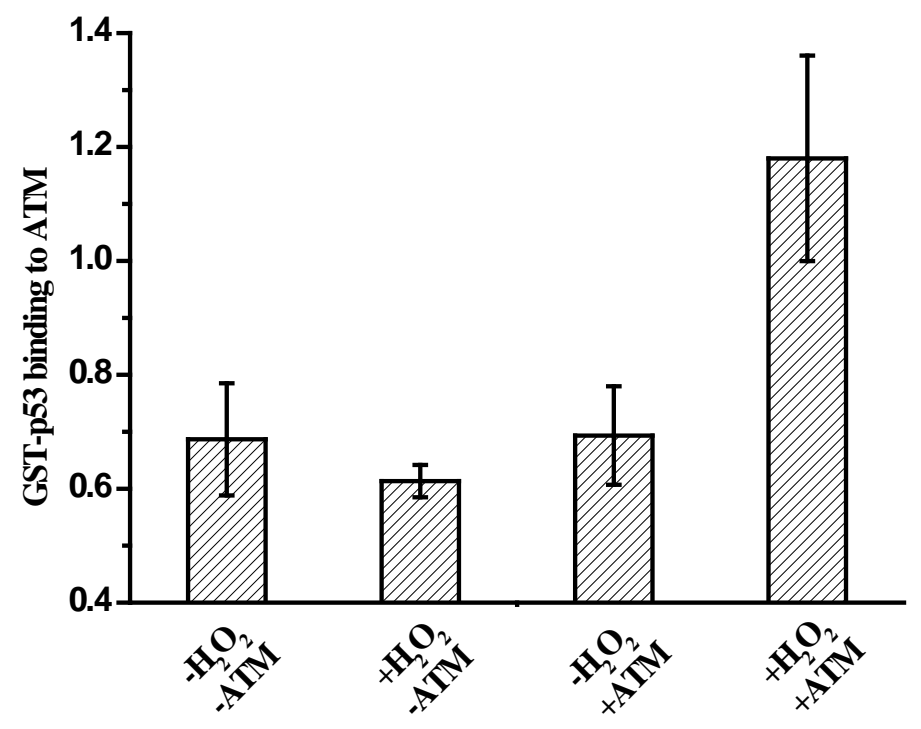

Figure $3.9 \mathrm{H}_{2} \mathrm{O}_{2}$ helps ATM bind substrates . $\mathrm{H}_{2} \mathrm{O}_{2}$ increases the efficiency of GST-p53 binding by ATM. Biotinylated ATM was bound to streptavidin beads (Promega) and incubate with GST-p53 in the presence or absence of $\mathrm{H}_{2} \mathrm{O}_{2}$. The amount of GST-p53 substrate bound was quantified with western blotting using an anti-GST antibody (GE). Three independent experiments were performed and the average of these is shown here with the error bars indicating the standard deviation. 


\begin{tabular}{|c|c|c|c|c|c|c|c|c|}
\hline ATM & \multicolumn{9}{|c|}{+} \\
\hline ATP $(\mu \mathrm{M})$ & \multicolumn{2}{|c|}{62.5} & \multicolumn{2}{|c|}{125} & \multicolumn{2}{|c|}{250} & \multicolumn{2}{c|}{500} \\
\hline $\mathrm{H}_{2} \mathrm{O}_{2}$ & - & + & - & + & - & + & - & + \\
\hline $\begin{array}{c}\text { Phospho-p53 } \\
\text { Ser15 }\end{array}$ & \multicolumn{7}{|c}{} \\
\hline
\end{tabular}

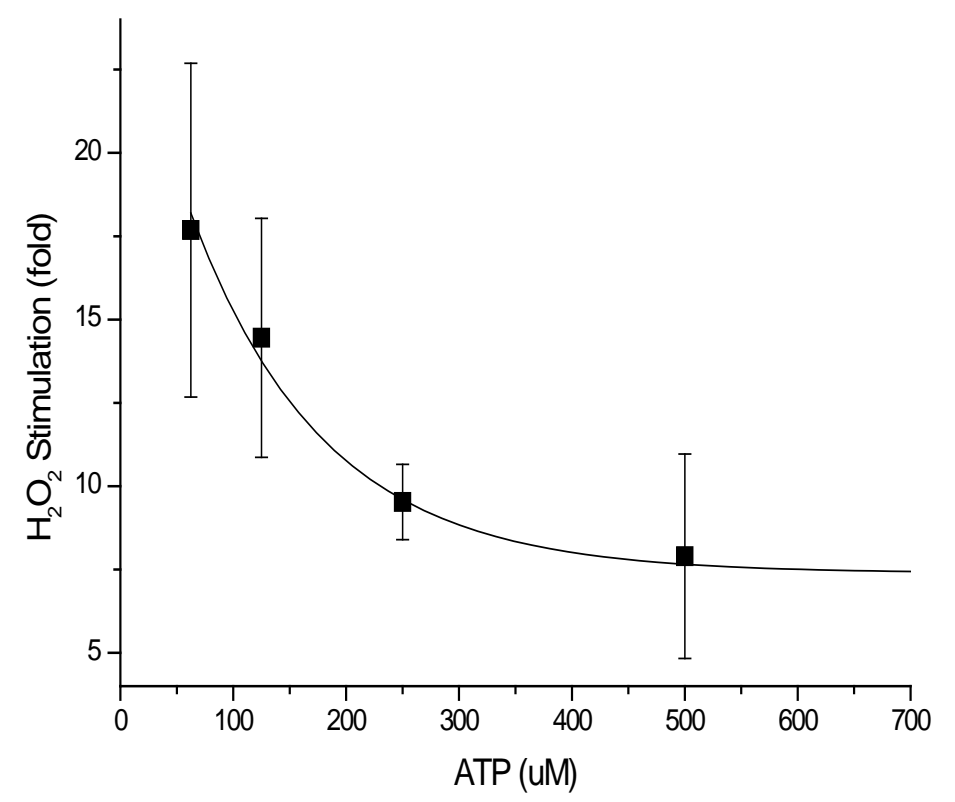

Figure $3.10 \mathrm{H}_{2} \mathrm{O}_{2}$ stimulate ATP binding by ATM. ATM was treated with $0.8 \mathrm{mM} \mathrm{H}_{2} \mathrm{O}_{2}$ and the stimulation in 553 phosphorylation was measured with different concentrations of ATP in the presence of $2.5 \mathrm{mM}$ manganese chloride. Phosphorylation of p53 on serine 15 was quantified with Odyssey software (Li-Cor). The y axis shows the ratio of the level of p53 phosphorylation in the presence of $\mathrm{H}_{2} \mathrm{O}_{2}$ over the level of p53 phosphorylation in the absence of $\mathrm{H}_{2} \mathrm{O}_{2}$. Three independent experiments were performed and the average of these is shown here with the error bars indicating the standard deviation. 


\section{ATM oxidative activation compensates MRN/DNA dependent activation}

I also investigated if a pathway of ATM activation by $\mathrm{H}_{2} \mathrm{O}_{2}$ coexists with the MRN and DNA dependent pathway in cells. Oxidation has been shown to reduce the ability of many DNA-binding proteins $[112,113]$. The MRN complex acts as sensor for DSBs, so I hypothesized that oxidative stress may also reduce the ability of MRN recognizing DSBs and attenuate MRN-dependent ATM activation. In this way, direct activation of ATM through oxidization may complement the overall ATM activation if the MRN-mediated pathway is attenuated. I performed in vitro binding assays which showed that MRN bound DNA less efficiently in the presence of $\mathrm{H}_{2} \mathrm{O}_{2}$, and ATM activation by MRN and DNA were attenuated (Figure 3.11A). However, higher concentrations of $\mathrm{H}_{2} \mathrm{O}_{2}$ stimulated ATM activity and complemented the loss of MRN and DNA dependent pathway. (Figure 3.11B)

These results provide evidence for a novel ATM activation pathway in cells. ATM can be activated through oxidation by $\mathrm{H}_{2} \mathrm{O}_{2}$, independent of the MRN complex and DSBs. Oxidized ATM phosphorylates traditional ATM substrates, like p53 and Chk2. Oxidation by $\mathrm{H}_{2} \mathrm{O}_{2}$ can also induce ATM autophosphorylation on serine 1981 in cells but not in vitro. The active form of oxidized ATM appears to be a dimer with an increased ability to bind substrates. In cells, the oxidation pathway of ATM activation complements MRN and DNA dependent pathway when cells suffer oxidative stress. In this pathway ATM serves as a sensor of changes in redox potential in addition to its important role in sensing DNA damage. 
A

\begin{tabular}{|c|c|c|c|c|}
\hline Bio-DNA & \multicolumn{2}{|c|}{-} & \multicolumn{2}{|c|}{} \\
\hline $\mathrm{H}_{2} \mathrm{O}_{2}$ & - & + & - & + \\
\hline Rad50 & - & - \\
\hline NBS1 & \multicolumn{3}{|c|}{} \\
\hline
\end{tabular}

B

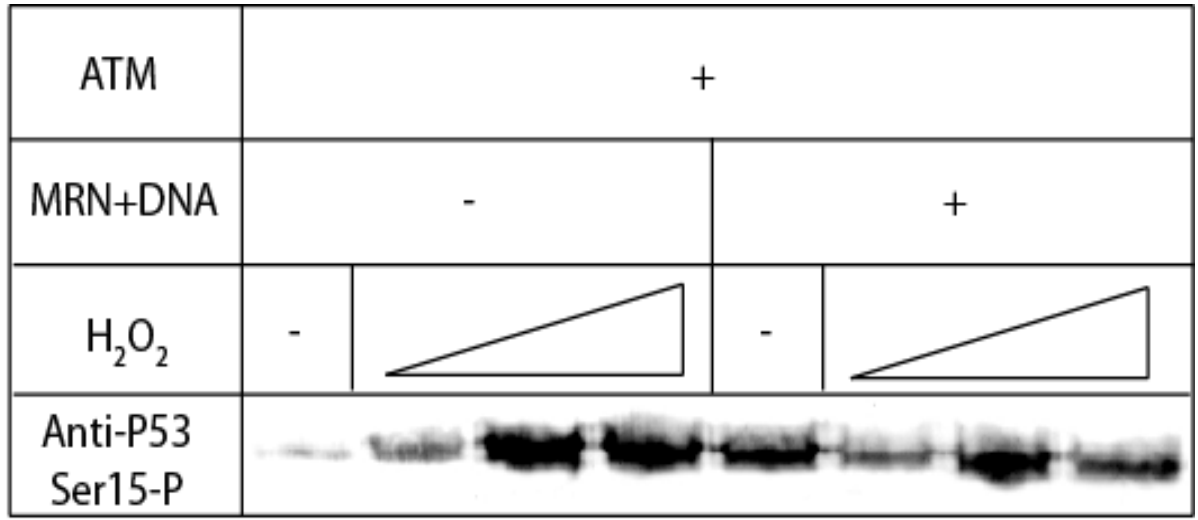

Figure $3.11 \mathrm{H}_{2} \mathrm{O}_{2}$ attenuates $M R N$ - and DNA-dependent ATM activation. (A) $\mathrm{H}_{2} \mathrm{O}_{2}$ inhibited MRN binding to linear DNA. Biotinylated DNA was prepared as described and bound to streptavidin beads (invitrogen). Purified MRN was incubated with DNA bound beads in the presence or absence of $\mathrm{H}_{2} \mathrm{O}_{2}(0.5 \mathrm{mM})$ and the amount of MRN bound to the DNA were determined by western blotting for Rad50 and NBS1. (B) $\mathrm{H}_{2} \mathrm{O}_{2}$ inhibits MRNand DNA- dependent ATM activation. 


\section{CHAPTER 4: ATM MUTAGENESIS}

\section{OXIDATION OF CYSTEINE RESIDUES IS RESPONSIBLE FOR ATM ACTIVATION}

ATM activation by $\mathrm{H}_{2} \mathrm{O}_{2}$ can be attenuated by reducing reagents like NAC or DTT (Figure 3.1B), indicating that the ability of $\mathrm{H}_{2} \mathrm{O}_{2}$ to oxidize some protein residues may be important for the activation. Because cysteine, of all the protein residues, is most susceptible to oxidization, we used diamide in cells (Figure 3.3) as well as in the in vitro kinase assay to demonstrate the importance of cysteine oxidation. These experiments showed that diamide can induce the activation of ATM in vitro in a purified system (Figure 4.1). Titration of diamide showed a similar pattern of ATM activation as $\mathrm{H}_{2} \mathrm{O}_{2}$, although the maximal activation is less, which might be due to the size difference between diamide and $\mathrm{H}_{2} \mathrm{O}_{2}$ molecules. It may be more difficult for the relatively bulky molecules of diamide to access critical residues in ATM. This observation, together with the fact that ATM was crosslinked by interdimer disulfide bonds, suggests that oxidization of cysteine residues into disulfide bonds is likely to be important for ATM activation by $\mathrm{H}_{2} \mathrm{O}_{2}$. 


\begin{tabular}{|c|c|c|}
\hline ATM & \multicolumn{2}{|c|}{+} \\
\hline Diamide & - & \\
\hline $\mathrm{H}_{2} \mathrm{O}_{2}$ & $\square$ & - \\
\hline $\begin{array}{c}\text { Phospho-p53 } \\
\text { (S15) }\end{array}$ & 14 & id bla b \\
\hline
\end{tabular}

B

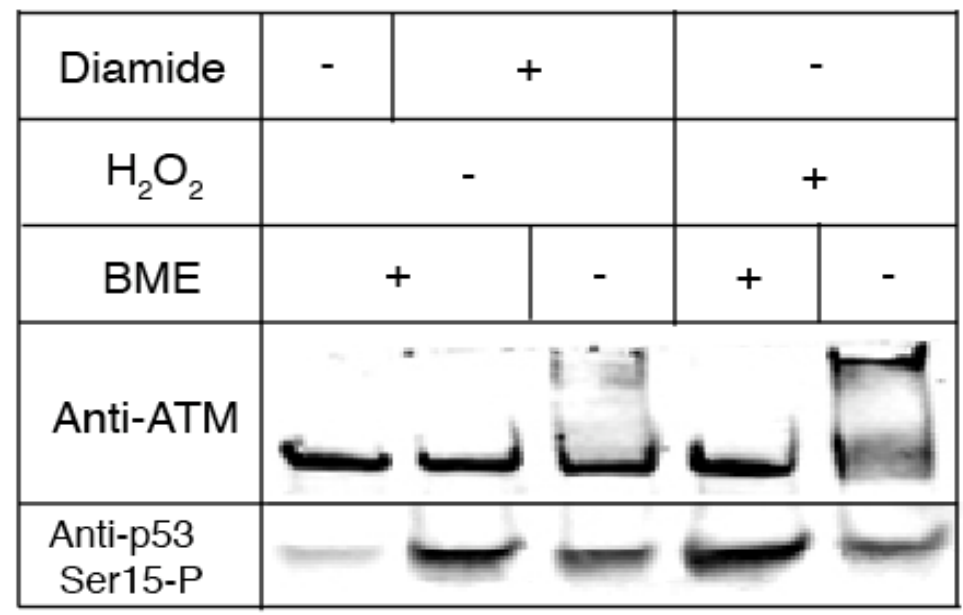

Figure 4.1 ATM is activated and dimerized by diamide in vitro. (A) ATM activation by diamide was compared to ATM activation by $\mathrm{H}_{2} \mathrm{O}_{2}$. ATM kinase assays were performed with dimeric purified ATM as described in Figure 3.6, except that $\mathrm{H}_{2} \mathrm{O}_{2}(0.09,0.27,0.8$, 2.4, 7.3 and $22 \mathrm{mM})$ and diamide $(0.9,2.7,8.3,25,75$ and $225 \mathrm{uM})$ were included in the reactions. (B) ATM is dimerized by diamide. ATM was activated by $\mathrm{H}_{2} \mathrm{O}_{2}(0.27 \mathrm{mM})$ and diamide (8.3 $\mathrm{uM})$ in vitro, and reactions were assayed for ATM dimerization as shown in Figure 3.7 as well as for p53 phosphorylation on serine 15. Phospho-p53 and ATM were separated on 6-12\% gel and detected by relevant antibodies. 


\section{CONSERVED CYSTEINE RESIDUES IN ATM}

ATM is a large protein with 3056 amino acids and 89 cysteines. There may be one or multiple cysteines responsible for ATM activation. To demonstrate that oxidationmediated ATM activation is separate from the MRN/DNA pathway, we attempted to identify the cysteine residues responsible for the activation of ATM by $\mathrm{H}_{2} \mathrm{O}_{2}$. We first looked at the conserved cysteines among ATM in different species. Most of the conserved cysteines are in the kinase, FAT, or FATC domains. While these cysteines are well conserved among mammals, most of them are not conserved in Tel1, the ATM orthologue in yeast. Unlike ATM, Tel1 is not the major kinase regulating cell cycle arrest in yeast. Tel1 function is partially redundant with the ATR homolog, Mec1 in DNA damage checkpoints. I tested the sensitivity of a $\Delta$ tell strain of budding yeast to $\mathrm{H}_{2} \mathrm{O}_{2}$, but found that $\Delta$ tell cells showed wild-type level of survival (Figure 4.2). The $\Delta y a p 1$ shown was used as a reference as yap1 is a critical factor controlling survival of oxidative stress in yeast [93]. Therefore, Tel1 does not appear to regulate cellular responses to oxidative stress in yeast. Then I looked for cysteine residues that were conserved in higher organisms but not in yeast. According to the alignment of ATM from different species, cysteine 1948 and 2704 are conserved in all organisms but S. cerevisiae. I mutated these two residues to serine, but found that the purified proteins still could be activated by $\mathrm{H}_{2} \mathrm{O}_{2}$ similar to wild-type ATM (data not shown).

Examination of the A-T database showed that $\mathrm{C} 2824 \mathrm{Y}$ is the only cysteine point mutation found in A-T patient (Leiden Open Variation database). I also found that the 

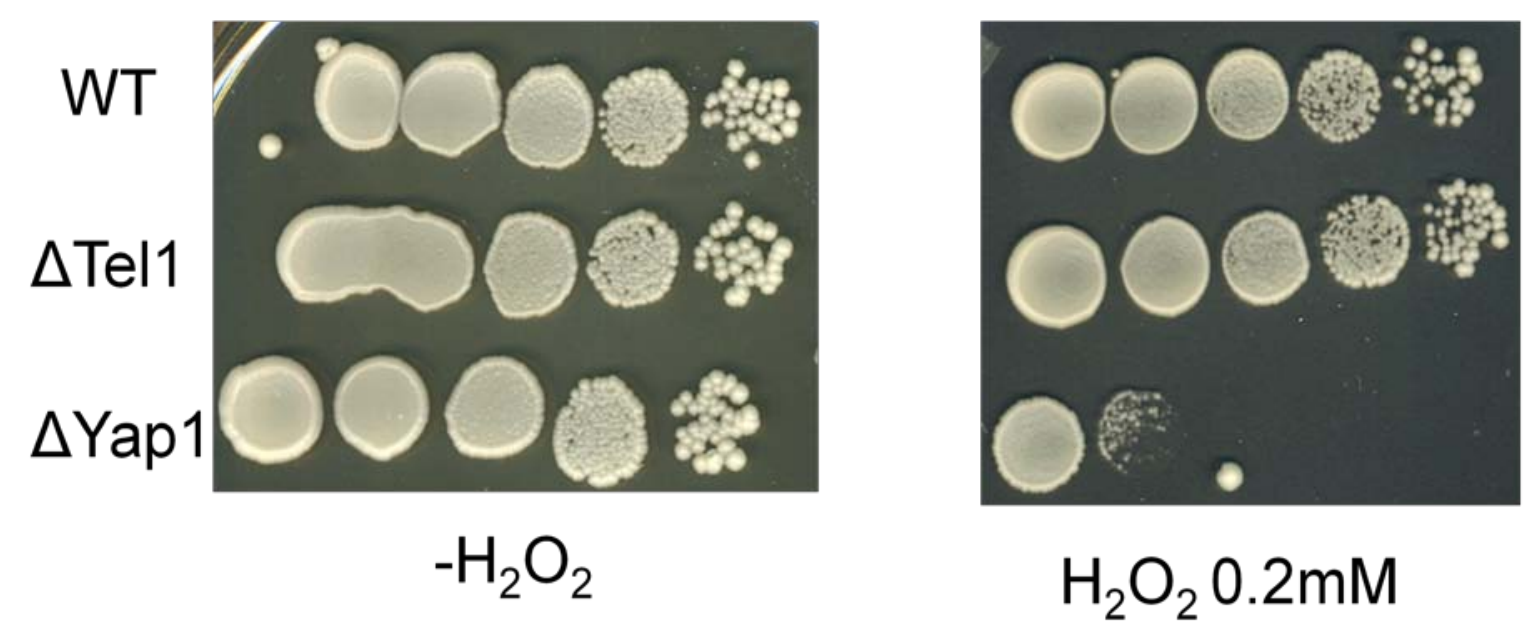

\section{$\mathrm{H}_{2} \mathrm{O}_{2} 0.2 \mathrm{mM}$}
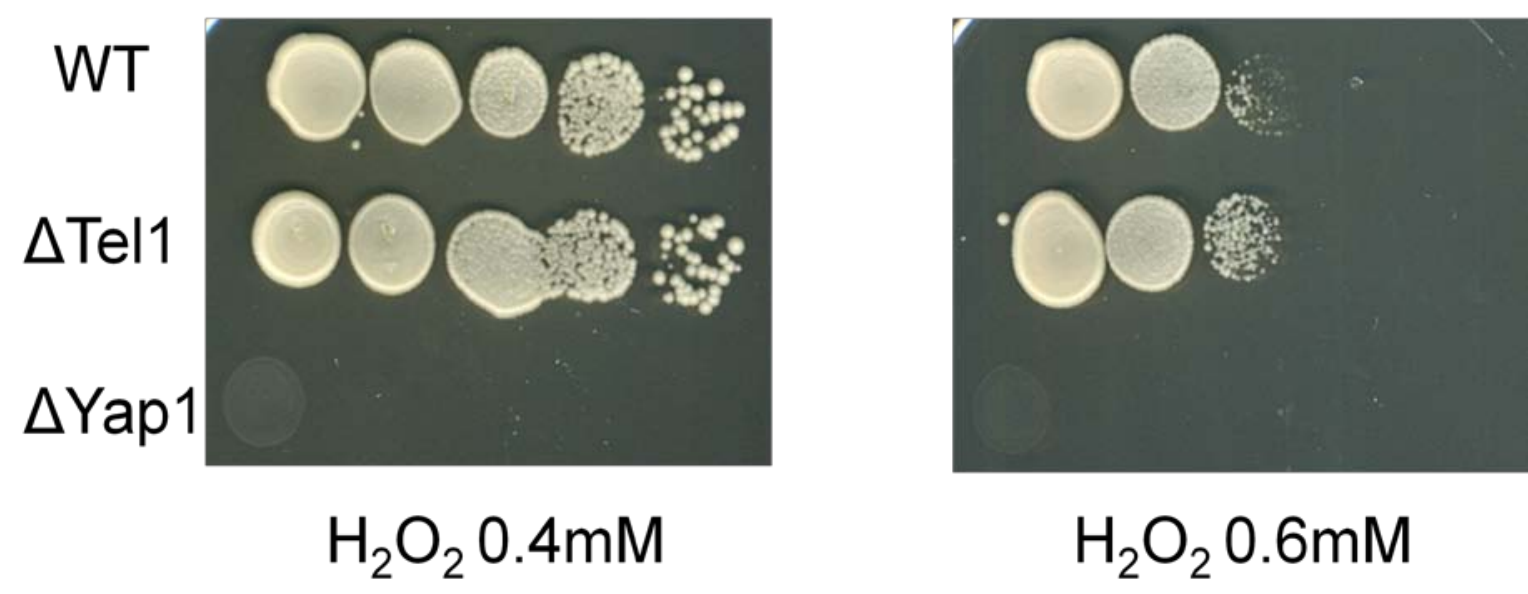

$\mathrm{H}_{2} \mathrm{O}_{2} 0.6 \mathrm{mM}$

Figure 4.2 Tel1 does not regulate cellular response to oxidative stress in yeast. The survivals of WT, $\Delta$ tel1 and $\Delta$ yap 1 strains were compared within various different concentration of $\mathrm{H}_{2} \mathrm{O}_{2}$. 
C540S mutation was found in colorectal adenocarcinoma in a large scale tumor sequencing project. Cysteines 1251 and 1286 are around the conserved leucine zipper motif, which had been demonstrated to be important for ATM function in human cells [114]. C783 and C786 are in a 'CXXC' motif, which has been found to regulate the activity of some redox-sensitive proteins $[115,116]$. These sites and their position in ATM domain are summarized in Table 4.1 and Figure 4.3. Each of these cysteines was individually changed to serine in the full-length protein, but the purified mutants still could be activated by $\mathrm{H}_{2} \mathrm{O}_{2}$ in vitro (data not shown, Table 4.1).

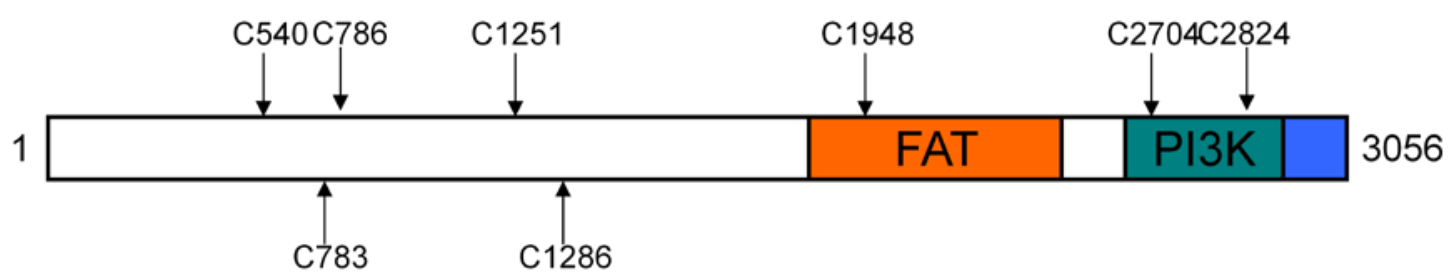

Figure 4.3 Map of conserved cysteine in ATM

\section{IDENTIFY ACTIVE CYSTEINE RESIDUES WITH MASS SPECTROMETRY}

Mass spectrometry has been widely used to identify modified amino acid residues. I also considered using this powerful tool to identify the sites of difulfide bonds in oxidized ATM. Preliminary experiments with ATM using whole protein in-gel trypsin digestion after oxidation in vitro were not successful (data not shown). The primary reason for this was the large size of ATM. With a molecular weight of $350 \mathrm{KD}$, wholeprotein digestion of ATM gave too many peptides to differentiate. 
Therefore I needed to separate our target peptides containing disulfide bonds from the sea of ATM tryptic digestion products. For this purpose, I used a biotin labeling reagent, EZ-link Biotin-HPDP (N-[6-(Biotinamido)hexyl]-3'-(2'pyridyldithio)propionamide). EZ-link Biotin-HPDP reacts reversibly with sulfhydryl (SH) groups. The disulfide bond between the target sulfhydryl and the biotin group can be cleaved by reducing agents to release the biotin group and regenerate the peptide in its unmodified form (Figure 4.4). Labeling peptides containing sulfhydryl groups with Biotin-HPDP enable us to pull down cysteine-containing peptides with streptavidin beads and recover the peptides from the beads by cleaving the disulfide bonds with a reducing reagent.

To use the BiotinHPDP reagent to identify sites of disulfide bonds, some changes were made to the standard in-gel tryptic digestion procedure. First target peptides need to be separated from other cysteine-containing peptides whose oxidation or reduction is not involved in ATM activation. Of the 89 cysteines in ATM, I hypothesized that some of them are in disulfide form and some are in sulfhydryl form before $\mathrm{H}_{2} \mathrm{O}_{2}$ treatment. I also hypothesized that the sulfhydryl group oxidation of some cysteine residues are important for the activation while others are not, although we do not know if the important disulfide(s) are intramolecular within an ATM monomer or intermolecular between two ATM polypeptides. There was also a possibility that some sulfhyryl group may never get oxidized during the $\mathrm{H}_{2} \mathrm{O}_{2}$ treatment. ATM was first oxidized with $\mathrm{H}_{2} \mathrm{O}_{2}$ then exposed to iodoacetamide to alkylate (block) any free sulfhydryl groups in ATM. Disulfide bonds 
were then reduced and labelled with Biotin-HPDP. By comparing streptavidin-bound tryptic peptides from treated vs untreated samples, the residues that are already in disulfide form before oxidation can be identified, as well as residues whose disulfide formation is induced by oxidation. The in-gel digestion protocol is detailed in the Chapter 2. Using this protocol I was able to identify cysteines $819,1045,1177,1396,2021$, and 2801 from several repeated experiments (Figure 4.5 and Table 4.1). 


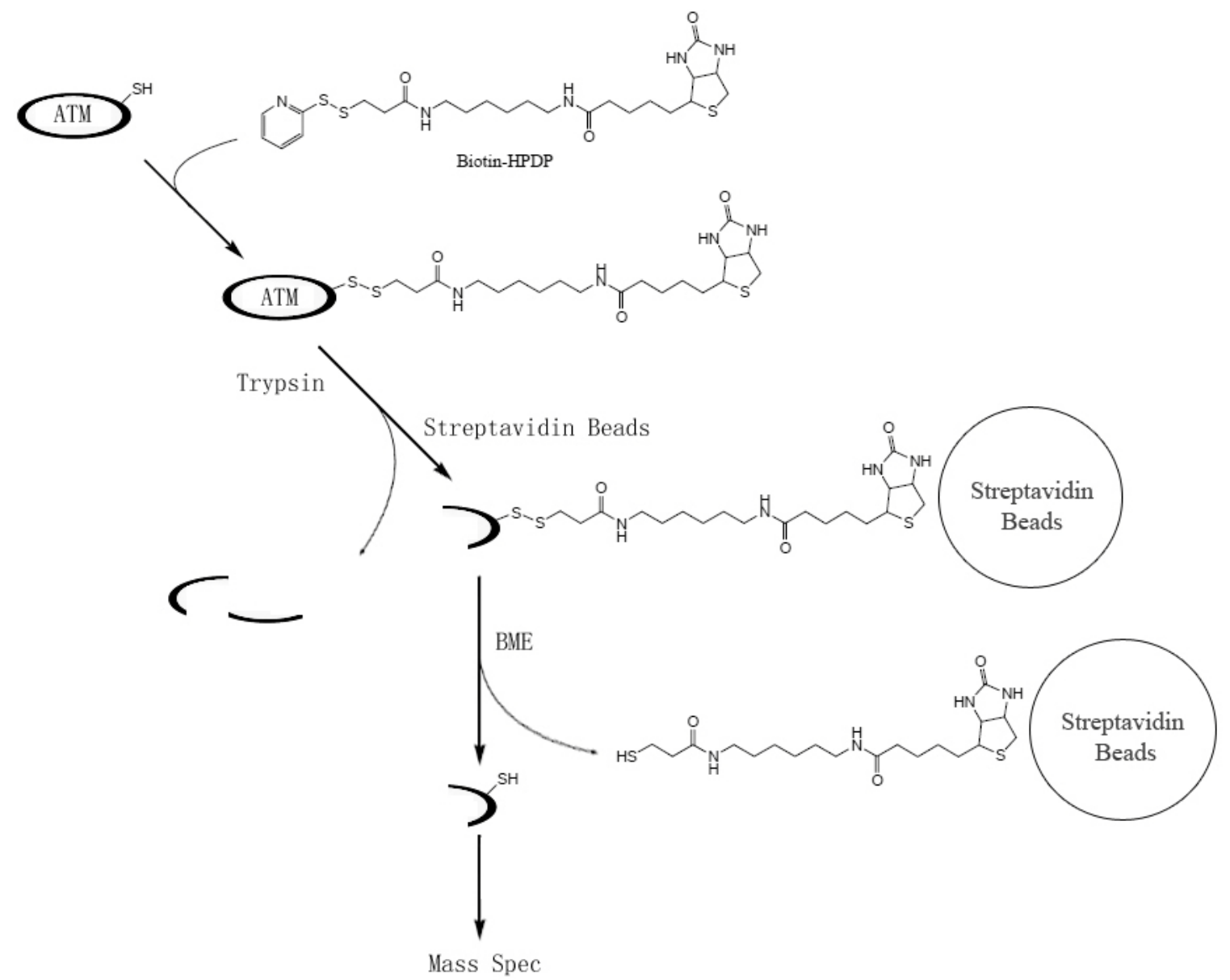

Figure 4.4 Reaction scheme for biotinylation of ATM with Biotin-HPDP. Sulfhydryl groups of ATM react with Biotin-HPDP (Pierce). Biotinylated ATM was trypsin-digested. Biotinylated peptides bound to streptavidin beads (Promega) were then cut off the beads by $\beta$-mercaptolethanol (BME, Sigma) and ready for analysis by mass spec.

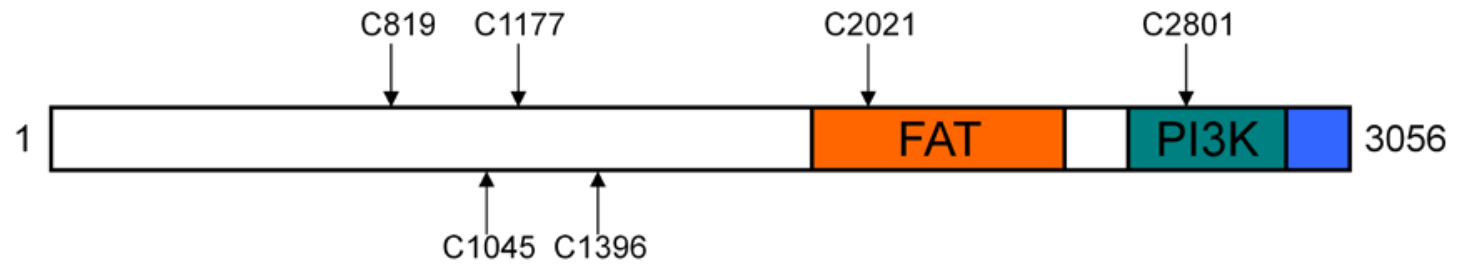

Figure 4.5 Map of ATM cysteine mutations identified by mass spectrometry 


\section{SELECTIVE CYANYLATION OF CYSTEINE RESIDUES IN ATM}

In a separate strategy, we also tried to selectively cyanylate the target cysteines. ATM was treated by $\mathrm{H}_{2} \mathrm{O}_{2}$ and free cysteines were blocked by iodoacetamide as described before. I used tris(2-carboxyethyl)phosphine (TCEP), which can selectively and completely reduces alkyl disulfide over a wide $\mathrm{pH}$ range, to reduce disulfide bond(s) at $\mathrm{pH}$ 3. Then I used 1-cyano-4-dimethylamino-pyridinium tetrafluoroborate (CDAP) to cyanylate the reduced cysteines residues. ATM was then cleaved at the sites of cyanylation as the $\mathrm{pH}$ was raised from 3 to 12 (Figure 3.3) as previously decided for other proteins cantaining disulfide bonds [117]. The approximate distance from the cleavage sites to $\mathrm{N}$ terminus was determined by the length of polypeptides recognized by an anti-Flag antibody (ATM contains an N-terminal Flag tag). Cysteines 2021, 540, 541, 1494 and 1495 were identified using this method (Figure 4.6 and Table 4.1).

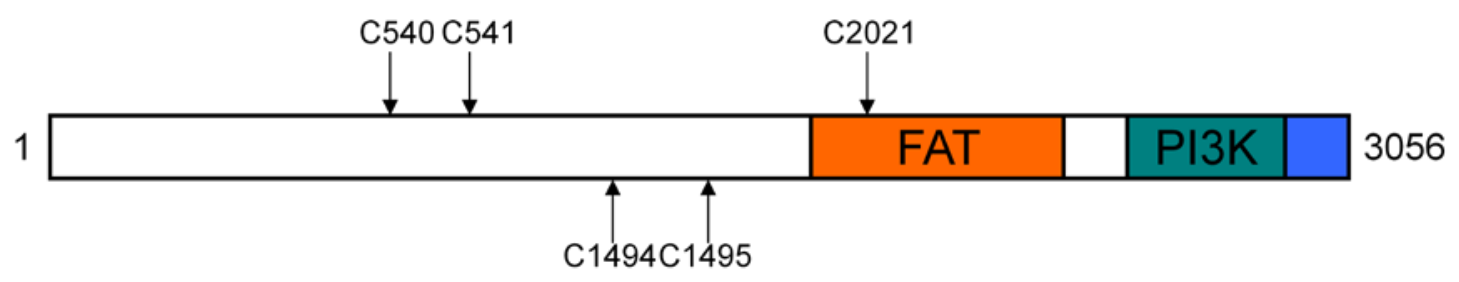

Figure 4.6 Map of ATM cysteine mutation identified by selective cyanylation

Most of the proteins found to sense redox state in cells are either activated or inactivated by forming a disulfide bond between two cysteine residues. Our titration of ATM activation against $\mathrm{H}_{2} \mathrm{O}_{2}$ or diamide concentration didn't show the existence of 
intermediates between inactive and active status of ATM (Figure 3.10), suggesting maybe the formation of only one pair of disulfide bond is critical for the activation. I mutated the cysteine residues identified by mass spec and cyanylation individually, and tested their effects on ATM activation (Table 4.1).

Although it is possible that these residues are the sites of disulfide bonds in ATM, mutation of these sites did not abolish ATM activation by $\mathrm{H}_{2} \mathrm{O}_{2}$. During $\mathrm{H}_{2} \mathrm{O}_{2}$ treatment of the samples for mass spectrometry analysis, many cysteines were oxidized and it is possible that other oxidization events concealed the critical one. Detection of peptides by mass spectrometry depends on their ability to be ionized, thus not all peptides will be easily detected. Unfortunately, none of the sites identified by mass spectrometry and selective cyanylation appeared to be the critical one we were looking for.

\section{MUTATION OF CYSTEINE 2991 ABOLISHES ATM ACTIVATION BY $\mathrm{H}_{2} \mathrm{O}_{2}$}

mTOR is a member of the PIKK family and is known to sense cellular stress caused by change in cellular nutrient and energy levels as well as redox status [118]. mTOR contains 2 conserved cysteines (2460 and 2467) in the FATC domain that are disulfide linked after oxidation and lead to stabilization of the protein upon oxidative stress [119]. These 2 cysteines are not conserved in ATM, but in the ATM FATC domain, cysteine 2991 is conserved in all mammals (Figure 4.7). In zebrafish this residue is a theronine while in sea urchin it is a leucine. We mutated cysteine 2991 to leucine or theronine, purified the mutant proteins and found that both these mutations completely 
abolish activation by $\mathrm{H}_{2} \mathrm{O}_{2}$ but not the activation by MRN and DNA (Figure 4.8). Besides its similar location in the C-terminus of mTOR, the FATC domain of ATM also has lower PI (predicted to be around 5.35) compared to the whole protein (PI=6.39) and other conserved domains (e.g. kinase domain PI=7.65, table 4.2). Therefore, cysteine 2991 is predicted to be well deprotonized under physiological conditions, which is the precondition for disulfide formation.

$\begin{array}{lll}\text { Mouse } & \text { LHSTPNADDQECK-----QSLSDTDQSFNK } & 3014 \\ \text { Rat } & \text { LQSTPSADDQECK-----RSLSDTDQSFNK } & 2952 \\ \text { Human } & \text { LHPTLNADDQECK-----RNLSDIDQSFNK } & 3004 \\ \text { Chimp } & \text { LHPTLNADDQECK----RNLSDIDQSFNK } & 3004 \\ \text { Dog } & \text { LHSTPSGDDQECK-----RSLSDSDQSFNK } & 3004 \\ \text { Horse } & \text { LHSTPHADDQECK-----RNLSDVDQSFNK } & 3005 \\ \text { Pig } & \text { LHSTPRADDQECK-----RNLSDTDQSFNK } & 3004 \\ \text { Cattle } & \text { LHSTLNADDQECK-----RNLSDIDQSFNK } & 3002 \\ \text { Chicken } & \text { MSSTLGADPQACK-----RKASSDDQSFNK } & 2958 \\ \text { Xenopus } & \text { LNATLGGDDPECN-----RNSCDS-QSVNK } & 3009 \\ \text { Zebrafish } & \text { LNPTPGGDEIETH-----RKASDS-QSFNK } & 2721 \\ \text { Seaurchin } & \text { LNTTTDGHQDILH-PTNGASSPTTSREEV } & 3066\end{array}$

Figure 4.7 Alignment of ATM FATC domain. 


\begin{tabular}{|c|c|c|c|}
\hline cysteine site & description & MRN\&DNA & $\mathrm{H} 2 \mathrm{O} 2$ \\
\hline 540 & tumor & + & + \\
\hline 541 & cyanylation & N/A & + \\
\hline 783,786 & CxxC site & + & + \\
\hline 819 & Mass spec site & N/A & + \\
\hline 1045 & Mass spec site & + & + \\
\hline 1177 & Mass spec site & N/A & + \\
\hline 1251 & Conserved & N/A & + \\
\hline 1286 & Conserved & N/A & + \\
\hline 1396 & Mass spec site & N/A & + \\
\hline 1494,1495 & cyanylation & N/A & + \\
\hline 1948 & Conserved & + & + \\
\hline 2021 & MS \& cyanylation & N/A & + \\
\hline 2704 & Conserved & N/A & + \\
\hline 2801 & Mass spec site & + & + \\
\hline 2824 & A-T patient & $\mathrm{N} / \mathrm{A}$ & + \\
\hline 2991 & Conserved & + & - \\
\hline
\end{tabular}

Table 4.1 ATM mutagenesis results. Each ATM mutant was overexpressed in 293T cells and purified as described (Chapter 2). The activation of full-length mutant proteins by $\mathrm{H}_{2} \mathrm{O}_{2}$ or MRN/DNA were compared to wildtype ATM. If mutants had wildtype-like activation, it was marked as'+'. If the mutant could not be activated it was marked as'-‘. 


\begin{tabular}{|c|c|c|}
\hline Domain & theoretical pI & M.W. \\
\hline ATM & 6.39 & 350687.46 \\
\hline N-terminus (1-1969) & 6.44 & 224505.50 \\
\hline FAT domain (1970-2565) & 5.90 & 69902.16 \\
\hline Kinase domain (2683-2962) & 7.65 & 32308.41 \\
\hline FATC domain (2963-3057) & 5.35 & 10726.23 \\
\hline
\end{tabular}

Table 4.2 Predicted pI of ATM domains. The PI and M.W. were calculated with Expasy PI and M.W. prediction tool http://ca.expasy.org/tools/pi_tool.html. 


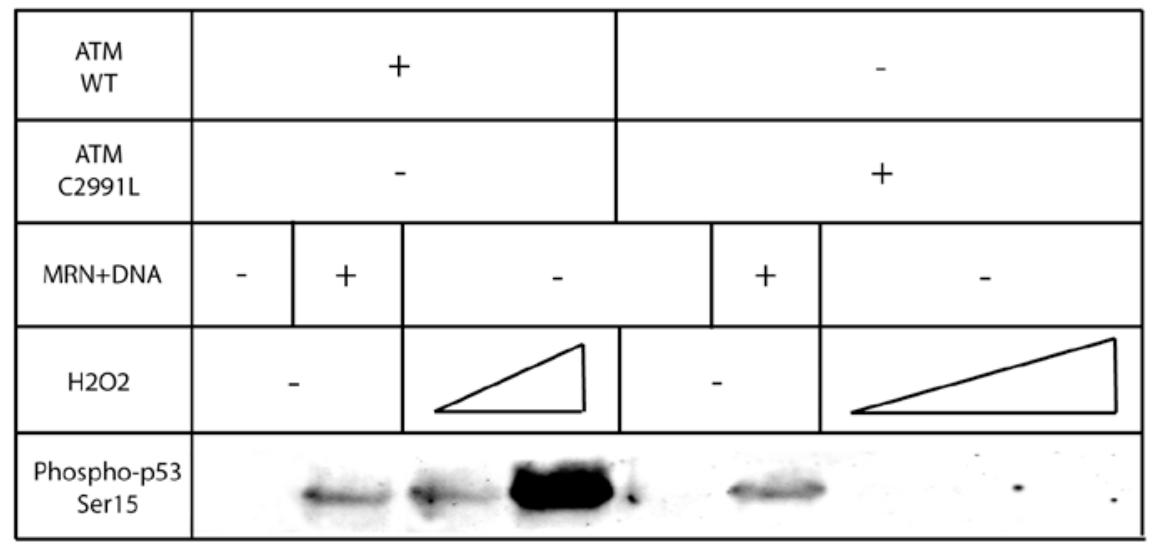

\begin{tabular}{|c|c|c|c|c|c|}
\hline $\begin{array}{c}\text { ATM } \\
\text { WT }\end{array}$ & \multicolumn{3}{|c|}{ - } & \multicolumn{2}{c|}{+} \\
\hline ATM \\
C2991T
\end{tabular}

Figure 4.8 ATM C2991L and C2991T kinase assay. ATM mutant proteins were normalized with WT-ATM. ATM activation by $\mathrm{H}_{2} \mathrm{O}_{2}$ and MRN/DNA was analyzed as described in Figure 3.1. 
We also found that the ATM C2991L mutant can be oxidized into the dimer form, which is not surprising considering all the disulfides identified by mass spectrometry and selective cyanylation. The next question is whether it is an intermolecular or intramolecular disulfide bond. In the case of mTOR, an intramolecular disulfide bond is formed between C2460 and C2467 [119]. Unlike ATM, mTOR is a monomer and functions as mTOR complex1 (mTORC1, associated with regulatory proteins, includes Raptor, G $\beta$ L and PRAS40) or mTOR complex2 (mTORC2, associated with Rictor, G $\beta$ L, and mSIN1). Though ATM only has one conserved cysteine in FATC domain, it is in dimer form before activation and the two FATC domains were predicted to be close in space [42]. Therefore it is possible that a disulfide formed between two 2991 cysteines in an ATM dimer is responsible for its activation.

To test this model of an interdimer disulfide between C2991 residues, we coexpressed ATM wildtype and C2991L protein and purified heterodimers. Flag-tagged C2991L mutant and HA-tagged wildtype ATM were used to transfect 293T cells, and the heterodimer was purified by sequential anti-Flag and anti-HA affinity chromatography. The activation of the heterodimer by $\mathrm{H}_{2} \mathrm{O}_{2}$ was tested. The heterodimer cannot be activated by $\mathrm{H}_{2} \mathrm{O}_{2}$, as shown in Figure 4.9, suggesting that a cysteine 2991 residue in each monomer is required for activation. The simplest explanation for this is that an intermolecular disulfide forms within the dimer at this position. However, it is also possible that both cysteine residues have to be engaged in separate disulfide bonds (in traor intermolecular) for activation. 


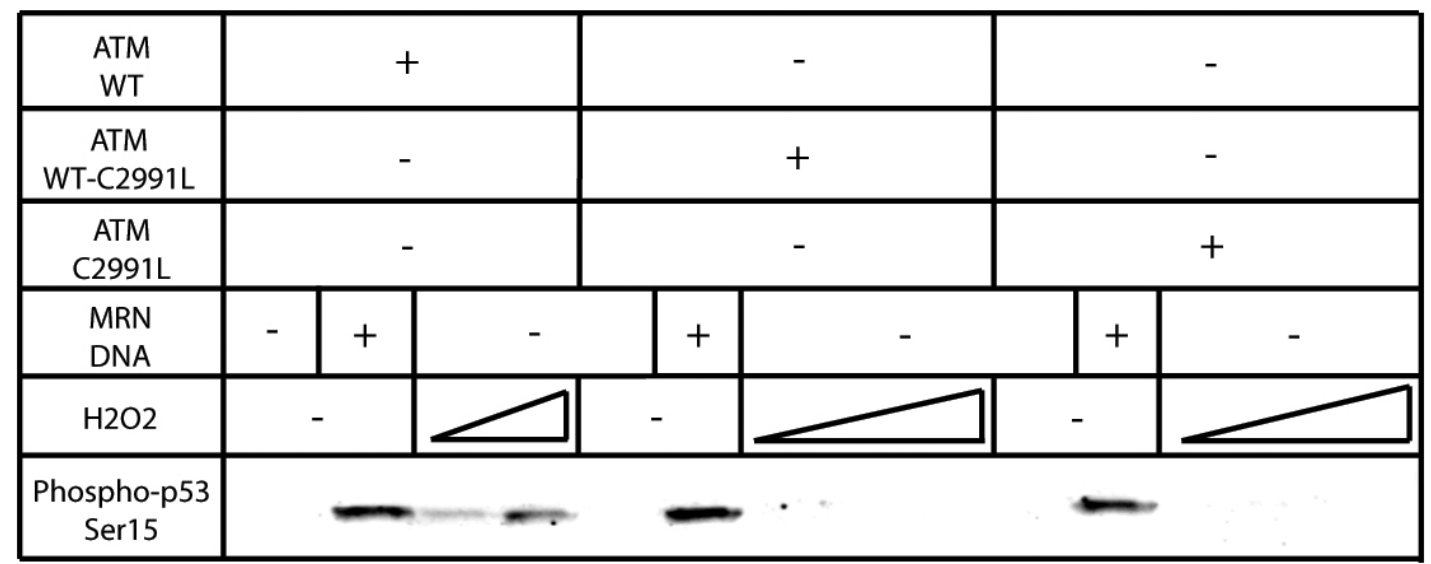

Figure 4.9 ATM heterodimer C2991L-WT kinase assay. ATM C2991L-WT heterodimer were normalized with wt and C2991L ATM homodimers. The activation of the heterodimer was tested in a titration of $\mathrm{H}_{2} \mathrm{O}_{2}$. 


\section{CHAPTER 5: DISCUSSION}

\section{ATM REGULATES CELLULAR RESPONSE TO DNA DAMAGE AND OXIDATIVE STRESS}

Reactive oxidative species (ROS) are highly toxic to cells. ROS are produced as a natural byproduct of the normal metabolism of oxygen and are also generated by exogenous sources, such as ionizing radiation. Cells use the combination of enzymes, including superoxide dismutases, catalases, and glutathione peroxidases, as well as ROS scavengers, such as ascorbic acid, tocopherol, uric acid, and glutathione, to defend themselves [60, 74]. However, the defense system is not $100 \%$ efficient and residual ROS persist in cells, which play an important role in cell signaling. ROS levels can increase dramatically due to the dysfunction of cellular defense system, either from environmental stress or genetic mutations. Accumulation of ROS can result in significant damage to DNA, RNA, lipids and proteins, a situation known as oxidative stress. ROS can react with both bases and the deoxyribose backbone of DNA. Direct attack on the 4'-hydrogen of deoxyribose leads to breaks in the sugar-phosphate backbone. Of the four DNA bases, guanine is the most sensitive to ROS attack. The product, 8-Oxo-7, 8-dihydroguanine, can pair with adenine, leading to GC->AT mutations. In humans, it is primarily repaired through the BER pathway. Some damaged bases, like uracil radicals, can react with deoxyribose and transfer the damage to sugar-phosphate backbone, leading to DNA single strand breaks (SSBs) as well. SSBs are the most common damage induced by 
ROS. When two SSBs occur on opposite DNA strands within 10-20 bp of each other, DSBs are formed [120].

DSBs in mammalian cells are primarily repaired through non-homologous recombination. The Ku70/80 complex is regarded as the cornerstone of NHEJ because of its role in detecting and binding to DSBs $[121,122]$. The Ku complex was shown to be inhibited by oxidation and to lose its ability to bind to the ends of DSBs with high affinity [112]. Homologous recombination is the other important DNA repair pathway when homologous chromosomes are available in $\mathrm{S}$ or $\mathrm{G}_{2}$ phase of cell cycle. My in vitro DNA binding experiment showed that the MRN complex, a crucial component of homologous recombination mechanisms in mammalian cells, also lost its binding ability towards DNA after exposure to $\mathrm{H}_{2} \mathrm{O}_{2}$. Hence, under oxidative stress both the major DSB repair pathways are less efficient. As a result, serious long-term oxidative stress is always accompanied by DSBs in mammalian cells.

ATM is in the major kinase regulating DNA damage response. ATM has been shown to be activated by DSBs induced by ionizing radiation, Bleomycin, NCS and other DNA damaging reagents $[11,36,123]$. ATM also plays an important role in regulating cellular responses to oxidative stress as ATM-deficient cells exhibit high levels of ROS and a dysfunctional cellular antioxidant system [60]. In vivo, the effects of oxidative stress and DSBs on ATM are difficult to distinguish since long term oxidative stress can induce DNA damage and DSB-inducing reagents, like IR, often induce oxidative stress at the same time by promoting ROS production. I carefully chose the concentration of 
oxidants and extent of treatment to distinguish the effects of oxidative stress from DSB responses in cells. I was able to detect ATM autophosphorylation and p53 phosphorylation in the absence of H2AX and Kap1 phosphorylation, suggesting the existence of another ATM activation pathway that is DSB-independent. Furthermore, under the same conditions $\mathrm{H}_{2} \mathrm{O}_{2}$ can also induce p53 and Chk2 phosphorylation by ATM in NBS cells, which express low level of truncated NBS1 protein. NBS cells are defective in ATM activation in response to DSBs because of the limited amount of MRN in these cells and the mutation in NBS1. As the MRN complex is necessary for ATM activation by facilitating DSB detection, it is reasonable to suggest that DSB-independent ATM activation is responsible for the phosphorylation of p53 and Chk2 in NBS cells.

\section{ATM ACTIVATION INDEPENDENT OF DNA DAMAGE}

My in vitro kinase assay provides the most direct proof of DSB-independent ATM activation. ATM ectopically expressed and purified from 293T cells was used in our in vitro kinase assay. In the absence of DNA and the MRN complex, ATM was activated by the addition of $\mathrm{H}_{2} \mathrm{O}_{2}$. The level of ATM activation is comparable to MRN and DNA dependent ATM activation. The range of $\mathrm{H}_{2} \mathrm{O}_{2}$ concentrations effective in ATM activations is from $100 \mu \mathrm{M}$ to $2 \mathrm{mM}$ (Figure 3.6). The optimal concentration of $\mathrm{H}_{2} \mathrm{O}_{2}$ may vary because a reducing reagent must be present in the storage buffer of purified ATM. Nonetheless, the patterns of ATM activation with $\mathrm{H}_{2} \mathrm{O}_{2}$ titration are always similar; ATM activity increases with $\mathrm{H}_{2} \mathrm{O}_{2}$ concentration and decreases above the optimal concentration, which might be due to the disruption of protein structure by 
nonspecific oxidization caused by high concentrations of $\mathrm{H}_{2} \mathrm{O}_{2}$. Several experiments were done to confirm that increased p53 phosphorylation by ATM in kinase assay is dependent on the activation of ATM kinase: similar titration curves were obtained when GST-Chk2 and full length p53 are used, and the ATM kinase specific inhibitor, Ku-55933, inhibits the phosphorylation of p53 induced by $\mathrm{H}_{2} \mathrm{O}_{2}$. These experiments prove that the activation is catalyzed by ATM and is not substrate specific.

In cells, $\mathrm{H}_{2} \mathrm{O}_{2}$ can be converted to highly reactive hydroxyl radicals through the fenton reaction but in the in vitro kinase assay such mechanisms are absent, suggesting that $\mathrm{H}_{2} \mathrm{O}_{2}$ might activate ATM through direct oxidation. The fact that reducing reagents like NAC and DTT inhibit ATM activation by $\mathrm{H}_{2} \mathrm{O}_{2}$ also suggests this. Diamide, a reagent that specific induces disulfide crossinks between adjacent cysteine residues, activates ATM both in cells and in vitro. This result suggests that disulfide formation induced through direct oxidation by $\mathrm{H}_{2} \mathrm{O}_{2}$ is critical for ATM activation.

ATM is an inactive dimer before activation. Disulfides induced by $\mathrm{H}_{2} \mathrm{O}_{2}$ keep ATM in a dimer form. Unlike the DSB-dependent ATM activation pathway, in which ATM dissociates to active monomers, ATM is in an active dimer form in the oxidative activation pathway. In our titration of $\mathrm{H}_{2} \mathrm{O}_{2}$ concentration, ATM activation is correlated with dimer formation. This also suggests that important interdimer disulfides might be important for activation by keeping ATM in active dimer form. 
ATM autophosphorylation on serine 1981 is a hallmark of ATM activation and has been proposed to be important for ATM dimer dissociation [42]. In 293 cells treated with $\mathrm{H}_{2} \mathrm{O}_{2}$, ATM autophosphorylation on serine 1981 is induced though autophosphorylated ATM is still in dimer form. In NBS cells, no ATM autophosphorylation was detected though ATM clearly was active and phosphorylates p53 and Chk2. Whether ATM autophosphorylation is necessary for ATM activation is controversial $[24,50]$. My in vitro experiments suggest that ATM autophosphorylation on serine 1981 is not necessary for ATM activation by $\mathrm{H}_{2} \mathrm{O}_{2}$ because S1981A ATM can be activated by $\mathrm{H}_{2} \mathrm{O}_{2}$ in vitro similar to wildtype ATM. In addition, $\mathrm{H}_{2} \mathrm{O}_{2}$ did not induce ATM autophosphorylation in vitro. ATM autophosphorylation may still be an important event induced by $\mathrm{H}_{2} \mathrm{O}_{2}$ in wildtype cells but it is not required for ATM activation via oxidative stress. The MRN complex seems to be important for ATM autophosphorylation although it is not required for ATM oxidative activation.

The MRN complex activates ATM by promoting ATM dimer dissociation and substate binding [24, 26]. My work shows that $\mathrm{H}_{2} \mathrm{O}_{2}$ oxidation keeps ATM in a dimer form that nevertheless exhibits increased activity. The activation of ATM by $\mathrm{H}_{2} \mathrm{O}_{2}$ is at least partially due to an increase in substrate binding. The substrate binding domains of ATM are not well defined. Previous research showed that $\mathrm{N}$ - terminal heat repeats are important for the interaction between ATM and its substrates p53 and Chk2 [3]. Deletion of N-terminal heat repeats in ATM blocks the ability of ATM to phosphorylate p53 or Chk2 in vitro although it has an intact PI3K kinase domain. It is possible that, when 
treated with $\mathrm{H}_{2} \mathrm{O}_{2}$, either the conformation or orientation of these domains is changed making them more accessible for substrate binding.

\section{THE FATC DOMAIN IS IMPORTANT FOR ATM ACTIVATION BY $\mathrm{H}_{2} \mathrm{O}_{2}$}

Oxidation of the C-terminal FATC domain of mTOR, also a member of the PIKK family, was shown to contribute to its stabilization [119]. The Oxidized FATC domain of mTOR consists of a disulfide-bonded loop between two conserved cysteine residues. The mutation of these residues indicates that the cellular redox potential can affect the amount of the mTOR protein by influencing its degradation. These results are consistent with the idea that the C-terminus of ATM is important for ATM regulation by $\mathrm{H}_{2} \mathrm{O}_{2}$. Cysteine 2991 is the only conserved cysteine in the ATM FATC domain. C2991L and C2991T (L and T were chosen according to the alignment of ATM homologs) exhibited wildtype level of activation by MRN and DNA in vitro but were deficient in the response to $\mathrm{H}_{2} \mathrm{O}_{2}$. The fact that we were able to differentiate two distinct kinds of activation in vitro suggests that these are two independent pathways contributing to ATM activation in vivo in response to different stimuli. MRN and DNA recruit ATM to DSBs and activate ATM in situ at the site of DSBs in chromatin. ATM can also sense the change in redox state

during cell stress and be activated ex situ. These two pathways share downstream targets like p53 and Chk2, while it is also possible that each pathway has distinct targets to regulate different cell defenses against either DSBs or oxidative stress. 
The fact that ATM heterodimers, containing wildtype and C2991L proteins are also deficient in response to $\mathrm{H}_{2} \mathrm{O}_{2}$ suggests that a critical interdimer disulfide forms between two 2991 cysteine residues. Unlike MRN and DNA dependent activation, which dissociate ATM dimers and presumably makes the kinase domain more accessible to substrates, the oxidative activation pathway retains dimer form. I hypothesize that oxidation induces significant changes in the conformation of the kinase domain which may be functionally equivalent to the conformation of ATM in the presence of MRN and DNA.

Cysteine 2991 of ATM is located in FATC domain but the function of FATC domain is not clear. FATC domain is well conserved in mammals and birds but less in other metazoans. A peroxisome localization signal was proposed in the c-terminus of FATC domain which suggests a possible form of extranuclear ATM [16]. Supporting this idea, A-T fibroblasts exhibit dramatically decreased catalase activity in peroxisomes. Thus the ATM FATC domain might be important for ATM to sense increases in ROS level and regulate peroxisome function.

We used three different strategies to search for important cysteine residues in ATM and mutated 18 out of 89 total cysteines as candidates. Of the 18 candidates we were able to identify cysteine 2991 to be critical for ATM activation by $\mathrm{H}_{2} \mathrm{O}_{2}$. All the candidates from Mass spectrometer analysis of disulfide-linked cysteines and cyanylation cleavage proved to be negative. Although these cysteines were oxidized during $\mathrm{H}_{2} \mathrm{O}_{2}$ treatment, their oxidation was not essential for the oxidation pathway. The ATM C2991 
mutant was also shown to be crosslinked by disulfide bonds after $\mathrm{H}_{2} \mathrm{O}_{2}$ treatment, which supports the idea of excessive disulfide formation. At this point, we do not know if intermolecular dimer formation is essential for ATM activation via this pathway, we are also seeking to confirm whether disulfide bonds occur between C2991 residues within an active dimer. This is the expected result, but it is also possible that C2991 is oxidized without disulfide bond formation.

Another critical part of my ongoing work is to express the ATM C2991L mutant in A-T cells to determine how the mutation affects the cellular responses to oxidative stress and DNA damage. My hypothesis is that the C2991 mutant will be able to respond to DNA damage although it might be less efficient that wt-ATM, but the mutant will not respond to $\mathrm{H}_{2} \mathrm{O}_{2}$ or diamide, and will not rescue A-T cells from oxidative stress.

\section{DIRECT ACTIVATION BY OXIDATIVE STRESS IS IMPORTANT FOR ATM FUNCTION IN CELLS}

Based on my results, I propose a new pathway for ATM activation: ATM can be oxidized and activated directly in the absence of DSB. This pathway reveals a new role of ATM as a sensor to redox conditions as a regulator of cellular defenses against deleterious ROS in cells (Figure 5.1), which offers explanations for a number of clinical and experimental observations. Neurodegeneration, the most striking character of AT patients, has long been attributed to genome instability induced by ATM deficiency. However, ATM is not regarded as a major regulator for DNA repair. It is more likely that 
loss of ATM sensitizes A-T cells to accumulated intrinsic ROS due to the high level of metabolism in neuronal cells. Elevated ROS causes multiple forms of cellular damage and finally leads to cell death.

Ionizing radiation (IR) damages DNA by direct deposition of energy to the sugarphosphate backbone and by the indirect production of ROS. IR is widely used to induce DSBs in research focused on DNA damage response (DDR). After IR treatment ATM is quickly autophosphorylated and activated throughout the nucleus. With the MRN and DNA-dependent pathway, ATM must be recruited to the DSB sites, activated, and then released to phosphorylate non-DNA-binding substrates. In addition, my results show that ATM can also be oxidatively activated by the ROS induced throughout the nucleus, which provides a reasonable explanation for the contradiction between broad, pannuclear activation of ATM and the small number of DSB foci formed after low doses of IR.

Like IR, many radiomimetic drugs also induce oxidative stress. Oxidative stress decreases the DNA-binding ability of many proteins, including the Ku70/80 complex [113], which leads to the inhibition of DNA-PKcs. DNA-PKcs phosphorylates H2AX at DSB sites and then phosphorylated H2AX acts as a loading dock for the recruitment of DDR machinery, which includes MDC1, BrcaI, 53BP1, and the MRN complex and is crucial for ATM activation in DSB foci. Active ATM phosphorylates more distant H2AX to amplify the signal of DDR. Because oxidative stress attenuates DNA-PK-mediated recognition of DSB, it might inhibit ATM activation in DSB foci, making cells less 


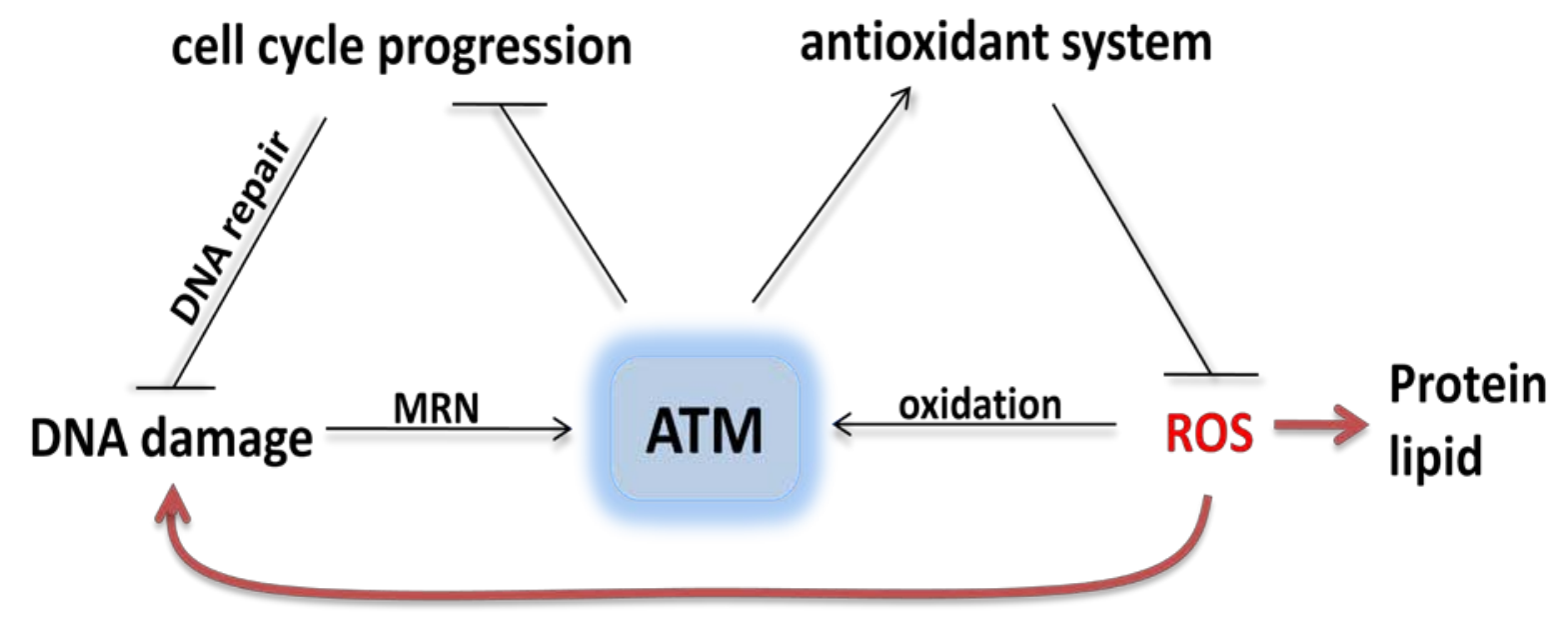

Figure 5.1 Model for the activation pathways of ATM through MRN/DSBs and through oxidative stress. 
efficient in the DNA damage response. However, the ATM oxidative activation pathway may help to overcome this. ATM can be activated directly by oxidative stress and then phosphorylate H2AX at the DSB sites to help the recruitment of DDR machinery under conditions when DNA-PKcs activity is inhibited. Therefore, oxidative activation of ATM may be important for efficient DNA damage response under oxidative stress.

In vitro kinase assays showed that ATM can be activated by MRN and DNA directly without the recruitment of other members of DDR machinery. In this case MRN is the DSB sensor and helps the recruitment of ATM to DSB sites. My experiments showed that ATM activation by MRN and DNA in vitro is attenuated under oxidative stress probably because of the inhibition of MRN-DNA binding. The oxidative activation of ATM compensates for the loss of MRN-dependent activation and may regulate normal ATM-dependent DNA damage response.

The fact that ATM- deficient cells have reduced antioxidant capacity and are vulnerable to ROS attack [60] suggests that ATM might play an important role in the cellular defense system against ROS through its oxidative activation pathway. The ability of ATM to increase its activity with the level of ROS enables cells to regulate defense by elevating antioxidant production. Little is known about the downstream targets of ATM in the oxidative activation pathway. Catalase activity in A-T fibroblasts is significantly reduced although its expression and distribution appear to be normal [16]. This suggests a role of ATM in regulating catalase activity and perhaps also peroxisome function. 


\section{DOWNSTREAM TARGETS OF ATM OXIDATIVE ACTIVATION PATHWAY}

There have been reports about possible crosstalk between ATM and the mitogen activated protein kinase (MAPK) pathways [124, 125], which is a signal transduction cascade responding to environmental stresses, including oxidative stress. ATM dependent activation of ATF3 is also dependent on the p38 and JNK MAPkinases phosphorylating ATF2 and the activation of ATF3 by $\mathrm{H}_{2} \mathrm{O}_{2}$ can be inhibited by NAC. In an experiment comparing A-T and healthy fibroblasts treated with pro-oxidant $\mathrm{CdCl}_{2}$, ATM was shown to function as a sensor of oxidative stress and to inhibit c-Jun phosphorylation by JNK MAPkinase [126]. In AT neurosphere cells not only the activity of the p38 MAPK was enhanced but the AKT pathways are also disrupted [127]. The AKT pathway plays a key role in survival by inhibition of apoptotic signals and promotion of cell cycle progression, and its activation was shown to be mediated through ATM. The crosstalk between AKT and ATM pathways was also confirmed in an effort to analyze extensive protein networks regulated by ATM and ATR [30].

Downstream of the AKT pathway, forkhead transcription factors (FOXO) are negatively regulated by AKT $[30,127]$. FOXO transcription factors were shown to regulate the expression of enzymes that protect against or repair oxidative damage. For instance, Foxo1a directly targets thioredoxin interacting protein (TXNIP) [128]. Because TXNIP inhibits the reducing activity of thioredoxin (TRX), downregulation of foxo1a enhances cellular response to oxidative stress. Foxo3 was also shown to be essential for normal ATM expression, and Foxo3-null cells show sensitivity to ROS similar to A-T 
cells [129]. Interestingly, the C-terminus of Foxo3a was shown to interact with the FAT domain of ATM to promote autophosphorylation on serine 1981, which suggests a role of foxo3a in DNA damage response [130]. The activity of foxo transcription factors is controlled by phosphorylation by kinases like AKT or JNK, both of which are partially regulated by ATM [131].

p66shc is an important protein controlling the oxidative stress response and life span in mammals [132]. In a study of longevity of C. elegans, $\mathrm{H}_{2} \mathrm{O}_{2}$ negatively regulates the activity of forkhead proteins in a p66shc-dependent way [133] . In p66shc-null cells, redox-dependent inactivation of forkhead proteins is reduced. When treated with $\mathrm{H}_{2} \mathrm{O}_{2}$, p66shc is phosphorylated and promotes p53-dependent apoptosis [134]. As a sensor of intracellular ROS level, the p53-p66shc pathway is also a possible downstream target of ATM.

In another systematic study of phosphorylation networks, NF- $\kappa$ B2, a member of NF- $\kappa \mathrm{B}$ transcriptional factor family, was identified to be possible downstream of ATM [135]. Oxidative stress leads to the activation of NF- $\kappa B$ [87]. $\mathrm{H}_{2} \mathrm{O}_{2}$ induces sumolation of NF- $\kappa \mathrm{B}$ essential modulator (NEMO) and ATM activation, which together leads to the activation of NF-אB in a DNA damage-independent manner [136, 137]. Interestingly, ATM was also shown to phosphorylate NEMO to promote its nuclear export, and ATM itself is also exported in a NEMO-dependent manner to cytoplasm. Oxidative stress also activates the TSC2 tumor suppressor in an ATM-dependent way, in which ATM activates 
AMPK through LKB1 to regulate mTORC1 and induce autophagy (Cheryl Walker personal communication).

Here I propose a new oxidative activation pathway of ATM, but how ATM regulates cellular responses to oxidative stress is still not clear. Although several pathways regulated by MAP kinase, AKT and foxo shown above crosstalk with ATM pathway, systematic research is needed to search for ATM targets in response to oxidative stress. This is also part of our future work. We plan to borrow a simple and efficient approach from previous research of looking for potential CDK targets in complex cell lysates [138]. We will use a kinase engineering strategy to make ATM mutants able to utilize ATP analogue, like PE-ATP- $\gamma$-S. Then the thiophosphorylated peptide can be enriched with thiopropyl sepharose 6B and analyzed with mass spectrometry to identify potential ATM targets.

More attention needs to be paid to FATC domain to better understand ATM oxidative activation. As mentioned above, the FATC domain may change in structure upon oxidation and could induce an overall conformational change of ATM dimer that is critical for ATM activation. We plan to overexpress FATC domain alone and with PI3K kinase domain in order to get enough protein to do structural analysis by NMR or crystallography.

We also want to better understand the physiological role of ATM oxidative activation, which not only contributes to ATM activation in the absence of DNA DSBs 
but may also play an important role in the DNA damage response, as many DNA damaging reagents also induce oxidative stress. The main function of DNA-PKcs is to regulate non-homologous end-joining, and also regulates the DNA damage response redundantly with ATM [139]. The ability of ATM to be activated under oxidative stress conditions might compensate for the loss of DNA-PKcs. We would also like to test if ATM plays a more dominant role in DNA damage response under oxidative conditions. 


\section{References}

1. Lavin, M.F., Ataxia-telangiectasia: from a rare disorder to a paradigm for cell signalling and cancer. Nat Rev Mol Cell Biol, 2008. 9(10): p. 759-69.

2. Khanna, K.K., Cancer risk and the ATM gene: a continuing debate. J Natl Cancer Inst, 2000. 92(10): p. 795-802.

3. Shiloh, Y., ATM and related protein kinases: safeguarding genome integrity. Nat. Rev. Cancer, 2003. 3(3): p. 155-68.

4. Savitsky, K., et al., A single ataxia telangiectasia gene with a product similar to PI-3 kinase. Science, 1995. 268(5218): p. 1749-53.

5. $\quad$ Kastan, M.B., et al., A mammalian cell cycle checkpoint pathway utilizing p53 and GADD45 is defective in ataxia-telangiectasia. Cell, 1992. 71(4): p. 587-97.

6. Beamish, H. and M.F. Lavin, Radiosensitivity in ataxia-telangiectasia: anomalies in radiation-induced cell cycle delay. Int J Radiat Biol, 1994. 65(2): p. 175-84.

7. Brumbaugh, K.M., et al., The mRNA surveillance protein hSMG-1 functions in genotoxic stress response pathways in mammalian cells. Mol Cell, 2004. 14(5): p. 585-98.

8. $\quad$ Bredemeyer, A.L., et al., ATM stabilizes DNA double-strand-break complexes during V(D)J recombination. Nature, 2006. 442(7101): p. 466-70.

9. Vacchio, M.S., et al., ATM deficiency impairs thymocyte maturation because of defective resolution of T cell receptor alpha locus coding end breaks. Proc Natl Acad Sci U S A, 2007. 104(15): p. 6323-8.

10. Lumsden, J.M., et al., Immunoglobulin class switch recombination is impaired in Atm-deficient mice. J Exp Med, 2004. 200(9): p. 1111-21.

11. Canman, C.E., et al., Activation of the ATM kinase by ionizing radiation and phosphorylation of p53. Science, 1998. 281(5383): p. 1677-9.

12. Yang, D.Q. and M.B. Kastan, Participation of ATM in insulin signalling through phosphorylation of eIF-4E-binding protein 1. Nat Cell Biol, 2000. 2(12): p. 893-8. 
13. Schneider, J.G., et al., ATM-dependent suppression of stress signaling reduces vascular disease in metabolic syndrome. Cell Metab, 2006. 4(5): p. 377-89.

14. Barlow, C., et al., ATM is a cytoplasmic protein in mouse brain required to prevent lysosomal accumulation. Proc Natl Acad Sci U S A, 2000. 97(2): p. 871-6.

15. Biton, S., et al., ATM-mediated response to DNA double strand breaks in human neurons derived from stem cells. DNA Repair (Amst), 2007. 6(1): p. 128-34.

16. Watters, D., et al., Localization of a portion of extranuclear ATM to peroxisomes. J Biol Chem, 1999. 274(48): p. 34277-82.

17. Maser, R.S., et al., hMre11 and hRad50 nuclear foci are induced during the normal cellular response to DNA double-strand breaks. Mol. Cell. Biol., 1997. 17(10): p. 6087-6096.

18. Paull, T.T., et al., A critical role for histone $H 2 A X$ in recruitment of repair factors to nuclear foci after DNA damage. Curr Biol, 2000. 10(15): p. 886-95.

19. Burma, S., et al., ATM phosphorylates histone H2AX in response to DNA doublestrand breaks. J Biol Chem, 2001. 276(45): p. 42462-7.

20. Rogakou, E.P., et al., DNA double-stranded breaks induce histone H2AX phosphorylation on serine 139. J. Biol. Chem., 1998. 273(10): p. 5858-68.

21. Kolas, N.K., et al., Orchestration of the DNA-damage response by the RNF8 ubiquitin ligase. Science, 2007. 318(5856): p. 1637-40.

22. Lukas, C., et al., Mdc1 couples DNA double-strand break recognition by Nbs1 with its H2AX-dependent chromatin retention. Embo J, 2004. 23(13): p. 2674-83.

23. Stucki, M., et al., MDC1 directly binds phosphorylated histone H2AX to regulate cellular responses to DNA double-strand breaks. Cell, 2005. 123(7): p. 1213-26.

24. Lee, J.H. and T.T. Paull, ATM activation by DNA double-strand breaks through the Mre11-Rad50-Nbs1 complex. Science, 2005. 308(5721): p. 551-4.

25. Uziel, T., et al., Requirement of the MRN complex for ATM activation by DNA damage. EMBO J., 2003. 22(20): p. 5612-5621.

26. Lee, J.H. and T.T. Paull, Direct activation of the ATM protein kinase by the Mre11/Rad50/Nbs1 complex. Science, 2004. 304(5667): p. 93-6. 
27. Kitagawa, R., et al., Phosphorylation of SMC1 is a critical downstream event in the ATM-NBS1-BRCA1 pathway. Genes Dev, 2004. 18(12): p. 1423-38.

28. Bartek, J. and J. Lukas, Mammalian G1- and S-phase checkpoints in response to DNA damage. Curr Opin Cell Biol, 2001. 13(6): p. 738-47.

29. Pearce, A.K. and T.C. Humphrey, Integrating stress-response and cell-cycle checkpoint pathways. Trends Cell Biol, 2001. 11(10): p. 426-33.

30. Matsuoka, S., et al., ATM and ATR substrate analysis reveals extensive protein networks responsive to DNA damage. Science, 2007. 316(5828): p. 1160-6.

31. Banin, S., et al., Enhanced phosphorylation of p53 by ATM in response to DNA damage. Science, 1998. 281(5383): p. 1674-7.

32. Bartek, J., J. Falck, and J. Lukas, CHK2 kinase--a busy messenger. Nat Rev Mol Cell Biol, 2001. 2(12): p. 877-86.

33. Kim, S.T., B. Xu, and M.B. Kastan, Involvement of the cohesin protein, Smc1, in Atm-dependent and independent responses to DNA damage. Genes Dev, 2002. 16(5): p. 560-70.

34. Yazdi, P.T., et al., SMC1 is a downstream effector in the ATM/NBS1 branch of the human S-phase checkpoint. Genes Dev, 2002. 16(5): p. 571-82.

35. $\mathrm{Mu}$, J.J., et al., A proteomic analysis of ataxia telangiectasia-mutated (ATM)/ATM-Rad3-related (ATR) substrates identifies the ubiquitin-proteasome system as a regulator for DNA damage checkpoints. J Biol Chem, 2007. 282(24): p. 17330-4.

36. Goodarzi, A.A., et al., ATM signaling facilitates repair of DNA double-strand breaks associated with heterochromatin. Mol Cell, 2008. 31(2): p. 167-77.

37. Lee, K., Y. Zhang, and S.E. Lee, Saccharomyces cerevisiae ATM orthologue suppresses break-induced chromosome translocations. Nature, 2008. 454(7203): p. 543-6.

38. Greenwell, P.W., et al., TEL1, a gene involved in controlling telomere length in S. cerevisiae, is homologous to the human ataxia telangiectasia gene. Cell, 1995. 82(5): p. 823-9. 
39. Bi, X., et al., Drosophila ATM and ATR checkpoint kinases control partially redundant pathways for telomere maintenance. Proc Natl Acad Sci U S A, 2005. 102(42): p. 15167-72.

40. Denchi, E.L. and T. de Lange, Protection of telomeres through independent control of ATM and ATR by TRF2 and POT1. Nature, 2007. 448(7157): p. 106871.

41. Goodarzi, A.A. and S.P. Lees-Miller, Biochemical characterization of the ataxiatelangiectasia mutated (ATM) protein from human cells. DNA Repair (Amst), 2004. 3(7): p. 753-67.

42. Bakkenist, C.J. and M.B. Kastan, DNA damage activates ATM through intermolecular autophosphorylation and dimer dissociation. Nature, 2003. 421(6922): p. 499-506.

43. Sun, Y., et al., DNA damage-induced acetylation of lysine 3016 of ATM activates ATM kinase activity. Mol Cell Biol, 2007. 27(24): p. 8502-9.

44. Lim, D.S., et al., ATM binds to beta-adaptin in cytoplasmic vesicles. Proc Natl Acad Sci U S A, 1998. 95(17): p. 10146-51.

45. Fernandes, N., et al., DNA damage-induced association of ATM with its target proteins requires a protein interaction domain in the $N$ terminus of ATM. J Biol Chem, 2005. 280(15): p. 15158-64.

46. Llorca, O., et al., Electron microscopy and 3D reconstructions reveal that human ATM kinase uses an arm-like domain to clamp around double-stranded DNA. Oncogene, 2003. 22(25): p. 3867-74.

47. Berkovich, E., R.J. Monnat, Jr., and M.B. Kastan, Roles of ATM and NBS1 in chromatin structure modulation and DNA double-strand break repair. Nat Cell Biol, 2007. 9(6): p. 683-90.

48. Falck, J., J. Coates, and S.P. Jackson, Conserved modes of recruitment of ATM, ATR and DNA-PKCs to sites of DNA damage. Nature, 2005. 434(7033): p. 605-11.

49. Lou, Z., et al., MDC1 is coupled to activated CHK2 in mammalian DNA damage response pathways. Nature, 2003. 421(6926): p. 957-61. 
50. Pellegrini, M., et al., Autophosphorylation at serine 1987 is dispensable for murine Atm activation in vivo. Nature, 2006. 443(7108): p. 222-5.

51. Kozlov, S.V., et al., Involvement of novel autophosphorylation sites in ATM activation. EMBO J, 2006. 25(15): p. 3504-14.

52. Goodarzi, A.A., et al., Autophosphorylation of ataxia-telangiectasia mutated is regulated by protein phosphatase 2A. EMBO J, 2004. 23(22): p. 4451-61.

53. Ali, A., et al., Requirement of protein phosphatase 5 in DNA-damage-induced ATM activation. Genes Dev, 2004. 18(3): p. 249-54.

54. Dupre, A., L. Boyer-Chatenet, and J. Gautier, Two-step activation of ATM by DNA and the Mre11-Rad50-Nbs1 complex. Nat Struct Mol Biol, 2006. 13(5): p. 451-7.

55. Ismail, I.H., et al., Activation of ataxia telangiectasia mutated by DNA strand break-inducing agents correlates closely with the number of DNA double strand breaks. J Biol Chem, 2005. 280(6): p. 4649-55.

56. You, Z., et al., Rapid activation of ATM on DNA flanking double-strand breaks. Nat Cell Biol, 2007. 9(11): p. 1311-8.

57. Jazayeri, A., et al., Mre11-Rad50-Nbs1-dependent processing of DNA breaks generates oligonucleotides that stimulate ATM activity. EMBO J, 2008. 27(14): p. 1953-62.

58. Kim, Y.C., et al., Activation of ATM depends on chromatin interactions occurring before induction of DNA damage. Nat Cell Biol, 2009. 11(1): p. 92-6.

59. Liu, N., et al., ATM deficiency induces oxidative stress and endoplasmic reticulum stress in astrocytes. Lab Invest, 2005. 85(12): p. 1471-80.

60. Barzilai, A., G. Rotman, and Y. Shiloh, ATM deficiency and oxidative stress: $a$ new dimension of defective response to DNA damage. DNA Repair (Amst), 2002. 1(1): p. 3-25.

61. Stern, N., et al., Accumulation of DNA damage and reduced levels of nicotine adenine dinucleotide in the brains of Atm-deficient mice. J Biol Chem, 2002. 277(1): p. 602-8. 
62. Ito, K., et al., Regulation of oxidative stress by ATM is required for self-renewal of haematopoietic stem cells. Nature, 2004. 431(7011): p. 997-1002.

63. Chen, K., et al., Activation of $p 53$ by oxidative stress involves platelet-derived growth factor-beta receptor-mediated ataxia telangiectasia mutated (ATM) kinase activation. J Biol Chem, 2003. 278(41): p. 39527-33.

64. Ito, K., et al., Reactive oxygen species act through p38 MAPK to limit the lifespan of hematopoietic stem cells. Nat Med, 2006. 12(4): p. 446-51.

65. Kani, S., et al., Chk2 kinase is required for methylglyoxal-induced G2/M cellcycle checkpoint arrest: implication of cell-cycle checkpoint regulation in diabetic oxidative stress signaling. Genes Cells, 2007. 12(8): p. 919-28.

66. Schafer, F.Q. and G.R. Buettner, Redox environment of the cell as viewed through the redox state of the glutathione disulfide/glutathione couple. Free Radic Biol Med, 2001. 30(11): p. 1191-212.

67. Sen, C.K., Redox signaling and the emerging therapeutic potential of thiol antioxidants. Biochem Pharmacol, 1998. 55(11): p. 1747-58.

68. Bandyopadhyay, S., et al., Thioltransferase (glutaredoxin) reactivates the DNAbinding activity of oxidation-inactivated nuclear factor I. J Biol Chem, 1998. 273(1): p. 392-7.

69. Hwang, C., A.J. Sinskey, and H.F. Lodish, Oxidized redox state of glutathione in the endoplasmic reticulum. Science, 1992. 257(5076): p. 1496-502.

70. Bellomo, G., et al., Demonstration of nuclear compartmentalization of glutathione in hepatocytes. Proc Natl Acad Sci U S A, 1992. 89(10): p. 4412-6.

71. Arrigo, A.P., Gene expression and the thiol redox state. Free Radic Biol Med, 1999. 27(9-10): p. 936-44.

72. Allen, R.G. and A.K. Balin, Oxidative influence on development and differentiation: an overview of a free radical theory of development. Free Radic Biol Med, 1989. 6(6): p. 631-61.

73. Li, N. and T.D. Oberley, Modulation of antioxidant enzymes, reactive oxygen species, and glutathione levels in manganese superoxide dismutase- 
overexpressing NIH/3T3 fibroblasts during the cell cycle. J Cell Physiol, 1998. 177(1): p. 148-60.

74. Barzilai, A. and K. Yamamoto, DNA damage responses to oxidative stress. DNA Repair (Amst), 2004. 3(8-9): p. 1109-15.

75. Furuyama, A., et al., Induction of oxidative stress and inhibition of plasminogen activator inhibitor-1 production in endothelial cells following exposure to organic extracts of diesel exhaust particles and urban fine particles. Arch Toxicol, 2006. 80(3): p. 154-62.

76. Hengstler, J.G. and H.M. Bolt, Induction and control of oxidative stress. Arch Toxicol, 2007. 81(12): p. 823-4.

77. Mena, S., A. Ortega, and J.M. Estrela, Oxidative stress in environmental-induced carcinogenesis. Mutat Res, 2009. 674(1-2): p. 36-44.

78. Maynard, S., et al., Base excision repair of oxidative DNA damage and association with cancer and aging. Carcinogenesis, 2009. 30(1): p. 2-10.

79. Minelli, A., et al., Oxidative stress-related aging: A role for prostate cancer? Biochim Biophys Acta, 2009. 1795(2): p. 83-91.

80. Clopton, D.A. and P. Saltman, Low-level oxidative stress causes cell-cycle specific arrest in cultured cells. Biochem Biophys Res Commun, 1995. 210(1): p. 189-96.

81. Gehen, S.C., et al., $h S M G-1$ and ATM sequentially and independently regulate the G1 checkpoint during oxidative stress. Oncogene, 2008. 27(29): p. 4065-74.

82. Leroy, C., C. Mann, and M.C. Marsolier, Silent repair accounts for cell cycle specificity in the signaling of oxidative DNA lesions. EMBO J, 2001. 20(11): p. 2896-906.

83. Antunes, F. and E. Cadenas, Cellular titration of apoptosis with steady state concentrations of $\mathrm{H}(2) \mathrm{O}(2)$ : submicromolar levels of $\mathrm{H}(2) \mathrm{O}(2)$ induce apoptosis through Fenton chemistry independent of the cellular thiol state. Free Radic Biol Med, 2001. 30(9): p. 1008-18. 
84. Antunes, F., E. Cadenas, and U.T. Brunk, Apoptosis induced by exposure to a low steady-state concentration of $\mathrm{H} 2 \mathrm{O} 2$ is a consequence of lysosomal rupture. Biochem J, 2001. 356(Pt 2): p. 549-55.

85. Naderi, J., M. Hung, and S. Pandey, Oxidative stress-induced apoptosis in dividing fibroblasts involves activation of p38 MAP kinase and over-expression of Bax: resistance of quiescent cells to oxidative stress. Apoptosis, 2003. 8(1): p. 91100.

86. Haghnazari, E. and W.D. Heyer, The Hog1 MAP kinase pathway and the Mec1 DNA damage checkpoint pathway independently control the cellular responses to hydrogen peroxide. DNA Repair (Amst), 2004. 3(7): p. 769-76.

87. Gloire, G., S. Legrand-Poels, and J. Piette, NF-kappaB activation by reactive oxygen species: fifteen years later. Biochem Pharmacol, 2006. 72(11): p. 1493505.

88. Imlay, J.A. and S. Linn, DNA damage and oxygen radical toxicity. Science, 1988. 240(4857): p. 1302-9.

89. Charames, G.S. and B. Bapat, Genomic instability and cancer. Curr Mol Med, 2003. 3(7): p. 589-96.

90. Mitra, S., et al., Complexities of the DNA base excision repair pathway for repair of oxidative DNA damage. Environ Mol Mutagen, 2001. 38(2-3): p. 180-90.

91. Ishikawa, T. and H. Sies, Cardiac transport of glutathione disulfide and Sconjugate. Studies with isolated perfused rat heart during hydroperoxide metabolism. J Biol Chem, 1984. 259(6): p. 3838-43.

92. Burgoyne, J.R., et al., Cysteine redox sensor in PKGIa enables oxidant-induced activation. Science, 2007. 317(5843): p. 1393-7.

93. Okazaki, S., et al., Multistep disulfide bond formation in Yap1 is required for sensing and transduction of H2O2 stress signal. Mol Cell, 2007. 27(4): p. 675-88.

94. Gopalakrishna, R. and W.B. Anderson, Ca2+- and phospholipid-independent activation of protein kinase $C$ by selective oxidative modification of the regulatory domain. Proc Natl Acad Sci U S A, 1989. 86(17): p. 6758-62. 
95. Durocher, D. and S.P. Jackson, DNA-PK, ATM and ATR as sensors of DNA damage: variations on a theme? Curr Opin Cell Biol, 2001. 13(2): p. 225-31.

96. Veal, E.A., A.M. Day, and B.A. Morgan, Hydrogen peroxide sensing and signaling. Mol Cell, 2007. 26(1): p. 1-14.

97. Abraham, R.T., Cell cycle checkpoint signaling through the ATM and ATR kinases. Genes Dev, 2001. 15(17): p. 2177-96.

98. Kamata, H. and H. Hirata, Redox regulation of cellular signalling. Cell Signal, 1999. 11(1): p. 1-14.

99. Sasaki, M., H. Ikeda, and Y. Nakanuma, Activation of ATM signaling pathway is involved in oxidative stress-induced expression of mito-inhibitory p21WAF1/Cip1 in chronic non-suppurative destructive cholangitis in primary biliary cirrhosis: an immunohistochemical study. J Autoimmun, 2008. 31(1): p. 73-8.

100. Kobayashi, M., et al., ATM activation by a sulfhydryl-reactive inflammatory cyclopentenone prostaglandin. Genes Cells, 2006. 11(7): p. 779-89.

101. Scher, J.U. and M.H. Pillinger, 15d-PGJ2: the anti-inflammatory prostaglandin? Clin Immunol, 2005. 114(2): p. 100-9.

102. Bencokova, Z., et al., ATM activation and signaling under hypoxic conditions. Mol Cell Biol, 2009. 29(2): p. 526-37.

103. Zhao, H., et al., Oxidative stress induces cell cycle-dependent Mre11 recruitment, ATM and Chk2 activation and histone H2AX phosphorylation. Cell Cycle, 2008. 7(10): p. 1490-5.

104. Ziv, Y., et al., Expression and assay of recombinant ATM. Methods Mol Biol, 2000. 99: p. 99-108.

105. Lee, J.H. and T.T. Paull, Purification and biochemical characterization of ataxiatelangiectasia mutated and Mre11/Rad50/Nbs1. Methods Enzymol, 2006. 408: p. 529-39.

106. Lee, J.a.P., TT, in preparation, 2009. 
107. Long, X., M.J. Goldenthal, and J. Marin-Garcia, Oxidative stress enhances phosphorylation of p53 in neonatal rat cardiomyocytes. Mol Cell Biochem, 2007. 303(1-2): p. 167-74.

108. Zhao, H., et al., Cytometric assessment of DNA damage by exogenous and endogenous oxidants reports aging-related processes. Cytometry A, 2007. 71(11): p. 905-14.

109. Ziv, Y., et al., Chromatin relaxation in response to DNA double-strand breaks is modulated by a novel ATM- and KAP-1 dependent pathway. Nat Cell Biol, 2006. 8(8): p. 870-6.

110. Carney, J.P., et al., The hMre11/hRad50 protein complex and Nijmegen breakage syndrome: linkage of double-strand break repair to the cellular DNA damage response. Cell, 1998. 93(3): p. 477-86.

111. Maser, R.S., R. Zinkel, and J.H. Petrini, An alternative mode of translation permits production of a variant NBS1 protein from the common Nijmegen breakage syndrome allele. Nat Genet, 2001. 27(4): p. 417-21.

112. Andrews, B.J., J.A. Lehman, and J.J. Turchi, Kinetic analysis of the Ku-DNA binding activity reveals a redox-dependent alteration in protein structure that stimulates dissociation of the Ku-DNA complex. J Biol Chem, 2006. 281(19): p. 13596-603.

113. Kosower, N.S. and E.M. Kosower, Diamide: an oxidant probe for thiols. Methods Enzymol, 1995. 251: p. 123-33.

114. Chen, S., P. Paul, and B.D. Price, ATM's leucine-rich domain and adjacent sequences are essential for ATM to regulate the DNA damage response. Oncogene, 2003. 22(41): p. 6332-6339.

115. Hutson, S.M., et al., Redox regulation and trapping sulfenic acid in the peroxidesensitive human mitochondrial branched chain aminotransferase. Methods Mol Biol, 2008. 476: p. 139-52.

116. Hall, A., et al., Redox-dependent dynamics of a dual thioredoxin fold protein: evolution of specialized folds. Biochemistry, 2009. 48(25): p. 5984-93. 
117. Wu, J. and J.T. Watson, A novel methodology for assignment of disulfide bond pairings in proteins. Protein Sci, 1997. 6(2): p. 391-8.

118. Abraham, R.T., PI 3-kinase related kinases: 'big' players in stress-induced signaling pathways. DNA Repair (Amst), 2004. 3(8-9): p. 883-7.

119. Dames, S.A., et al., The solution structure of the FATC domain of the protein kinase target of rapamycin suggests a role for redox-dependent structural and cellular stability. J Biol Chem, 2005. 280(21): p. 20558-64.

120. Mahaney, B.L., K. Meek, and S.P. Lees-Miller, Repair of ionizing radiationinduced DNA double-strand breaks by non-homologous end-joining. Biochem J, 2009. 417(3): p. 639-50.

121. Critchlow, S.E. and S.P. Jackson, DNA end-joining: from yeast to man. Trends Biochem. Sci., 1998. 23(10): p. 394-8.

122. Collis, S.J., et al., The life and death of DNA-PK. Oncogene, 2005. 24(6): p. 94961.

123. Hosoi, Y., et al., A phosphatidylinositol 3-kinase inhibitor wortmannin induces radioresistant DNA synthesis and sensitizes cells to bleomycin and ionizing radiation. Int J Cancer, 1998. 78(5): p. 642-7.

124. Kim, J. and P.K. Wong, Loss of ATM Impairs Proliferation of Neural Stem Cells Through Oxidative Stress-Mediated p38 MAPK Signaling. Stem Cells, 2009.

125. Kool, J., et al., Induction of ATF3 by ionizing radiation is mediated via a signaling pathway that includes ATM, Nibrin1, stress-induced MAPkinases and ATF-2. Oncogene, 2003. 22(27): p. 4235-42.

126. Lee, S.A., A. Dritschilo, and M. Jung, Role of ATM in oxidative stress-mediated c-Jun phosphorylation in response to ionizing radiation and CdCl2. J Biol Chem, 2001. 276(15): p. 11783-90.

127. Viniegra, J.G., et al., Full activation of PKB/Akt in response to insulin or ionizing radiation is mediated through ATM. J Biol Chem, 2005. 280(6): p. 4029-36. 
128. de Candia, P., et al., A combination of genomic approaches reveals the role of FOXO1a in regulating an oxidative stress response pathway. PLoS ONE, 2008. 3(2): p. e1670.

129. Yalcin, S., et al., Foxo3 is essential for the regulation of ataxia telangiectasia mutated and oxidative stress-mediated homeostasis of hematopoietic stem cells. J Biol Chem, 2008. 283(37): p. 25692-705.

130. Tsai, W.B., et al., Functional interaction between FOXO3a and ATM regulates DNA damage response. Nat Cell Biol, 2008. 10(4): p. 460-7.

131. Essers, M.A., et al., FOXO transcription factor activation by oxidative stress mediated by the small GTPase Ral and JNK. EMBO J, 2004. 23(24): p. 4802-12.

132. Migliaccio, E., et al., The p66shc adaptor protein controls oxidative stress response and life span in mammals. Nature, 1999. 402(6759): p. 309-13.

133. Nemoto, S. and T. Finkel, Redox regulation of forkhead proteins through a p66shc-dependent signaling pathway. Science, 2002. 295(5564): p. 2450-2.

134. Trinei, M., et al., A p53-p66Shc signalling pathway controls intracellular redox status, levels of oxidation-damaged DNA and oxidative stress-induced apoptosis. Oncogene, 2002. 21(24): p. 3872-8.

135. Linding, R., et al., Systematic discovery of in vivo phosphorylation networks. Cell, 2007. 129(7): p. 1415-26.

136. Wuerzberger-Davis, S.M., et al., NF-kappaB activation by combinations of NEMO SUMOylation and ATM activation stresses in the absence of DNA damage. Oncogene, 2007. 26(5): p. 641-51.

137. Wu, Z.H., et al., Molecular linkage between the kinase ATM and NF-kappaB signaling in response to genotoxic stimuli. Science, 2006. 311(5764): p. 1141-6.

138. Chi, Y., et al., Identification of CDK2 substrates in human cell lysates. Genome Biol, 2008. 9(10): p. R149.

139. Callen, E., et al., Essential role for DNA-PKcs in DNA double-strand break repair and apoptosis in ATM-deficient lymphocytes. Mol Cell, 2009. 34(3): p. 285-97. 


\section{VITA}

Zhi Guo was born in Tianjin, China on the $21^{\text {th }}$ of April, 1978. After attending Tianjin No.1 High School, he entered Tsinghua University, Beijing to do his Bachelor degree in chemical engineering in the year 1996. He received his Master Degree in the year 2003, major in biochemistry and molecular biology, also from Tsinghua University. He enrolled for the Ph.D degree in cell and molecular biology at the University of Texas at Austin in the fall of 2003.

Permanent Address: 3569 Lake Austin Blvd. Apt. D, Austin, Texas 78703

This manuscript was typed by the author. 